Aus dem Institut für Neuropathologie

(Prof. Dr. med. C. Stadelmann-Nessler)

der Medizinischen Fakultät der Universität Göttingen

\title{
Charakterisierung von Peroxiredoxin 2 im zentralen Nervensystem bei Multipler Sklerose
}

\author{
INAUGURAL-DISSERTATION \\ zur Erlangung des Doktorgrades \\ der Medizinischen Fakultät der \\ Georg-August-Universität zu Göttingen
}

vorgelegt von

David Andreas Voigt

aus

Langenhagen

Göttingen 2019 
Dekan:

Referent:

Ko-Referent:

Drittreferent:

Datum der mündlichen Prüfung:
Prof. Dr. med. W. Brück

Prof. Dr. med. W. Brück

Prof. Dr. rer. nat. Michael Müller

Prof. Dr. mult. Thomas Meyer

21. Oktober 2021 
Hiermit erkläre ich, die Dissertation mit dem Titel „Charakterisierung von Peroxiredoxin 2 im zentralen Nervensystem bei Multipler Sklerose" eigenständig angefertigt und keine anderen als die von mir angegebenen Quellen und Hilfsmittel verwendet zu haben.

Göttingen, den 13. Oktober 2021

David Andreas Winkler (Geburtsname Voigt) 
Die Daten, auf denen die vorliegende Arbeit basiert, wurden teilweise publiziert:

Voigt D, Scheidt U, Derfuss T, Brück W, Junker A (2017): Expression of the Antioxidative Enzyme Peroxiredoxin 2 in Multiple Sclerosis Lesions in Relation to Inflammation. Int J Mol Sci 1으, 760 


\section{INHALTSVERZEICHNIS}

Verzeichnis der Abbildungen .....................................................................................II

Verzeichnis der Tabellen................................................................................................. IV

Verzeichnis der Abkürzungen .................................................................................. V

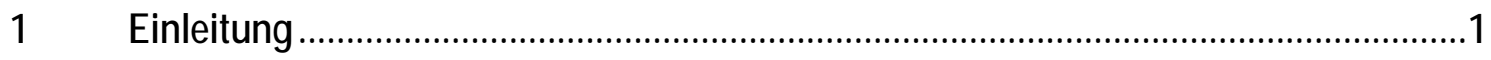

1.1 Epidemiologie, Ätiologie und Klinik der Multiplen Sklerose ........................................................

1.2 Immunpathogenese der Multiplen Sklerose

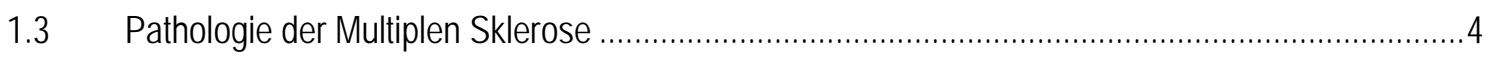

1.3.1 Läsionen der weißen Substanz / white matter lesions .................................................................

1.3.2 Läsionen der grauen Substanz / grey matter lesions ..........................................................

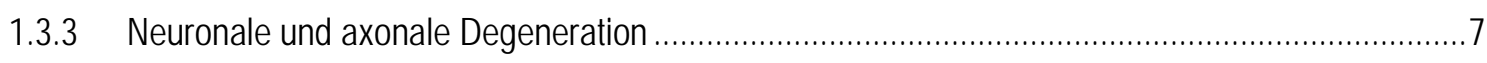

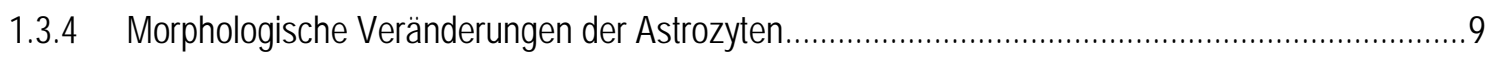

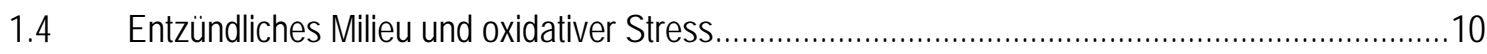

1.4.1 Das Entzündungsgeschehen bei Multipler Sklerose wird durch Zytokine mediiert.......................10

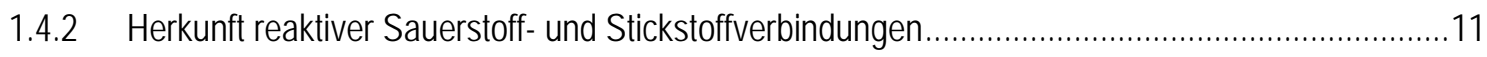

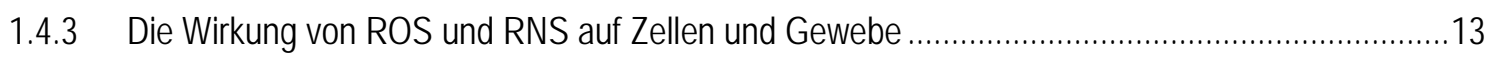

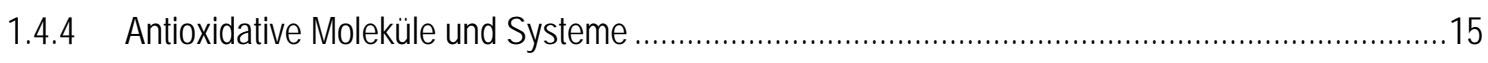

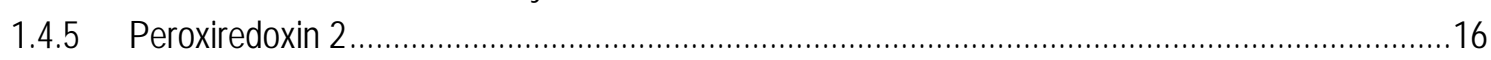

1.4.6 Oxidativer Stress als Pathomechanismus der Gewebeschädigung bei Multipler Sklerose ...........17

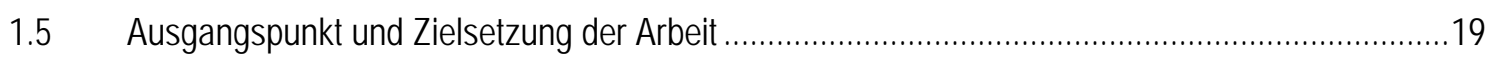

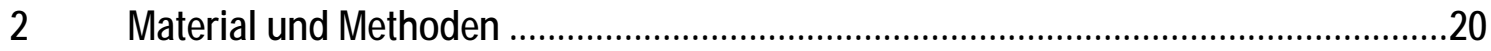

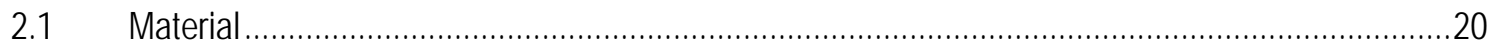

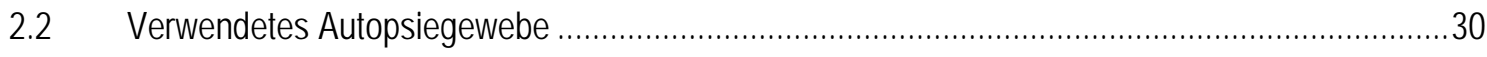

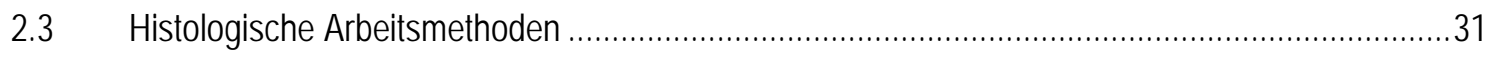

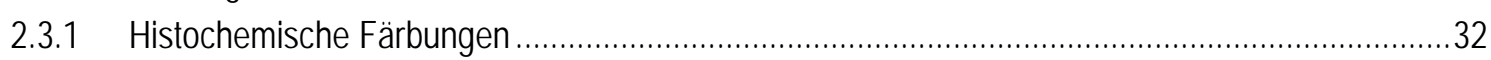

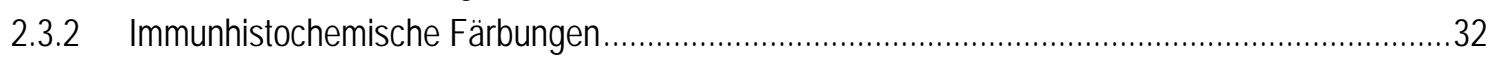

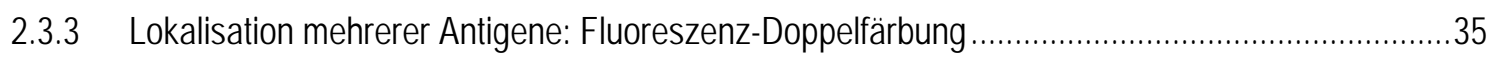

2.4 Morphometrische Auswertung der immunhistochemisch gefärbten Gewebeschnitte......................35

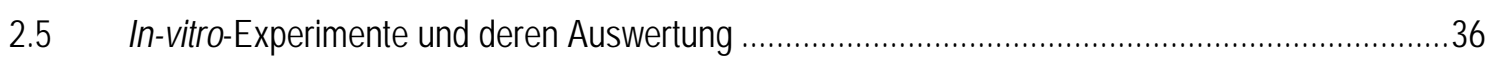

2.5.1 Isolation primärer Astrozyten aus neonatalen Mäusen ........................................................36

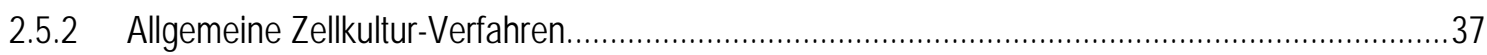

2.5.3 Stimulation von Zellkulturen mit Glukose-Oxidase und Zytokinen ............................................

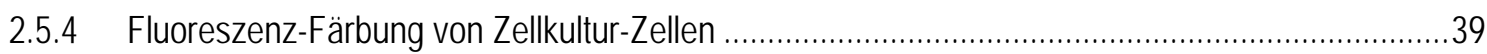

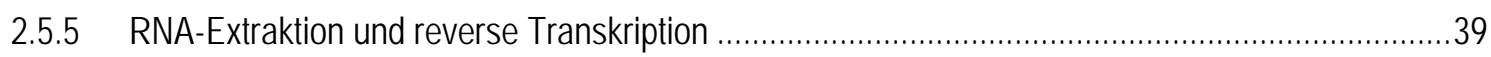

2.5.6 Entwicklung und Test von Primern für humane Zellen ............................................................ 40

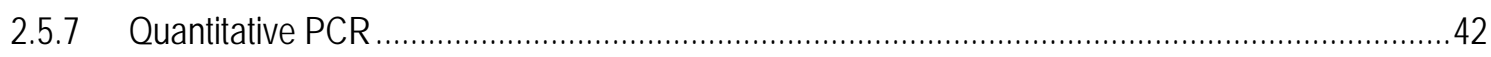

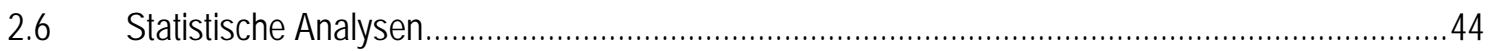




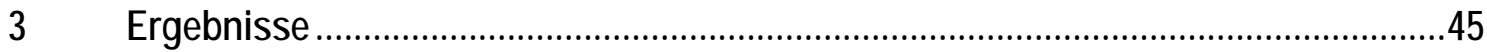

3.1 Neuropathologische Beurteilungen des Gewebes / Klassifikation der Läsionen ............................45

3.2 Peroxyredoxin 2 in der weißen Substanz / white matter .......................................................4

3.2.1 PRDX2 wird vorwiegend von Astrozyten exprimiert ...................................................................4

3.2.2 Die astrozytäre Expression von PRDX2 korreliert mit dem Entzündungsgrad und dem

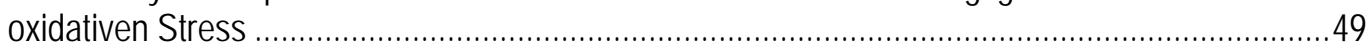

3.3 Peroxyredoxin 2 in der kortikalen grauen Substanz / cortical grey matter ...................................54

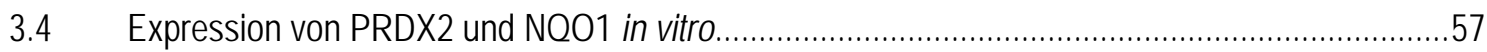

3.4.1 Oxidativer Stress führt zu einer vermehrten astrozytären Expression von NQO1, nicht aber

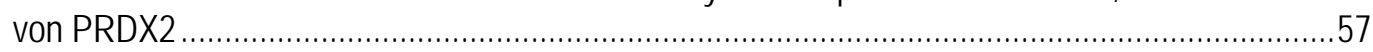

3.4.2 Durch Zytokine findet sich keine Veränderung der astrozytären Expression von PRDX2 und

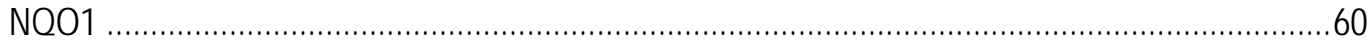

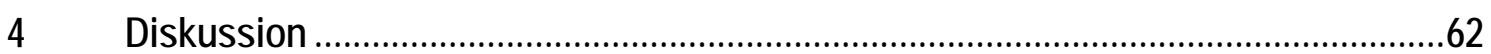

4.1 Peroxiredoxin 2 trägt zur Widerstandsfähigkeit einzelner Zellpopulationen gegenüber

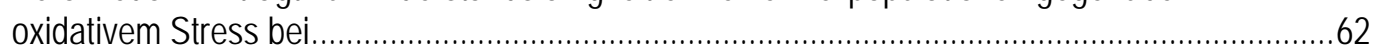

4.2 Der Zusammenhang zwischen Entzündung und dem Vorkommen von Peroxiredoxin 2 in

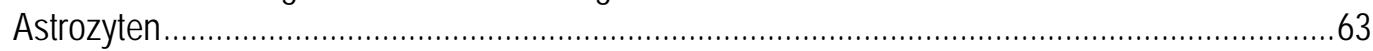

4.2.1 Der Einfluss von oxidativem Stress auf die Expression von PRDX2 ….....................................64

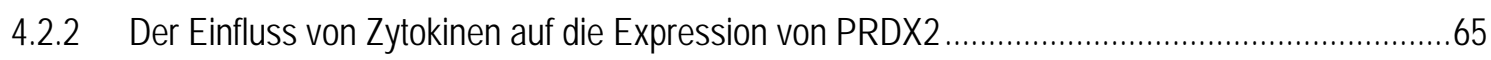

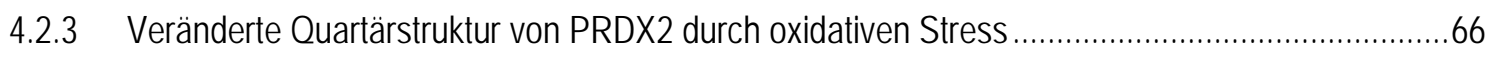

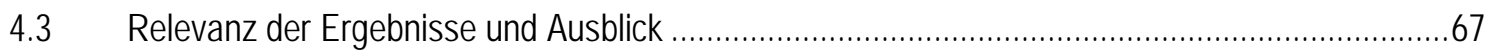

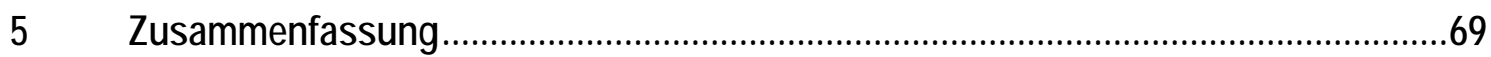

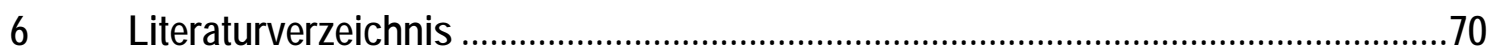




\section{VERZEICHNIS DER ABBILDUNGEN}

Abbildung 1: Schematische Darstellung verschiedener immunhistochemischer Verfahren.......................34

Abbildung 2: PCR-Produkte der Primer in der Gelelektrophorese ........................................................... 41

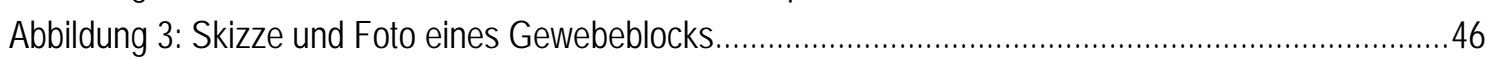

Abbildung 4: PRDX2 findet sich in MS- und Kontrollfällen vorwiegend in Astrozyten .................................48

Abbildung 5: PRDX2 findet sich nur vereinzelt in schaumzelligen Makrophagen/aktivierter Mikroglia........49

Abbildung 6: PRDX2- und NQO1-positive Astrozyten finden sich vermehrt in CAPs.................................50

Abbildung 7: Die PRDX2-Expression korreliert mit dem Entzündungsausmaß und dem oxidativen

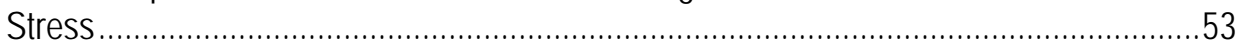

Abbildung 8: In leukokortikalen Läsionen zeigt sich eine erhöhte Entzündungsaktivität ..............................55

Abbildung 9: Insbesondere in leukokortikalen Läsionen finden sich PRDX2-positive Neurone ...................56

Abbildung 10: PRDX2- und NQO1-Expression nach der Inkubation humaner Zelllinien mit GOD...............58

Abbildung 11: PRDX2- und NQO1-Expression nach der Inkubation muriner Astrozyten mit GOD.............59

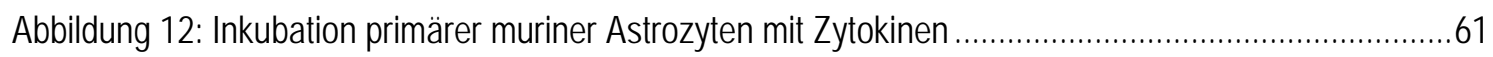




\section{VERZEICHNIS DER TABELLEN}

Tabelle 1: Einteilung kortikaler Läsionen nach Lokalisation und deren Charakteristika ............................7

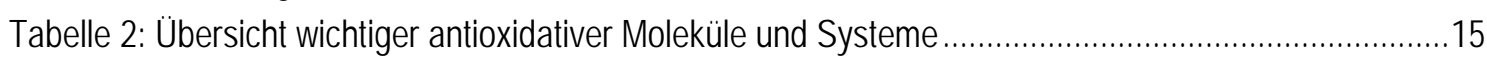

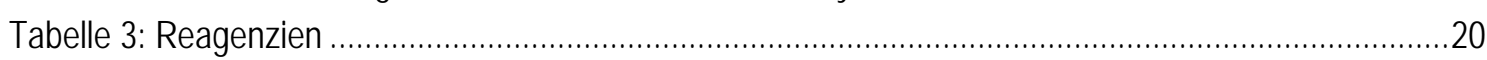

Tabelle 4: Lösungen und Puffer für Histochemie und Immunhistochemie .................................................2

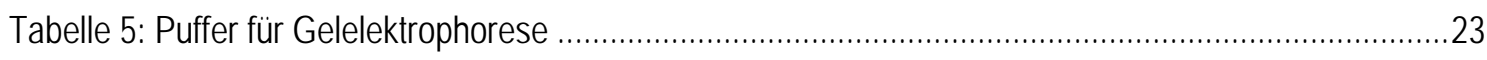

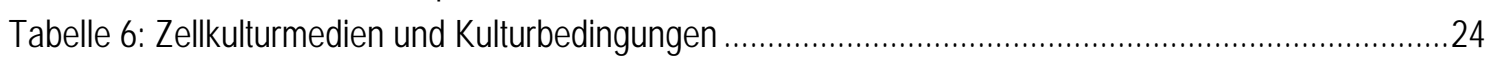

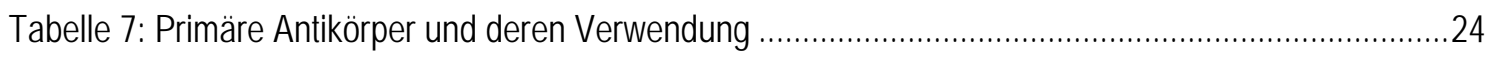

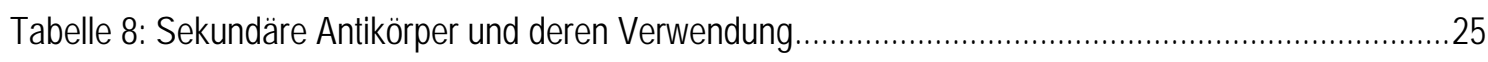

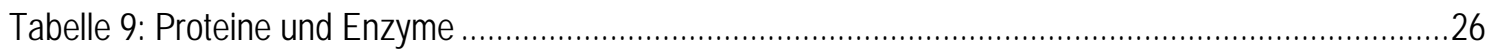

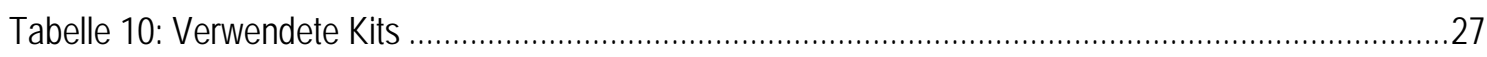

Tabelle 11: TaqMan Expression Assays/Primer für die Genexpressions-Analyse muriner Zellen ...............27

Tabelle 12: Oligonukleotidprimer für die Genexpressions-Analyse humaner Zellen ...................................28

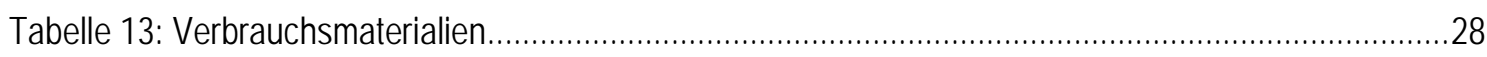

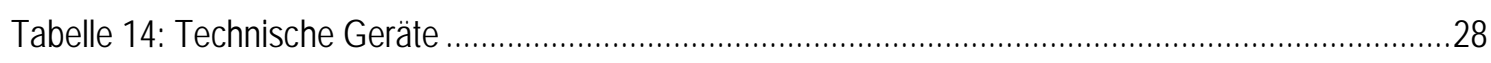

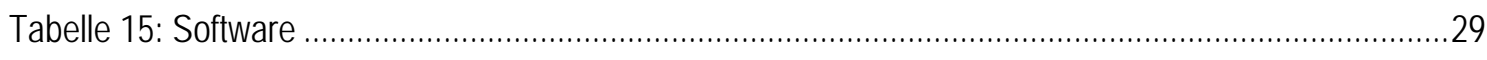

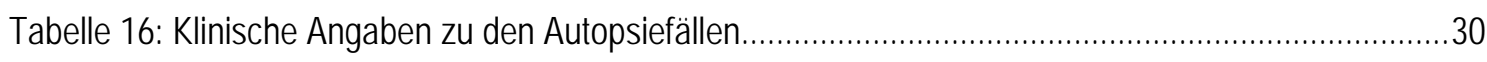

Tabelle 17: Anzahl und statistische Charakteristika der verwendeten Gewebeproben.............................31

Tabelle 18: Übereinstimmung der sequenzierten PCR-Produkte mit den Referenzsequenzen ...................41

Tabelle 19: PRC-Konditionen für die quantitative PCR ….................................................................... 43 


\section{VERZEICHNIS DER ABKÜRZUNGEN}

AG

AK

APP

ATP

BDNF

CAP

$\mathrm{CD}$

CIP

CNPase

DAPI

DNA

EAE

FCS

GFAP

GM

GML

GOD

IFN-y

$\lg$

IL-1 $\beta$

Keap1

MAG

$M B P$

MDA

$\mathrm{MHC}$

MRP 8/14

MRT

MS

MOG

NADP

NAGM

NAWM

NOS

Nrf2

NQO1

PBS

PCR

PLP

PPMS
Antigen

Antikörper

amyloid precursor protein

Adenosintriphosphat

brain-derived neurotrophic factor

Chronisch aktiver Plaque

cluster of differentiation

Chronisch inaktiver Plaque

cyclic nucleotide phosphodiesterase

Diaminophenylindol

deoxyribonucleic acid (Desoxyribonukleinsäure)

experimental autoimmune enzephalomyelitis

fetal calf serum

glial fibrillary acidic protein

grey matter (graue Hirnsubstanz)

grey matter lesion

Glukose-Oxidase

Interferon gamma

Immunglobulin

Interleukin 1 beta

kelch-like ECH-associated protein 1

myelin-associated glycoprotein

myelin basic protein

Malondialdehyd

major histocompatibility complex

myeloid-related protein 8/14

Magnetresonanztomographie

Multiple Sklerose

myelin oligodendrocyte glycoprotein

Nicotinamid-Adenin-Dinucleotid-Phosphat

normal-appearing grey matter

normal-appearing white matter

NO-Synthetase

NF-E2-related factor 2

$N A D(P) H$ :quinone oxidoreductase 1

phosphate-buffered saline

polymerase chain reaction

proteolipid protein

primary progressive multiple sclerosis 


$\begin{array}{ll}\text { PRDX2 } & \text { Peroxiredoxin } 2 \\ \text { RNA } & \text { ribonucleic acid (Ribonukleinsäure) } \\ \text { RNS } & \text { reactive nitrogen species } \\ \text { ROS } & \text { reactive oxygen species } \\ \text { RRMS } & \text { relapsing-remitting multiple sclerosis } \\ \text { SPMS } & \text { secondary progressive multiple sclerosis } \\ \text { TGF- } \beta & \text { transforming growth factor beta } \\ \text { TH1-Zellen } & \text { T-Helferzellen vom Typ 1 } \\ \text { TNF-a } & \text { Tumornekrosefaktor alpha } \\ \text { WM } & \text { white matter (weiße Hirnsubstanz oder Marklager) } \\ \text { WML } & \text { white matter lesion } \\ \text { ZNS } & \text { Zentrales Nervensystem }\end{array}$




\section{EINLEITUNG}

\subsection{Epidemiologie, Ätiologie Und KLiniK der Multiplen SKLerose}

Multiple Sklerose (MS) ist eine chronisch entzündliche Erkrankung des zentralen Nervensystems (ZNS), die mit einem Verlust der Myelinscheiden (Entmarkung/Demyelinisierung) bei relativem Erhalt des axonalen Gerüstes einhergeht. Die Gesamtzahl der in Deutschland Erkrankten wird mit ca. 122.000 (Hein und Hopfenmüller 2000) und in neueren Untersuchungen mit bis zu 200.000 (Petersen et al. 2014) angegeben, wobei das mediane Erkrankungsalter bei 28 Jahren liegt. Die Hälfte der Patienten ist innerhalb von 15 Jahren auf eine Gehhilfe angewiesen (Noseworthy et al. 2000), womit MS die häufigste Ursache erworbener, nicht traumatisch bedingter Behinderung im jungen Erwachsenenalter ist (Dutta und Trapp 2007).

Die Ätiologie der MS ist nach wie vor nicht zufriedenstellend geklärt. Lediglich Faktoren, die eine Erkrankung an MS wahrscheinlicher machen oder mit bestimmten klinischen Verlaufsformen assoziiert sind, konnten identifiziert werden. Epidemiologische Untersuchungen zeigen eine familiäre Häufung von MS und eine erhöhte Prävalenz in einigen Bevölkerungsgruppen (Ebers et al. 1995). Zu den definierten genetischen Risikofaktoren gehören Suszeptibilitätsgene bzw. -allele aus der Gruppe der für den major histocompatibility complex (MHC) kodierenden Gene (HLA-DRB1, HLA-DRB2, HLA-DQB2) sowie beschriebene Polymorphismen (single-nucleotide polymorphisms) verschiedener Zytokinrezeptoren (IL2RA, IL7RA) und Membranproteine (CD58, CTLA-4) (Mäurer et al. 2002; International Multiple Sclerosis Genetics Consortium et al. 2007). Virusinfektionen mit Humanen Herpesviren, insbesondere dem Epstein-Barr-Virus (Thacker et al. 2006; Libbey et al. 2013), Umweltfaktoren wie Vitamin D3-Mangel (Smolders et al. 2008) und Rauchen (Hawkes 2007) erhöhen ebenfalls das Risiko an MS zu erkranken.

Die klinische Symptomatik der MS hängt von der Lokalisation und Ausdehnung der entzündlich entmarkten Herde/Läsionen ab. Häufig kommen motorische, sensible und kognitive Einschränkungen, Blasenentleerungsstörungen bei spinalen Läsionen und eine Ataxie bei Beteiligung des Kleinhirns vor. Anatomisch weniger gut zuordnen lässt sich das von ca. 50 \% der MS-Patienten beschriebene „nicht beherrschbare Gefühl der Erschöpfung“ (Fatigue) (Kroner-Milsch et al. 2012, S. 13), als dessen Ursache Störungen des Metabolismus und der Signaltransduktion von Neuronen diskutiert werden (Krupp 2003). 
Die Diagnose der MS stützt sich auf drei Säulen: Klinische Symptomatik, Bildgebung mittels Magnetresonanztomographie (MRT) und Liquordiagnostik. Die aktuell gültigen Diagnosekriterien wurden im Jahr 2000 von einem internationalen Konsortium definiert und seitdem mehrfach überarbeitet (McDonald et al. 2001; Polman et al. 2005; Polman et al. 2011; Thompson et al. 2018). Sie beziehen sich im Wesentlichen auf den Nachweis einer örtlichen und zeitlichen Dissemination von Läsionen und sind nur gültig, wenn kein anderer Krankheitsprozess vorliegt. Eine örtliche Dissemination liegt vor, wenn mindestens zwei Läsionen klinisch oder mittels MRT nachweisbar sind. Eine zeitliche Dissemination liegt vor, wenn zwei Schubereignisse eintreten oder mittels MRT verschiedene Läsionsalter (unterschiedliche Kontrastmittelanreicherung oder neue Läsionen in Folgeuntersuchungen) nachweisbar sind. Ein Schub ist definiert als Episode neurologischer Symptome, die länger als 24 h anhält und nicht mit Fieber oder einer Infektion verbunden ist. Das Vorhandensein oligoklonaler Banden im Liquor spielt ebenfalls eine diagnostische Rolle.

Ähnlich heterogen wie die beschriebenen Symptome ist der klinische Verlauf von MS. Man unterscheidet:

(1) Schubförmige Verläufe (relapsing-remitting multiple sclerosis, RRMS) mit anschließendem komplettem oder inkomplettem Rückgang der klinischen Symptome ohne Krankheitsprogression zwischen den Schüben und

(2) primär chronisch progrediente Verlaufsformen (primary progressive multiple sclerosis, PPMS) mit einer schleichend zunehmenden Beeinträchtigung und Behinderung des Patienten.

(3) Häufig beginnt die Erkrankung mit einem schubförmigen Verlauf und geht dann in eine sekundär progrediente Form mit oder ohne aufgelagerte Schübe über (secondary progressive multiple sclerosis, SPMS). Die Hälfte aller Patienten mit RRMS entwickelt innerhalb von elf bis 19 Jahren eine SPMS. Diese Zeitspanne ist kürzer bei höherem Erstdiagnose-Alter, bei männlichen Patienten und bei geringem Zeitintervall zwischen den ersten Schüben der Erkrankung (Vukusic und Confavreux 2003).

Besondere Relevanz, auch im Hinblick auf die therapeutischen Möglichkeiten, hat die Unterscheidung zwischen einer schubförmigen Erkrankung (1) und chronisch progredienten Erkrankungsformen (2 und 3). Akute Schübe kommen durch einen demyelinisierenden Entzündungsprozess zustande, der durch eingewanderte periphere Immunzellen induziert wird, und mit Immuntherapeutika (z. B. Glukokortikoiden) oder Plasmapherese beeinflussbar ist. Chronisch progrediente MS hat einen eher neurodegenerativen Charakter (Rovaris et al. 2006) und ist weitaus schlechter behandelbar. 


\subsection{ImMUNPATHOGENESE deR MULTIPLEN SKLEROSE}

Die in Schüben stattfindende Demyelinisierung bei MS ist auf eine T-Zell-vermittelte Entzündung im ZNS zurückzuführen, aufgrund derer die MS als entzündliche Autoimmunerkrankungen verstanden wird. Die wichtige Rolle von Lymphozyten in der Pathogenese von MS-Läsionen wird nicht zuletzt durch die Wirksamkeit von Therapien unterstrichen, die eine Migration dieser Zellen in das ZNS blockieren (z. B. Natalizumab, Fingolimod) oder periphere Immunzellen depletieren (z. B. Alemtuzumab oder Ocrelizumab).

Der Prozess von der Aktivierung des Immunsystems bis hin zur Demyelinisierung ist Gegenstand intensiver Forschung und im Wesentlichen in einem Tiermodell, der sog. experimental autoimmune enzephalomyelitis (EAE), erforscht worden. Die EAE wird entweder durch aktive Immunisierung der Tiere mit einem Myelinprotein (meistens myelin oligodendrocyte glycoprotein) als Modell für die immunologische Frühphase (aktive EAE) oder durch den Transfer autoreaktiver T-Helferzellen vom Typ 1 (TH1-Zellen) als Modell für die Effektorphase (passive EAE) induziert.

Auch bei Menschen, die nicht an MS erkrankt sind, lassen sich autoreaktive T-Zellen im Blut nachweisen, deren T-Zell-Rezeptor sich gegen Myelinbestandteile, insbesondere myelin basic protein, richtet (Ota et al. 1990; Pette et al. 1990). Das für die T-Zell-Aktivierung verantwortliche Antigen ist unbekannt. Hypothetisch wird davon ausgegangen, dass es zu einer Kreuzreaktivität zwischen viralen oder bakteriellen Proteinen und Myelinproteinen (molecular mimicry) kommt (Wucherpfennig und Strominger 1995). Zum endgültigen Verlust der Selbsttoleranz braucht es nicht nur die Aktivierung der T-Zellen durch antigenpräsentierende Zellen und die dazu nötigen kostimulatorischen Signale, sondern auch einen Ausfall weiterer Regulationsmechanismen, z. B. regulatorischer T-Zellen (Costantino et al. 2008).

Aktivierte T-Zellen patrouillieren durch das ZNS und können dort durch ortsständige Makrophagen und Mikroglia reaktiviert werden (Magnus et al. 2005). Die Aktivierung autoreaktiver T-Zellen im ZNS führt zu einer Freisetzung pro-entzündlicher Mediatoren. Dadurch werden weitere Entzündungszellen (T-Zellen, B-Zellen, Makrophagen) rekrutiert, die über die Blut-Hirn-Schranke (Chemotaxis, Adhäsion, Transmigration) in das ZNS einwandern. Des Weiteren kommt es zur intrathekalen Bildung von Antikörpern durch B-Zellen/Plasmazellen, zu einer Makrophagen/Mikroglia-Aktivierung und MyelinDegradation sowie zur Schädigung von Axonen und Oligodendrozyten. 


\subsection{Pathologie der Multiplen SkLerose}

Makropathologisch findet die Demyelinisierung bei MS in scharf begrenzten Herden/Läsionen/Plaques statt. Diese sind hellgrau oder rötlich (bei akuter Entzündung) und aufgrund der Gliose (siehe Kapitel 1.3.4, Seite 9) palpatorisch häufig von festerer Konsistenz (Kroner-Milsch et al. 2012, S. 11). Die Läsionen können überall im ZNS gefunden werden, treten aber vermehrt an Prädilektionsstellen wie den Sehnerven, dem periventrikulären Marklager, den Kleinhirnstielen und dem Rückenmark, sowie innerhalb des Kortex am häufigsten subpial auf (Stadelmann et al. 2008). Makroskopisch kann es schwer bzw. unmöglich sein, remyelinisierte und kortikale Läsionen zu erkennen.

Histopathologisch zeichnen sich MS-Läsionen durch einen meist scharf demarkierten selektiven Verlust der Myelinscheiden bei relativem Erhalt der Axone aus. Begleitet wird die Demyelinisierung, je nach Läsionsalter und Lokalisation, von einem Immunzellinfiltrat (Makrophagen, T- und B-Zellen), einer Aktivierung ortsständiger Mikroglia, neuroaxonalen Schäden und einer Astrogliose (Brück und Stadelmann 2003). Demyelinisierung und Entzündung sind in den folgenden Kapiteln über die Läsionen der weißen und grauen Substanz näher beschrieben. Den neuroaxonalen Schäden und den morphologischen Veränderungen der Astrozyten ist jeweils ein extra Kapitel gewidmet.

\subsubsection{LÄSIONEN DER WEIßEN SUBSTANZ I WHITE MATTER LESIONS}

Läsionen der weißen Substanz des ZNS, im Folgenden als white matter lesions (WML) bezeichnet, werden bei MS, je nach Fragestellung, unterschiedlich klassifiziert. Alle Klassifikationen orientieren sich am Ausmaß der Entzündung und der stattfindenden Demyelinisierung (Van der Valk und De Groot 2000).

Entzündliche Läsionen mit aktiver Demyelinisierung sind vorwiegend in Biopsie-Material zu finden und zeichnen sich durch die Phagozytose von Myelin-Bestandteilen durch Makrophagen und aktivierter Mikroglia aus. Dementsprechend finden sich in der Läsion schaumzellige Makrophagen, in deren Phagosomen sich bei früh-aktiven Läsionen die Myelinproteine myelin basic protein (MBP), proteolipid protein (PLP), myelin oligodendrocyte glycoprotein (MOG), myelin-associated glycoprotein (MAG) und cyclic nucleotide phosphodiesterase (CNPase) finden lassen. Die Myelinproteine MOG und CNPase, die nur einen geringen Anteil aller Myelinproteine ausmachen, werden nach Phagozytose rascher abgebaut als MBP und PLP (Van der Goes et al. 2005). So kann, unter zusätzlicher Zuhilfenahme der Makrophagen-Antigene myeloid-related protein 8 
(MRP8) und myeloid-related protein 14 (MRP14), das ungefähre Läsionsalter abgeschätzt werden (Brück et al. 1995). In spät-aktiven Läsionen, die vier bis zehn Tage alt sind, finden sich nur noch die Myelinproteine MBP und PLP in den Makrophagen, sowie bereits ein Verlust des frühen Aktivitäts-Markers MRP14. Anhand des Vorkommens von Plasmazellen, Komplement- und IgG-Ablagerungen sowie des Ausmaßes der Oligodendrozyten-Apoptose werden früh-aktive WML in verschiedene Subtypen eingeteilt (Lucchinetti et al. 2000). Die Subtypen I und II zeigen dabei Ähnlichkeiten mit einer durch T-Zellen vermittelten Enzephalomyelitis, die Subtypen III und IV sind primär gekennzeichnet durch die Degeneration von Oligodendrozyten (unter anderem einer beeinträchtigten MAG-Expression) und erinnern in ihrer Erscheinung eher an eine Virus- oder Toxin-induzierte Demyelinisierung. Subtyp III Läsionen sind zudem von einem Saum apoptotischer Oligodendrozyten umgeben, der von einigen Autoren (Lassmann 2011) als initial lesion bezeichnet wird (siehe unten) und die Läsionsgrenze unscharf erscheinen lässt. Es ist nicht geklärt, ob die verschiedenen Subtypen durch interindividuelle Unterschiede und unterschiedliche pathogenetische Mechanismen zustande kommen oder ob es sich um verschiedene Stadien innerhalb der Krankheitsentwicklung handelt.

Entzündliche Läsionen ohne aktive Demyelinisierung enthalten in den Arealen mit geschädigten Myelinscheiden reichlich schaumzellige Makrophagen, in deren Phagosomen sich jedoch keine Myelinbestandteile mehr finden (Van der Valk und De Groot 2000). Liegt der Schwerpunkt der Betrachtung auf der stattfindenden Demyelinisierung, so liegt es nahe, diese Läsionen als „inaktiv“ zu bezeichnen (Brück et al. 1995).

Chronisch inaktive Plaques (CIPs): Länger bestehende WML, in denen die Entzündung weitgehend zurückgegangen ist, haben ein hypozelluläres (Fehlen von Oligodendrozyten und Entzündungszellen), demyelinisiertes Zentrum, das von einem dichten Netz astrozytärer Fortsätze geprägt ist. Diese fibrilläre Astrogliose gibt den Läsionen im Rahmen einer Palpation während der Autopsie einen harten Aspekt, ähnlich einer Narbe, und wurde von Jean-Martin Charcot 1868 als la sclérose en plaques (Charcot 1868) beschrieben. Sind keine Makrophagen mit phagozytierten Myelinbestandteilen zu finden, werden die Läsionen als chronisch inaktiv bezeichnet.

Als chronisch aktive Plaques (CAPs) werden WML mit vollständig demyelinisiertem Zentrum und aktiver Demyelinisierung im Randbereich bezeichnet. Im Randbereich dieser Läsionen findet sich entsprechend ein Saum aktivierter Mikroglia und vereinzelt Myelin-phagozytierende Makrophagen/Mikroglia sowie einzelne Lymphozyten. 
In der nahen Umgebung von WML, aber auch ohne Assoziation zu Läsionen, können sich Veränderungen der weißen Hirnsubstanz (white matter, WM) bei MS finden, die nicht durch ein dichtes Immunzellinfiltrat oder Demyelinisierung charakterisiert sind. Zu diesen Veränderungen gehören aktivierte/ramifizierte Mikroglia (immunopositiv für CD45, CD68 und MHC-II) und Mikroglia-Knötchen (Henderson et al. 2009; Singh et al. 2013), sowie vereinzelte perivaskuläre aber auch parenchymatöse T-Zellen (Lassmann 2011).

In unmittelbarer Umgebung einiger aktiver WML werden zudem Auflockerungen des Myelins, apoptotische Oligodendrozyten (Barnett und Prineas 2004) und akute axonale Schäden (Sphäroide) beschrieben. Diese Veränderungen werden unter den Begriffen preactive lesion, pre-phagocytic lesion oder initial lesion zusammengefasst, auch wenn kausalpathologisch nicht geklärt ist, ob es sich wirklich um Vorläufer der aktiven WML handelt. Die beschriebene Schädigung der Oligodendrozyten und Axone in diesen Arealen wird unter anderem auf oxidativen Stress (Haider et al. 2011; Fischer et al. 2012) und mitochondriale Veränderungen zurückgeführt (Mahad et al. 2008).

\subsubsection{LÄSIONEN DER GRAUEN SUBSTANZ I GREY MATTER LESIONS}

Läsionen der grauen Substanz, grey matter lesions (GML), kommen bei MS sowohl im Kortex (cortical GML) (Brownell und Hughes 1962), Thalamus, Hypothalamus, Basalganglien, Amygdala und Claustrum (deep GML) (Vercellino et al. 2009), als auch im Kleinhirn (Kutzelnigg et al. 2007), Hirnstamm (Pons und medulla oblongata) und Rückenmark (Taylor 1894; Gilmore et al. 2006) vor. Kortikale Demyelinisierung findet sich bei über 90 \% aller MS-Patienten mit langer Krankheitsdauer und betrifft bei diesen Patienten im Mittel 20-40 \% des Kortex, kann aber auch wesentlich ausgedehnter sein (Kutzelnigg et al. 2005; Albert et al. 2007). Vergleicht man kortikale GML mit WML, so sind diese histopathologisch durch weniger Immunzellinfiltrat (Bø et al. 2003a), weniger Gliose (Peterson et al. 2001) und eine effektivere Remyelinisierung (Albert et al. 2007) gekennzeichnet. Diese histopathologischen Charakteristika sowie eine allgemein geringere Dichte des Myelins im Kortex machen GML in Routinefärbungen unauffälliger. Zudem sind GML mit konventionellen MRT-Techniken und -Sequenzen schwer darstellbar (Geurts et al. 2005).

Untersuchungen an Biopsiematerial zeigen, dass bei MS auch in frühen Krankheitsstadien kortikale GML auftreten. Diese frühen kortikalen GML sind mit wesentlich mehr entzündlicher Aktivität assoziiert als die beschriebenen chronischen GML. So finden sich schaumzellige, myelinphagozytierende Makrophagen (bei ca. 40 \% der untersuchten 
GML), perivaskuläre T-Zellen und ein meningeales B- und T-Zellinfiltrat (Lucchinetti et al. 2011).

Kortikale GML werden anhand ihrer Lokalisation innerhalb des Kortex eingeteilt. Dabei orientierte sich Kidd et al. (1999) an der durch Duvernoy et al. (1981) beschriebenen venösen Blutdrainage des Kortex. Diese Einteilung hat sich nicht vollständig gehalten und so unterscheidet man derzeit im Wesentlichen die in Tabelle 1 dargestellten drei Typen kortikaler GML (Peterson et al. 2001; Bø et al. 2003b).

Tabelle 1: Einteilung kortikaler Läsionen nach Lokalisation und deren Charakteristika

\begin{tabular}{ll}
\hline Typ I & Leukokortikale Läsionen \\
& Häufiger Läsionstyp mit vergleichsweise viel Entzündung und Gliose \\
& (Peterson et al. 2001; Lucchinetti et al. 2011). \\
\hline Typ II & Kleine, intrakortikale Läsionen \\
& Seltener Läsionstyp, der meist in der Umgebung kleiner Venen zu finden ist. \\
\hline Typ III & Subpiale Läsionen \\
& Häufigster und ausgedehntester Läsionstyp, der mit meningealen Lymphozyten-Aggregaten \\
& assoziiert ist und spezifisch für MS zu sein scheint (Fischer et al. 2013). \\
\hline
\end{tabular}

In Anbetracht ihrer histologischen Merkmale stellt sich die Frage, ob sich GML (insbesondere subpiale Läsionen) nicht auch hinsichtlich ihrer Pathogenese von WML unterscheiden (Stadelmann et al. 2008). Eine fehlende Korrelation zwischen der Ausdehnung von WML und GML (Kutzelnigg et al. 2005) spricht zudem gegen eine sekundäre Genese (Wegner und Stadelmann 2009).

\subsubsection{NeUronale und axonale Degeneration}

Die graue Hirnsubstanz, grey matter (GM), enthält per definitionem die neuronalen Perikaryen und synaptischen Verschaltungen. So liegt es nahe, den hier stattfindenden pathologischen Prozessen bei MS eine besondere Aufmerksamkeit im Hinblick auf kognitive Beeinträchtigung, Fatigue und Neurodegeneration zu schenken. Auf welche Weise Entzündung, Atrophie, Demyelinisierung und Neurodegeneration zusammenhängen, ist kausalpathogenetisch unklar. Beschränkt auf die kortikale GM wurden folgende Beobachtungen gemacht: 
(1) Kortikale Atrophie tritt bereits in frühen Krankheitsstadien auf und korreliert mit der neurologischen Beeinträchtigung (De Stefano et al. 2003; Fisher et al. 2008).

(2) Leukokortikale GML (Typ I), die verglichen mit den anderen GML-Typen relativ viel Entzündung und Gliose enthalten, zeigen eine reduzierte neuronale und synaptischen Dichte (Wegner et al. 2006) sowie akute axonale Schäden (Peterson et al. 2001).

(3) Bei vielen Patienten mit SPMS finden sich meningeale Lymphozyten-Aggregate. Diese Aggregate sind häufig mit subpialen GML (Typ III) assoziiert, stellen aber keine notwendige Voraussetzung für diesen Läsionstyp dar (Albert et al. 2007). Ebenso wird eine Reduktion aller kortikalen Zellen, sowohl in GML als auch im normal myelinisierten Kortex (normal-appearing grey matter, NAGM), bei Patienten mit SPMS beschrieben (Magliozzi et al. 2010). Eine reduzierte Anzahl von Neuronen wurde in dieser Studie nur in der Gruppe der Patienten mit meningealen Lymphozyten-Aggregaten, unabhängig von der Myelinisierung, gefunden.

Obwohl „Demyelinisierung“ als Verlust der Myelinscheiden bei relativem Erhalt der Axone definiert ist, was sie von einer Gewebenekrose unterscheidet, kommt es bei MS bereits in frühen Krankheitsstadien und im Verlauf der Erkrankung zu irreversiblen axonalen Schäden (Durchtrennung von Axonen und Waller'sche Degeneration), die mit der Zeit zu einer Reduktion der axonalen Dichte führen (Trapp et al. 1998; Dutta und Trapp 2007). Schädigung und Untergang von Axonen, untersucht in diversen bildgebenden und pathologischen Studien, gelten als wichtigstes Korrelat der klinischen Progression und irreversiblen Beeinträchtigung (De Stefano et al. 1995; Matthews et al. 1998).

Akuter axonaler Schaden in Form von dephosphoryliertem Neurofilament, gestörtem axonalen Transport (histologisch sichtbar durch die Akkumulation von amyloid precursor protein/APP in Sphäroiden) und durchtrennten Axonen korreliert stark mit der Anwesenheit von Makrophagen und zytotoxischen T-Zellen in aktiven und chronischen WML (Kuhlmann et al. 2002). Aber auch in chronisch demyelinisierten Läsionen mit wenig Entzündungsinfiltrat und in normal myelinisierter WM (normal-appearing white matter, NAWM) finden sich in geringerem Ausmaß APP-positive Sphäroide (Kornek et al. 2000). Dabei sind die Mechanismen der Schädigung von Axonen nicht vollständig geklärt. Unter anderem wird davon ausgegangen, dass die Axone durch ihre räumliche Nähe zum demyelinisierenden Entzündungsprozess (bystander pathway) und den Verlust der Myelinscheide (trophic pathway) geschädigt werden (Matthews et al. 1998). Auch hier, wie bereits für den Untergang von Oligodendrozyten in sog. initial lesions beschrieben, scheint oxidativer Stress (Smith und Lassmann 2002; Frischer et al. 2009; Haider et 
al. 2011) und die Beeinträchtigung der Mitochondrien eine wichtige Rolle zu spielen (Dutta et al. 2006; Witte et al. 2014).

\subsubsection{MORPHOLOGISCHE VeRÄNDERUNGEN DER AstrozyTEN}

Neben den Neuronen als kleinste funktionelle Einheit, den Oligodendrozyten als myelinbildende Zellen und der Mikroglia als ortsständige Phagozyten, erfüllen Astrozyten zahlreiche wichtige Aufgaben im ZNS. So spielen sie eine entscheidende Rolle in der Aufrechterhaltung der Homöostase (z. B. Regulation der extrazellulären Kalium- und Glutamat-Konzentration) und sind mit ihren Ausläufern (membrana limitans gliae perivascularis) am Aufbau der Blut-Hirn-Schranke beteiligt (Lüllmann-Rauch 2006, S. 181). Im Rahmen pathologischer Prozesse (z. B. bei Ischämien, Entzündungen, Neoplasien) modulieren sie immunologische Prozesse und Reparaturmechanismen (Meeuwsen et al. 2003). Nicht zuletzt können sie durch die Ausbildung von gliotischen Narben untergegangenes Gewebe „ersetzen“ (z. B. im Zentrum chronisch inaktiver MS-Läsionen) oder nach dem Abbau einer ischämischen Nekrose durch Makrophagen die liquorgefüllten Pseudozysten auskleiden.

Astrozyten reagieren auf pathologische Prozesse sehr sensibel mit einer Veränderung ihrer Morphologie (Astrogliose), was bei der lichtmikroskopischen Beurteilung von ZNSGewebe als eines der sichersten Zeichen für krankhafte Vorgänge gilt (Seilheyn et al. 2014, S. 11). Die in Ruhe sternförmigen Zellen zeigen im Rahmen akuter Prozesse einen vergrößerten, abgerundeten, plumpen Zellleib, was den Zellen insbesondere in der WM ein „gemästetes“ Aussehen gibt und zu dem Begriff „gemistozytäre Astrogliose“ geführt hat (Kuchelmeister 2012, S. 13). Das Zytoplasma dieser Astrozyten ist in der Hämatoxylin-Eosin(HE)-Färbung homogen eosinophil oder glasig-hyalin und zeigt in der immunhistochemischen Färbung des astrozytären Intermediärfilaments glial fibrillary acidic protein (GFAP) eine stark positive Färbung (Sofroniew und Vinters 2010). Meist findet sich zudem ein hypertropher, oft hyperchromatischer, exzentrisch liegender Zellkern. Neben der Zellhypertrophie kommt es im Laufe der reaktiven Astrogliose zu einer Hyperplasie der Astrozyten. Begleitet wird diese von Kernveränderungen wie z. B. Mehrkernigkeit (Kuchelmeister 2012, S. 16). Oft finden sich auch unterschiedlich große Mikronuklei. Die Astrozyten werden dann als Creutzfeld-Peters-Zellen bezeichnet und können in Biopsien einen entscheidenden Hinweis auf das Vorliegen einer demyelinisierenden Erkrankung geben. Reaktive Astrozyten finden sich bei MS in aktiven WML und der Umgebung chronisch aktiver und inaktiver WML. In GML ist die Astrogliose wesentlich geringer ausgeprägt. 
Bei chronischem Gewebeschaden (z. B. Nekrose oder Demyelinisierung) kommt es zu einer fibrillären Astrogliose. Die unter diesen Umständen nicht mehr hypertrophen Astrozyten bilden mit ihren Zellfortsätzen ein dichtes GFAP-positives Geflecht, das bereits bei der Beschreibung chronisch demyelinisierter WML zur Sprache kam.

\subsection{ENTZÜNDLICHES MILIEU UND OXIDATIVER STRESS}

\subsubsection{DAS ENTZÜNDUNGSGESCHEHEN BEI MULTIPLER SKLEROSE WIRD DURCH ZYTOKINE MEDIIERT}

Die Interaktion von Immunzellen untereinander und mit dem ZNS-Gewebe (Mikroglia, Endothel, Astrozyten, Neurone etc.) findet sowohl über direkte Zell-Zell-Kontakte als auch über lösliche Mediatoren statt. Zytokine sind Proteine von geringer molekularer Größe, die als Entzündungsmediatoren lokal entweder parakrin oder autokrin eine rezeptorvermittelte Wirkung entfalten (Navikas und Link 1996). Welche Zellen von dem lokalen Zytokinmilieu in welcher Weise beeinflusst werden, hängt entscheidend von den Rezeptoren und den daran gekoppelten Signalwegen der jeweiligen Zelle ab (John et al. 2003). Neben der groben Einteilung in pro-entzündliche Zytokine und anti-entzündliche Zytokine ist es daher wichtig, das vorherrschende Zytokinmilieu unter definierten Umständen (z. B. in entzündlichen Läsionen bei MS) und deren Wirkung auf einzelne Zellpopulationen (z. B. Astrozyten) zu beschreiben.

Entzündliche WML mit und ohne stattfindende Demyelinisierung zeichnen sich unter anderem durch die Anwesenheit aktivierter TH1-Zellen aus, die Interferon gamma (IFN- $\boldsymbol{\gamma}$ ) produzieren. Dies führt zur Aktivierung von Makrophagen, einer erhöhten MHCExpression und zur Rekrutierung weiterer Lymphozyten (homing) in das ZNS-Gewebe (Navikas und Link 1996). Während IFN- $\gamma$ präferenziell von Lymphozyten und NK-Zellen (Natural Killer Cells) sezerniert wird, können Interleukin 1 beta (IL-1ß), Tumornekrosefaktor alpha (TNF- $\boldsymbol{\alpha}$ ) und weitere Zytokine durch die Aktivierung des Transkriptionsfaktors NF- $\kappa \mathrm{B}$ auch von Makrophagen, Mikroglia und Astrozyten produziert werden (Brambilla et al. 2009; Brosnan und Raine 2013). TNF- $\alpha$ ist ein wichtiger entzündungsverstärkender Mediator in MS-Läsionen mit akut oder chronisch stattfindender Demyelinisierung (Selmaj et al. 1991).

Auch für die Limitierung der Entzündungsreaktion und die Initiation von Regenerationsprozessen (Remyelinisierung) spielen Zytokine eine wichtige Rolle. Ein Beispiel dafür ist der durch Lymphozyten, Makrophagen, Mikroglia und Astrozyten produzierte Wachs- 
tumsfaktor transforming growth factor beta 1 (TGF- $\beta 1$ ) (John et al. 2003). TGF- $\beta 1$ inhibiert die Produktion pro-entzündlicher Zytokine, wie TNF- $\alpha$ und IL-1 $\beta$ (Suzumura et al. 1993; Benveniste et al. 2001), fördert die Bildung von gliotischem Narbengewebe und ist in entzündlich aktiven WML sowie in chronisch demyelinisierten WML zu finden (De Groot et al. 1999).

Astrozyten sind nicht nur in der Lage durch die Produktion von Zytokinen das entzündliche Geschehen aktiv zu modulieren, sondern werden ihrerseits durch Zytokine beeinflusst. So exprimieren sie Rezeptoren für IFN- $\gamma$, IL-1 $\beta$, TNF- $\alpha$, TGF- $\beta 1$ (Meeuwsen et al. 2003). Besonders IFN- $\gamma$ und IL-1 $\beta$ bewirken eine reaktive Astrogliose (Giulian et al. 1988; Yong et al. 1991).

\subsubsection{HERKUnft REAKTIVER SAUERSTOFF- UND StickStofFVERBINDUNGEN}

Im Rahmen dieser Studie wurde das antioxidative Enzym Peroxiredoxin 2 im ZNS autopsierter MS-Patienten untersucht. Um die Ergebnisse der Arbeit einzuordnen, soll im Folgenden eine Einführung in die Herkunft reaktiver Sauerstoff- und Stickstoffverbindungen, sowie deren Wirkung auf Zellen und Gewebe gegeben werden. Reaktive Sauerstoff- und Stickstoffverbindungen entstehen (1) als Nebenprodukte der Atmungskette, (2) im Rahmen von Entzündungsprozessen und (3) enzymatischen Reaktionen sowie (4) durch exogene Einflüsse/Zufuhr.

Nebenprodukte der Atmungskette (1): Der zentrale energiebringende Mechanismus fast aller Zellen des menschlichen Organismus ist die Reduktion von Sauerstoff $\left(\mathrm{O}_{2}\right)$ in den Mitochondrien, die über die Atmungskette energetisch an die Bildung von Adenosintriphosphat (ATP) durch die ATP-Synthase (oxidative Phosphorylierung) gekoppelt ist (Mitchell 2015, S. 14). Wenn innerhalb der Atmungskette statt zweier Elektronen nur ein Elektron auf Sauerstoff übertragen wird, also eine Reduktion von Sauerstoff stattfindet, die nicht durch Addition zweier Protonen $\left(\mathrm{H}^{+}\right)$zu Wasser $\left(\mathrm{H}_{2} \mathrm{O}\right)$ führt, entsteht das Superoxidanion $\mathrm{O}^{2-}$ (Shadel und Horvath 2015). Diese fehlerhafte Übertragung eines Elektrons tritt immer dann vermehrt auf, wenn der vorgesehene Weg der Elektronen durch die Atmungskette gestört ist (Quinlan et al. 2013). Zellen und ihre Kompartimente, insbesondere die Mitochondrien selbst, sind in der Regel auf dieses immer in geringen Mengen anfallende Nebenprodukt der Atmungskette vorbereitet. So katalysiert das Enzym Superoxiddismutase die Reduktion von Superoxid zu Sauerstoff und Wasserstoffperoxid (Shadel und Horvath 2015). Wasserstoffperoxid $\left(\mathrm{H}_{2} \mathrm{O}_{2}\right)$ kann durch das Enzym 
Katalase, durch Glutathion-Peroxidase oder Peroxiredoxine zu Wasser und Sauerstoff abgebaut und damit unschädlich gemacht werden. Alternativ entsteht durch die Fenton-Reaktion $\left(\mathrm{H}_{2} \mathrm{O}_{2}+\mathrm{e}^{-} \rightarrow \cdot \mathrm{OH}+\mathrm{OH}^{-}\right)$das noch schädlichere Hydroxyl-Radikal $(\cdot \mathrm{OH})$. Die Fenton-Reaktion findet besonders in Anwesenheit von Ionen der Übergangsmetalle (z. B. Eisen $/ \mathrm{Fe}^{2+}$ ) als Elektronendonatoren statt (Reis und Spickett 2012). Radikale zeichnen sich durch ein ungepaartes Elektron aus und sind daher hochreaktiv und zellschädigend (Kumar et al. 2015, S. 47). Die beschriebenen reaktiven Sauerstoffverbindungen $\left(\mathrm{O}^{2-}\right.$, $\left.\mathrm{H}_{2} \mathrm{O}_{2}, \cdot \mathrm{OH}\right)$, sowie organische Hydroperoxide ( $\left.\mathrm{ROOH}\right)$ werden in der englischsprachigen Literatur und im Rahmen dieser Arbeit als reactive oxygen species (ROS) bezeichnet.

Produktion durch aktivierte Entzündungszellen (2): Entzündungszellen, insbesondere neutrophile Granulozyten, sind in der Lage Pathogene durch den gezielten Einsatz von reaktiven Sauerstoff- und Stickstoffverbindungen zu schädigen. Welche Auswirkungen es hat, wenn diese Funktion der Entzündungszellen beeinträchtig ist, wird bei der Septischen Granulomatose (chronic granulomatous disease), einer hereditären Immundefizienz, deutlich. Die Erkrankung ist auf Gendefekte einzelner Untereinheiten der NADPHOxidase zurückzuführen (Kuhns et al. 2010). Die fünf Untereinheiten des NADPH-Oxidase-Komplexes NOX2 sind p22phox (Genname: CYBA), gp91phox (CYBB), p47phox (NCF-1), p67phox (NCF-2) und p40phox (NCF-4). Für alle Untereinheiten sind Mutationen bekannt, die zu einer Immundefizienz führen. Aber auch wenn jeder einzelne Teil der NADPH-Oxidase funktionsfähig ist, wird die ROS-Produktion präzise durch die Phosphorylierung (Aktivierung) von p47phox sowie die Interaktion von p67phox mit den aktivierten Signalproteinen Rac1 oder Rac2 reguliert (Hordijk 2006). Auch eine hereditäre Rac2-Mutation, durch die es zu einer verminderten NADPH-Oxidase-Aktivität kommt, kann über den beschriebenen Mechanismus zu einer Immundefizienz führen (Williams et al. 2000).

Eine weitere mögliche Quelle reaktiver Moleküle im Rahmen von Entzündungsprozessen stellt die induzierbare NO-Synthetase (iNOS) dar. Verschiedene Isoformen der NO-Synthetasen generieren entweder konstitutiv oder fakultativ das kurzlebige Stickstoffmonoxid (nitric oxide, ·NO) aus der Aminosäure Arginin (Marletta 1993). Stickstoffmonoxid hat als Botenstoff innerhalb des Organismus wichtige physiologische Funktionen. Synthetisiert durch die endotheliale NOS (eNOS) sorgt es als vasoaktiver Botenstoff über die Aktivierung der löslichen Guanylatzyklase für eine Relaxation glatter Gefäßmuskulatur (Prieto 2007). Als neuronaler Botenstoff, synthetisiert durch die neuronale NOS (nNOS), ist es an der Modulation synaptischer Prozesse beteiligt (Hardingham et al. 2013). Im Gegensatz zur eNOS und nNOS, die über verschiedene Signalwege fakultativ aktiviert werden, ist die im Rahmen von Entzündungsprozessen exprimierte iNOS v.a. auf Transkriptionsebene reguliert (Nathan und Xie 1994). Proentzündliche Zytokine wie IL-1 und 
IFN- $\gamma$ sind, besonders in Kombination, ein potenter Expressions-Stimulus für humane Zellen (Liu et al. 2001). Stickstoffmonoxid erfüllt im Rahmen entzündlicher Prozesse seine Funktion als zellschädigendes Radikal, das potentielle Pathogene angreift. Besonders die durch Auto-Oxidation entstehenden Moleküle Stickstoffdioxid ( $\left.\mathrm{NO}_{2}\right)$, Stickstofftrioxid $\left(\mathrm{N}_{2} \mathrm{O}_{3}\right)$, S-Nitrosothiol (R-SNO) und das aus der Kombination mit Superoxid $\left(\mathrm{O}^{2-}\right)$ entstehende Peroxinitrit $\left(\mathrm{ONOO}^{-}\right)$sind hochreaktiv und greifen Lipide, Proteine und Desoxyribonukleinsäure (deoxyribonucleic acid, DNA) an (Liu et al. 2001). Die beschriebenen Stickstoffverbindungen werden in der englischsprachigen Literatur und im Rahmen dieser Arbeit als reactive nitrogen species (RNS) bezeichnet.

ROS/RNS werden auch durch einige weitere Enzyme (3) generiert: Myeloperoxidase, Peroxidase der eosinophilen Granulozyten, Lipoxigenase und Xanthinoxidase. Sie können ebenso als Nebenprodukt aller enzymatisch katalysierten Redoxreaktionen, z. B. im Rahmen der Entgiftung organischer Verbindungen durch Cytochrom-P450-Enzyme (Monoxygenasen), entstehen.

Exogen (4) bedingt entstehen freie Radikale durch UV- und Röntgenstrahlung und sie sind im Tabakrauch enthalten.

\subsubsection{Die Wirkung von ROS Und RNS AUf ZeLLen Und GeWebe}

Eine Zelle erfährt oxidativen Stress, wenn sie nicht mehr in der Lage ist, reaktive Sauerstoff- und Stickstoffverbindungen zu beseitigen und/oder es ihr nicht gelingt, die durch diese Moleküle verursachten Schäden zu beheben. Da ROS/RNS sehr kurzlebige Moleküle sind, ist es schwer, sie in Autopsiegewebe direkt zu messen. Indirekt gibt das Vorhandensein spezifischer Zellschäden (oxidierte Lipide, Proteine und DNA) eine Auskunft über die (ehemalige) Anwesenheit von ROS/RNS.

Fettsäuren (FS) sind ein integraler Bestandteil von Phospholipiden und damit Zellmembranen und Myelinscheiden. Mehrfach ungesättigte FS enthalten durch ihre Doppelbindungen präferierte Angriffspunkte für ROS/RNS. Je nach Reaktionspartner kann dadurch eine enorme Vielfalt oxidierter Phospholipide entstehen (Reis und Spickett 2012). Beispielsweise entziehen Hydroxyl-Radikale (·OH) an Doppelbindungen ungesättigter FS unter Bildung von Wasser ein Wasserstoffatom und hinterlassen ein ungepaartes Elektron, das mit molekularem Sauerstoff reagiert. Das so entstehende FS-Peroxylradikal (R-OO·) entzieht unter Bildung von FS-Hydroperoxid (R-OOH) anderen ungesättigten FS wiederum ein Wasserstoffatom und setzt damit eine Kettenreaktion in Gang (Reis und 
Spickett 2012). Unterbrochen wird diese Lipoxidationskette durch Radikalfänger wie $\alpha$-Tocopherol (Vitamin E) und Ascorbinsäure (Vitamin C) (Kumar et al. 2015, S. 48). Ein anderes durch Lipoxidation entstehendes Produkt ist Malondialdehyd (MDA, Propandial). MDA ist ein hochreaktives Dialdehyd, das z. B. Lysin-Addukte bildet (Onorato et al. 1998) und dadurch Proteine modifiziert. MDA ist durch spezifische Antikörper im Gewebe detektierbar, was es zu einem interessanten Marker für oxidativen Stress macht (Haider et al. 2011).

Proteine/Peptide können durch eine Veränderung der Seitenketten ihrer Aminosäuren modifiziert werden, was Auswirkungen auf ihre Funktion (z. B. Signaltransduktion, Enzymaktivität) hat. Insbesondere Peroxinitrit (ONOO-) ist in der Lage, Cystein (Cys, C) und Tyrosin (Tyr, Y) zu nitrieren (Hooper et al. 2000). Das dadurch entstehende Nitrotyrosin ( $\left.\mathrm{NO}_{2}-\mathrm{Tyr}^{-}\right)$kann als stabiler biochemischer Marker die (ehemalige) Anwesenheit von Peroxinitrit in Geweben anzeigen (Beckman und Koppenol 1996; Jack et al. 2007). Neben den Aminosäuren werden aktive Zentren von Metalloproteinen insbesondere durch Stickstoffmonoxid modifiziert. Als Beispiele sind an dieser Stelle die Inhibition antioxidativer Enzyme (Dobashi et al. 1997) und Komponenten der Atmungskette (Stadler et al. 1991) zu nennen.

Neben Lipiden und Peptiden können auch Nukleinsäuren durch ROS/RNS angegriffen werden, was unter anderem zu Strangbrüchen (Szabó 1996) und zur Bildung von 8-Nitroguanin (Yermilov et al. 1995) oder 8-Hydroxy-D-Guanosin (Inoue und Kawanishi 1995) führt. Ersteres ist instabil und kann sich spontan von seiner (Desoxy)Ribose lösen was zu einer apurinen Stelle führt. Letzteres ist stabiler und kann durch Antikörper in Geweben detektiert werden (Haider et al. 2011). Bei der Replikation oder Transkription kodieren sowohl apurine Stellen als auch 8-Hydroxy-D-Guanosin bevorzugt für Adenin statt Cytosin (Shibutani et al. 1991; Hiraku 2010) und auf diese Weise kommt es zu Punktmutationen bzw. fehlerhaften Transkripten.

Wie bereits beschrieben, sind Mitochondrien ein Produzent von ROS (Shadel und Horvath 2015). Gleichzeitig sind mitochondriale Nukleinsäuren und Proteine selbst anfällig für Schäden durch ROS/RNS. Auch wenn nahezu alle mitochondrialen Proteine durch die nukleäre DNA (nDNA) kodiert sind, haben Mitochondrien ein eigenes Genom, das für 13 an der Atmungskette beteiligte Polypeptide kodiert und als zirkuläre mitochondriale DNA (mtDNA) in mehreren Kopien in der mitochondrialen Matrix liegt (Lin und Beal 2006; Nunnari und Suomalainen 2012). Neben dem Aufbau der mtDNA unterscheiden sich auch die Replikations-, Transkriptions- und Reparaturmechanismen der mtDNA von 
der nDNA, was auf die bakterielle Herkunft der Mitochondrien hinweist (Endosymbiontentheorie). Mit dem Alter und durch die Einwirkung von ROS/RNS akkumulieren Deletionen und Mutationen in der mtDNA (Corral-Debrinski et al. 1992). Zudem können andere durch ROS/RNS vermittelte Schäden die Mitochondrien funktionell beeinträchtigen. So wurde gezeigt, dass Stickstoffmonoxid konzentrationsabhängig reversibel und irreversibel die ATP-Produktion senkt (Brorson et al. 1999). Durch die zentrale Funktion der Mitochondrien in der Energiebereitstellung und durch ihre Beteiligung an Vorgängen wie Apoptose und endogener ROS-Produktion wirken sich mitochondriale Schäden auf die ganze Zelle aus.

\subsubsection{ANTIOXIDATIVE MOLEKÜLE UND SYSTEME}

Eine ganze Gruppe verschiedener Moleküle ist in der Lage ROS/RNS abzufangen oder abzubauen, bevor Zellschäden entstehen. Dadurch können sie den oxidativen Stress der Zelle wortwörtlich reduzieren. Häufig sind mehrere Reaktionsschritte aneinandergekoppelt, in denen $\mathrm{NAD}(\mathrm{P}) \mathrm{H}$ als Elektronendonator dient. Eine Übersicht wichtiger antioxidativer Moleküle und Systeme gibt Tabelle 2.

Tabelle 2: Übersicht wichtiger antioxidativer Moleküle und Systeme

\begin{tabular}{ll} 
Gruppe & Molekülname \\
\hline Direkt katalytisch Enzyme & Superoxiddismutase (SOD) \\
& Katalase (CAT) \\
\hline GSH-System & Glutathione (GSH) \\
GSH-Synthese & Glutamat-Cystein-Ligase (GCL) \\
& Glutathionsynthase (GCL) \\
Reduktion von Wasserstoffperoxid & Glutathion-Peroxidase (GPX) \\
Regeneration & Glutathion-Reduktase (GR) \\
\hline TXN-System & Thioredoxin (TXN) \\
& Thioredoxin-Reduktase (TRXR2) \\
& Peroxiredoxine (PRDX) \\
\hline Andere & NAD(P)H:quinone oxidoreductase 1 (NQO1) \\
& a-Tocopherol (Vitamin E) \\
& Ascorbinsäure (Vitamin C) \\
\hline
\end{tabular}


Zellen können dynamisch auf die Anwesenheit von ROS/RNS reagieren. Eine wichtige Rolle für diese Anpassungsfähigkeit spielt der Transkriptionsfaktor NF-E2-related factor 2 (Nrf2), der durch viele Mechanismen reguliert wird (Ausführliches Review: Hayes und Dinkova-Kostova 2014). Am bedeutendsten scheint seine posttranslationale Regulation zu sein. Nrf2 (kodiert durch das Gen NFE2L2) wird unter physiologischen Bedingungen durch das homodimer kelch-like ECH-associated protein 1 (Keap1) im Zytoplasma gebunden. Diese Bindung ermöglicht die Ubiquitinylierung von Nrf2 durch cullin 3-RING-box protein 1 (Cul3-Rbx1). Anschließend löst sich die Nrf2-Keap1-Bindung, das ubiquitinylierte Nrf2 wird im 26S-Proteasom abgebaut und Keap1 kann erneut Nrf2 binden und der Ubiquitinylierung zuführen. Nrf2 hat auf diese Weise eine Halbwertszeit von 10-40 min im Zytoplasma (Lee et al. 2012). Thiol-reaktive Oxidantien (z. B. ·NO, ·HO, Fumarat) verändern Keap1 durch eine Modifikation von Cystein-Seitenketten. Keap1 ändert dadurch seine Konformation und kann Nrf2 zwar binden, aber nicht mehr der Ubiquitinylierung zuführen und sich selber auch nicht mehr von Nrf2 lösen. Das so blockierte Keap1 steht neu generiertem Nrf2 nicht mehr zur Verfügung und damit kann der Transkriptionsfaktor unmittelbar seiner Aufgabe im Nukleus nachkommen. Als Heterodimer mit einem Maf-Protein (MafF, MafG, MafK) bindet er an das antioxidant response element (ARE) und induziert die Transkription ARE-regulierter Genen (Motohashi et al. 2004). Zu den so regulierten ungefähr 200 Genen gehört die Superoxiddismutase, Katalase, Hämoxigenase 1 und $N A D(P) H: q u i n o n e ~ o x i d o r e d u c t a s e ~ 1(N Q O 1)$. NQO1 kann aus diesem Grund als Marker für die Aktivität von Nrf2 herangezogen werden (Van Horssen et al. 2006).

\subsubsection{PeROXIREDOXIN 2}

Neben den seit Langem bekannten, bereits erwähnten antioxidativen Enzymen gibt es die Proteinfamilie der Peroxiredoxine (PRDX oder PRX), auch Thioredoxin-Peroxidasen genannt, die 1994 erstmals beschrieben wurde (Chae et al. 1994). Diese, in vielen Organismen zu findende, Gruppe antioxidativer Enzyme katalysiert den Abbau von Wasserstoffperoxid und einer Vielzahl organischer Peroxide ( $\left.\mathrm{R}_{1} \mathrm{OOR}_{2}\right)$ (Hofmann et al. 2002). Zudem sind Peroxiredoxine die einzige bisher bekannte Enzymgruppe, die auch hochreaktives Peroxinitrit (ONOO-) abbaut (Bryk et al. 2000). Der Stellenwert der Peroxiredoxine innerhalb der Gesamtheit aller antioxidativer Systeme wurde aufgrund ihrer vermeintlich geringen katalytischen Aktivität lange unterschätzt (Hofmann et al. 2002). Neuere Untersuchungen zeigen, dass sie in humanen Zellen über $90 \%$ aller zytosolischen und mitochondrialen Peroxide abbauen (Peskin et al. 2007; Winterbourn 2008; Manta et al. 2009; Cox et al. 2010). 
Das zur Proteinfamilie der Peroxiredoxine gehörende Peroxiredoxin 2 (PRDX2) weist eine besonders hohe katalytische Aktivität und ein breites Vorkommen in humanen Zellen auf (Peskin et al. 2007; Winterbourn 2008). Über die antioxidativen Eigenschaften von PRDX2 hinaus sind weitere Funktionen bekannt, die es interessant machen, das Molekül im Rahmen entzündlicher Erkrankungen, wie MS, zu untersuchen. So beeinflusst PRDX2 die intrazelluläre Signaltransduktion von Wachstumsfaktoren und Zytokinen (Choi et al. 2005; Sobotta et al. 2015). Extrazelluläres PRDX2, das beispielsweise durch Zelllyse im Rahmen ischämischer Ereignisse ins Parenchym gelangt, hat über die Aktivierung von Toll-like Rezeptoren (TLR2 und TLR4) eine pro-entzündliche Wirkung (Shichita et al. 2012; Salzano et al. 2014).

\subsubsection{OXidativer Stress als Pathomechanismus der GeWebeschädigung bei MultipleR SKLEROSE}

Reaktive Sauerstoff- und Stickstoffverbindungen spielen sowohl bei akuten Entzündungsprozessen als auch im Rahmen von Zellalterung und neurodegenerativen Erkrankungen wie Morbus Alzheimer (Pappolla et al. 1992), Morbus Parkinson (Alam et al. 1997), Morbus Huntington (Tabrizi et al. 2000) und Amyotropher Lateralsklerose (Rosen et al. 1993) eine Rolle.

Für die entzündlich demyelinisierende Erkrankung MS wird seit Langem ebenfalls von einer Gewebeschädigung durch oxidativen Stress ausgegangen. In aktiven entzündlichen MS-Läsionen finden sich oxidierte Phospholipide in Oligodendrozyten, Neuronen und axonalen Sphäroiden (Haider et al. 2011; Fischer et al. 2013). Eine ähnliche Lokalisation zeigt sich auch für MDA in aktiven MS-Läsionen (Haider et al. 2011). Nitrierte Proteine, genauer Nitrotyrosin, können in Oligodendrozyten in MS-Läsionen (insbesondere in aktiven Läsionen des Subtyps III) nachgewiesen werden und sind bei MS zudem in Makrophagen und Astrozyten zu finden (Cross et al. 1998; Jack et al. 2007; Zeis et al. 2008). Schädigungen oligodendrozytärer DNA durch ROS/RNS sind in aktiven MS-Läsionen immunhistochemisch durch die Färbung von 8-Hydroxy-D-Guanosin ebenfalls demonstrierbar (Haider et al. 2011). Des Weiteren finden sich mitochondriale Veränderungen in MS-Läsionen, die auf eine oxidative Schädigung der Atmungskette hinweisen (Mahad et al. 2008; Fischer et al. 2012; Witte et al. 2014).

In allen angegebenen Studien korrelieren die auf oxidativen Stress zurückführbaren Gewebeschäden mit dem Ausmaß der lokalen Entzündung. In aktiven entzündlichen MS- 
Läsionen werden verschiedene Enzyme (NADPH-Oxidase, NO-Synthetase, Myeloperoxidase) für die Produktion von ROS/RNS verantwortlich gemacht. Einzelne Untereinheiten der bereits beschriebenen NADPH-Oxidase können immunhistochemisch in Makrophagen und Mikroglia nachgewiesen werden (Fischer et al. 2012; Fischer et al. 2013). Die induzierbare NO-Synthetase (iNOS) wird in aktiven MS-Läsionen verstärkt von Astrozyten und, zu einem geringeren Anteil, von Mikroglia exprimiert (Liu et al. 2001). Zudem scheint auch die neuronale NO-Synthetase (nNOS) an der Produktion von RNS bei MS beteiligt zu sein (Liñares et al. 2006; Zeis et al. 2008). Eine erhöhte Aktivität der von Mikroglia exprimierten Myeloperoxidase kann sowohl in WML (Gray et al. 2008b) als auch in GML nachgewiesen werden (Gray et al. 2008a). Neben diesen im Rahmen des akuten Entzündungsprozesses enzymatisch generierten ROS/RNS wird davon ausgegangen, dass bei MS aufgrund mitochondrialer Defekte vermehrt ROS als Nebenprodukt der Atmungskette anfallen (Dutta et al. 2006; Mahad et al. 2008; Fischer et al. 2012; Witte et al. 2014). Dem chronisch erhöhten Anfall von ROS in den Mitochondrien wird im Hinblick auf die neuroaxonale Degeneration und Krankheitsprogression eine bedeutende Rolle beigemessen (Lassmann und Van Horssen 2016).

Unter physiologischen Umständen herrscht eine Balance zwischen den in geringem Maße anfallenden ROS/RNS auf der einen Seite und antioxidativen Enzymen sowie Reparaturmechanismen auf der anderen Seite. Die Fähigkeit einzelner Zellpopulationen im ZNS auf das vermehrte Vorkommen reaktiver Sauerstoff- und Stickstoffverbindungen bei MS zu reagieren, kann deren Widerstandsfähigkeit gegenüber oxidativem Stress erklären. So zeigt sich die Expression von Superoxiddismutase und Katalase vorwiegend in Astrozyten und schaumzelligen Makrophagen (Van Horssen et al. 2008). Eine erhöhte Katalaseaktivität ist im Kortex von MS-Patienten unabhängig von kortikalen Läsionen zu finden und wird auf eine vermehrte Expression des Enzyms durch Mikroglia zurückgeführt (Gray et al. 2014). Die Proteine Hämoxigenase 1 und NQO1, deren Expression durch den bereits beschriebenen Transkriptionsfaktor Nrf2 bei oxidativem Stress gesteigert wird, sind bei MS ebenfalls vorwiegend in Astrozyten und aktivierter Mikroglia zu finden (Van Horssen et al. 2006; Van Horssen et al. 2008). Immunhistochemisch ist das zytoplasmatische Vorhandensein von Nrf2 in Astrozyten des ZNS (schwache Färbung) und in schaumzelligen Makrophagen demyelinisierter MS-Läsionen (starke Färbung) nachzuweisen (Van Horssen et al. 2010). Interessanterweise zeigt sich eine nukleäre Akkumulation des Transkriptionsfaktors Nrf2 bei untergehenden Oligodendrozyten in unmittelbarer Umgebung aktiver MS-Läsionen (Licht-Mayer et al. 2015). Antioxidative Enzyme des Thioredoxin-Systems (Thioredoxin, Thioredoxin-Reduktase, Peroxiredoxine) sind im ZNS ebenfalls vorwiegend für die astrozytäre Zellpopulation beschrieben. Eine erhöhte Expression der mitochondrialen Enzyme Thioredoxin 2 und Peroxiredoxin 3 kann 
in Astrozyten und in einzelnen Oligodendrozyten aktiver MS-Läsionen gezeigt werden (Nijland et al. 2014). Ein ähnliches Expressionsmuster zeigt sich für Peroxiredoxin 5 (Holley et al. 2007).

\subsection{AUSgANGSPUNKT UND ZIELSETZUNG DER ARBEIT}

Oxidativer Stress im Rahmen von Endzündungsprozessen kann bei vielen Erkrankungen zur Schädigung des Gewebes beitragen und wird seit Langem auch als ein Pathomechanismus bei Multipler Sklerose verstanden. Zellen sind reaktiven Sauerstoff- und Stickstoffverbindungen nicht schutzlos ausgeliefert, sondern in der Lage, diese Moleküle abzubauen und entstehende Schäden zu reparieren. Diese Fähigkeit wird entscheidend von der Ausstattung der Zelle mit antioxidativen Molekülen und den Anpassungsmöglichkeiten an oxidativen Stress (z. B. durch Aktivierung des Transkriptionsfaktors Nrf2) determiniert. Als wichtige antioxidative Proteinfamilie sind Peroxiredoxine im Gewebe des zentralen Nervensystems bis jetzt nur vereinzelt untersucht worden (Holley et al. 2007; Shichita et al. 2012; Nijland et al. 2014).

In einer von unserem Kooperationspartner Tobias Derfuss (Neurologische Klinik und Poliklinik, Universitätsspital Basel) durchgeführten Proteinanalyse kortikaler Gewebeproben waren vermehrt Moleküle mit antioxidativen Funktionen, darunter PRDX2, bei MSPatienten zu finden. Erste immunhistochemische Färbungen von ZNS-Gewebe autopsierter MS-Patienten zeigten zudem, dass PRDX2 auch in der weißen Hirnsubstanz durch Zellen mit astrozytärer Morphologie exprimiert wird.

Ziel dieser Arbeit war es, folgende Fragen zu klären:

(1) In welchen Hirnregionen und in welchen Zellpopulationen wird PRDX2 im ZNSGewebe autopsierter MS-Patienten und in einer neuropathologisch unauffälligen Kohorte (Kontrollen) exprimiert?

(2) Inwiefern lassen sich Unterschiede der regionalen PRDX2-Expression im ZNS-Gewebe in Zusammenhang mit dem lokalen Entzündunginfiltrat und dem Marker für oxidativen Stress NQO1 beschreiben?

(3) Lassen sich in vitro Faktoren identifizieren, die zu einer Veränderung der Expression von PRDX2 oder NQO1 führen? 


\section{Material Und Methoden}

\subsection{MATERIAL}

Tabelle 3: Reagenzien

\begin{tabular}{|c|c|c|}
\hline Reagenz & $\begin{array}{l}\text { Verwendung } \\
\text { Beschreibung }\end{array}$ & Hersteller \\
\hline Agarose & $\begin{array}{l}\text { Herstellung von Elektrophorese- } \\
\text { Gelen }\end{array}$ & $\begin{array}{l}\text { StarLab GmbH } \\
\text { Hamburg, Germany }\end{array}$ \\
\hline Chloroform & RNA-Extraktion & $\begin{array}{l}\text { Carl Roth GmbH + Co. KG } \\
\text { Karlsruhe, Germany }\end{array}$ \\
\hline Citronensäure-Monohydrat & $\begin{array}{l}\text { Pulver zur Herstellung von Citrat- } \\
\text { Puffer }\end{array}$ & $\begin{array}{l}\text { Merck Millipore } \\
\text { Darmstadt, Germany }\end{array}$ \\
\hline DePex & $\begin{array}{l}\text { Histochemie/Immunhistochemie } \\
\text { Eindecken von Gewebeschnitten }\end{array}$ & $\begin{array}{l}\text { Serva Electrophoresis GmbH } \\
\text { Heidelberg, Germany }\end{array}$ \\
\hline $\begin{array}{l}\text { Desoxynukleosid- } \\
\text { Triphosphat (dNTP) }\end{array}$ & Neukleotide für PCR & $\begin{array}{l}\text { Thermo Fisher Scientific } \\
\text { VWR international } \\
\text { Darmstadt, Germany }\end{array}$ \\
\hline Diaminobenzidin (DAB) & $\begin{array}{l}\text { Immunhistochemie } \\
\text { Peroxidase-Substrat } \\
\text { Stammlösung: } 2 \mathrm{~g}+80 \mathrm{~mL} \text { PBS }\end{array}$ & $\begin{array}{l}\text { Sigma-Aldrich Chemie GmbH } \\
\text { Steinheim, Germany }\end{array}$ \\
\hline Diaminophenylindol (DAPI) & Fluoreszenz-Kernfärbung & $\begin{array}{l}\text { Life Technologies } \\
\text { Carlsbad, California }\end{array}$ \\
\hline $\begin{array}{l}\text { Diethylpyrocarbonat(DEPC)- } \\
\text { Wasser }\end{array}$ & RNAse freies Wasser & $\begin{array}{l}\text { Carl Roth GmbH + Co. KG } \\
\text { Karlsruhe, Germany }\end{array}$ \\
\hline Dimethylsulfoxid (DMSO) & $\begin{array}{l}\text { Zellkultur } \\
10 \text { \% DMSO in FCS zum } \\
\text { Einfrieren von Zellen }\end{array}$ & $\begin{array}{l}\text { Sigma-Aldrich Chemie GmbH } \\
\text { Steinheim, Germany }\end{array}$ \\
\hline $\begin{array}{l}\text { Dulbecco's Modified Eagle's } \\
\text { Medium (DMEM), } \\
\text { High Glucose ( } 4,5 \mathrm{~g} / \mathrm{L}) \text {, } \\
\text { L-Glutamin, Natriumpyruvat }\end{array}$ & $\begin{array}{l}\text { Zellkultur } \\
\text { Basalmedium }\end{array}$ & $\begin{array}{l}\text { Gibco, Life Technologies GmbH } \\
\text { Darmstadt, Germany }\end{array}$ \\
\hline DMEM/F-12, L-Glutamin & $\begin{array}{l}\text { Zellkultur } \\
\text { Basalmedium }\end{array}$ & $\begin{array}{l}\text { Gibco, Life Technologies GmbH } \\
\text { Darmstadt, Germany }\end{array}$ \\
\hline DNA Loading Dye & $\begin{array}{l}\text { DNA-Elektrophorese } \\
\text { Färbung der DNA-Proben }\end{array}$ & $\begin{array}{l}\text { Thermo Fisher Scientific } \\
\text { VWR international } \\
\text { Darmstadt, Germany }\end{array}$ \\
\hline Eosin G & $\begin{array}{l}\text { Histochemie } \\
\text { Herstellung von Eosin-Lösung }\end{array}$ & $\begin{array}{l}\text { Merck Millipore } \\
\text { Darmstadt, Germany }\end{array}$ \\
\hline
\end{tabular}




\begin{tabular}{|c|c|c|}
\hline Reagenz & $\begin{array}{l}\text { Verwendung } \\
\text { Beschreibung }\end{array}$ & Hersteller \\
\hline $\begin{array}{l}\text { Essigsäure (Ethansäure), } \\
100 \%\end{array}$ & $\begin{array}{l}\text { Histochemie } \\
\text { Herstellung von Eosin-Lösung }\end{array}$ & $\begin{array}{l}\text { Merck Millipore } \\
\text { Darmstadt, Germany }\end{array}$ \\
\hline Ethanol, $100 \%$ & RNA-Extraktion & $\begin{array}{l}\text { Merck Millipore } \\
\text { Darmstadt, Germany }\end{array}$ \\
\hline Ethidiumbromid & DNA-Gelelektrophorese & $\begin{array}{l}\text { Sigma-Aldrich Chemie GmbH } \\
\text { Steinheim, Germany }\end{array}$ \\
\hline $\begin{array}{l}\text { Ethylendiamintetraacetat } \\
\text { (EDTA) }\end{array}$ & $\begin{array}{l}\text { Pulver zur Herstellung von Puffer- } \\
\text { lösung }\end{array}$ & $\begin{array}{l}\text { Carl Roth GmbH + Co. KG } \\
\text { Karlsruhe, Germany }\end{array}$ \\
\hline $\begin{array}{l}\text { F-518 Phusion HF } \\
\text { Reaction Buffer (5x) }\end{array}$ & $\begin{array}{l}\text { PCR-Puffer (5fach konzentriert) } \\
\text { (incl. 7,5mM } \mathrm{MgCl}_{2} \text { ) }\end{array}$ & $\begin{array}{l}\text { New England BioLabs Inc. } \\
\text { Ipswich, Massachusetts }\end{array}$ \\
\hline $\begin{array}{l}\text { Fetal Calf Serum (FCS), } \\
\text { steril }\end{array}$ & $\begin{array}{l}\text { Zellkultur, Immunhistochemie } \\
\text { Medium-Supplement, Blocking } \\
\text { Buffer }\end{array}$ & $\begin{array}{l}\text { Gibco, Life Technologies GmbH } \\
\text { Darmstadt, Germany }\end{array}$ \\
\hline $\begin{array}{l}\text { Fluorescent Mounting } \\
\text { Medium }\end{array}$ & $\begin{array}{l}\text { Fluoreszenz-Immunhistochemie } \\
\text { Eindecken von Gewebeschnitten }\end{array}$ & $\begin{array}{l}\text { Dako Deutschland GmbH } \\
\text { Hamburg, Germany }\end{array}$ \\
\hline Formalin, 37 \%, säurefrei & Fixierung von Gewebe & $\begin{array}{l}\text { Merck Millipore } \\
\text { Darmstadt, Germany }\end{array}$ \\
\hline $\begin{array}{l}\text { GeneRuler, } 1 \text { kb Plus DNA } \\
\text { ladder }\end{array}$ & $\begin{array}{l}\text { Referenzprobe bei DNA-Gelelekt- } \\
\text { rophorese }\end{array}$ & $\begin{array}{l}\text { Thermo Fisher Scientific } \\
\text { VWR international } \\
\text { Darmstadt, Germany }\end{array}$ \\
\hline Glycerol & $\begin{array}{l}\text { Zusatz, um Antikörper einfrieren } \\
\text { zu können }\end{array}$ & $\begin{array}{l}\text { Sigma-Aldrich Chemie GmbH } \\
\text { Steinheim, Germany }\end{array}$ \\
\hline $\begin{array}{l}\text { Hank's Balanced Salt Solu- } \\
\text { tion (HBSS) mit } \mathrm{Ca}^{2+} \text { und } \\
\mathrm{Mg}^{2+}\end{array}$ & Isolation muriner Astrozyten & $\begin{array}{l}\text { Sigma-Aldrich Chemie GmbH } \\
\text { Steinheim, Germany }\end{array}$ \\
\hline Isopropanol & Xylol-Alkohol-Reihe, Histochemie & $\begin{array}{l}\text { Merck Millipore } \\
\text { Darmstadt, Germany }\end{array}$ \\
\hline Luxol Fast Blue (LFB) & $\begin{array}{l}\text { Histochemie } \\
\text { Pulver zur Herstellung von LFB- } \\
\text { Lösung }\end{array}$ & $\begin{array}{l}\text { Clin-Tech } \\
\text { Guilford, United Kingdom }\end{array}$ \\
\hline Mayer's Hämalaun & $\begin{array}{l}\text { Histochemie } \\
\text { Gebrauchsfertige Hämalaun-Lö- } \\
\text { sung }\end{array}$ & $\begin{array}{l}\text { Merck Millipore } \\
\text { Darmstadt, Germany }\end{array}$ \\
\hline Natriumhydroxid $(\mathrm{NaOH})$ & $\begin{array}{l}\text { Zur Einstellung des pH-Wertes } \\
\text { von Lösungen und Puffern }\end{array}$ & $\begin{array}{l}\text { Merck Millipore } \\
\text { Darmstadt, Germany }\end{array}$ \\
\hline Normal Goat Serum (NGS) & $\begin{array}{l}\text { Immunhistochemie } \\
\text { Vermeidung unspezifischer AK- } \\
\text { Bindungen }\end{array}$ & $\begin{array}{l}\text { Sigma-Aldrich Chemie GmbH } \\
\text { Steinheim, Germany }\end{array}$ \\
\hline
\end{tabular}




\begin{tabular}{|c|c|c|}
\hline Reagenz & $\begin{array}{l}\text { Verwendung } \\
\text { Beschreibung }\end{array}$ & Hersteller \\
\hline Paraffin (Paraplast Plus) & Einbettung von Gewebe & $\begin{array}{l}\text { Tyco Healthcare } \\
\text { Neustadt, Germany }\end{array}$ \\
\hline Paraformaldehyd (PFA) & Fixierung von Gewebe & $\begin{array}{l}\text { Merck Millipore } \\
\text { Darmstadt, Germany }\end{array}$ \\
\hline $\begin{array}{l}\text { Penicillin-Streptomycin } \\
\text { (10000 U/mL | } 10 \text { mg/mL) }\end{array}$ & $\begin{array}{l}\text { Zellkultur } \\
\text { Antibiotikum }\end{array}$ & $\begin{array}{l}\text { Sigma-Aldrich Chemie GmbH } \\
\text { Steinheim, Germany }\end{array}$ \\
\hline Periodsäure & $\begin{array}{l}\text { Histochemie } \\
\text { Pulver zur Herstellung von Lösung }\end{array}$ & $\begin{array}{l}\text { Merck Millipore } \\
\text { Darmstadt, Germany }\end{array}$ \\
\hline $\begin{array}{l}\text { Phosphate-Buffered Salin } \\
\text { (PBS), Dulbecco's }\end{array}$ & $\begin{array}{l}\text { Pulver zur Herstellung von Puffer- } \\
\text { lösung }\end{array}$ & $\begin{array}{l}\text { AppliChem GmbH } \\
\text { Darmstadt, Germany }\end{array}$ \\
\hline $\begin{array}{l}\text { Phosphate-Buffered Salin } \\
\text { (PBS), Steril }\end{array}$ & $\begin{array}{l}\text { Zellkultur } \\
\text { Waschen etc. von Zellen }\end{array}$ & $\begin{array}{l}\text { Sigma-Aldrich Chemie GmbH } \\
\text { Steinheim, Germany }\end{array}$ \\
\hline QiAzol Lysis Reagent & $\begin{array}{l}\text { Lyse und Homogenisierung von } \\
\text { Geweben und Zellen zur RNA Ex- } \\
\text { traktion }\end{array}$ & $\begin{array}{l}\text { Qiagen GmbH } \\
\text { Hilden, Germany }\end{array}$ \\
\hline Salzsäure (HCl), 25 \% & $\begin{array}{l}\text { Histochemie } \\
\text { Herstellung von } \mathrm{HCl}-\text { Lösung }\end{array}$ & $\begin{array}{l}\text { Merck Millipore } \\
\text { Darmstadt, Germany }\end{array}$ \\
\hline Schiff'sches Reagenz & $\begin{array}{l}\text { PAS-Färbung } \\
\text { Gebrauchsfertige Lösung }\end{array}$ & $\begin{array}{l}\text { Sigma-Aldrich Chemie GmbH } \\
\text { Steinheim, Germany }\end{array}$ \\
\hline Triton X 100 & $\begin{array}{l}\text { Permeabilisierung der Zellmemb- } \\
\text { ran } \\
\text { Fluoreszenz-Färbungen von Zell- } \\
\text { kulturzellen }\end{array}$ & $\begin{array}{l}\text { MP Biomedicals Germany GmbH } \\
\text { Eschwege, Germany }\end{array}$ \\
\hline Tris, TRISMA base & $\begin{array}{l}\text { Pulver zur Herstellung von Puffer- } \\
\text { lösung }\end{array}$ & $\begin{array}{l}\text { Carl Roth } \mathrm{GmbH}+\mathrm{Co} . \mathrm{KG} \\
\text { Karlsruhe, Germany }\end{array}$ \\
\hline Trypanblau & $\begin{array}{l}\text { Zellkultur } \\
\text { Anfärben toter Zellen }\end{array}$ & $\begin{array}{l}\text { Sigma-Aldrich Chemie GmbH } \\
\text { Steinheim, Germany }\end{array}$ \\
\hline $\begin{array}{l}\text { Wasserstoffperoxid }\left(\mathrm{H}_{2} \mathrm{O}_{2}\right) \text {, } \\
30 \%\end{array}$ & $\begin{array}{l}\text { Immunhistochemie } \\
\text { Blockade der gewebseigenen Per- } \\
\text { oxidase }\end{array}$ & $\begin{array}{l}\text { Merck Millipore } \\
\text { Darmstadt, Germany }\end{array}$ \\
\hline Xylol & Xylol-Alkohol-Reihe & $\begin{array}{l}\text { Th. Geyer GmbH + Co. KG } \\
\text { Renningen, Germany }\end{array}$ \\
\hline
\end{tabular}


Tabelle 4: Lösungen und Puffer für Histochemie und Immunhistochemie

\begin{tabular}{|c|c|c|}
\hline Lösung & Zusammensetzung & Verwendung \\
\hline Citrat-Puffer & $1 \mathrm{~L}$ Aqua bidest & Immunhistochemie \\
\hline $10 \mathrm{mM}$ & 2,1 g Citronensäure-Monohydrat & Antigendemaskierung \\
\hline pH 6 & Mit $\mathrm{NaOH}$ auf den gewünschten $\mathrm{pH}$-Wert titrieren & \\
\hline \multirow[t]{2}{*}{ Blocking Buffer } & PBS & Immunhistochemie \\
\hline & $10 \%$ FCS/NGS & \\
\hline \multirow[t]{3}{*}{ DAB Lösung } & $50 \mathrm{~mL}$ PBS & Immunhistochemie \\
\hline & $25 \mathrm{mg} \mathrm{DAB}$ & \\
\hline & $20 \mu \mathrm{L} \mathrm{H}_{2} \mathrm{O}_{2}, 30 \%$ & \\
\hline \multirow[t]{4}{*}{$1 \%$ Eosin } & Isopropanol, $70 \%$ & Histochemie \\
\hline & $1 \%$ Eosin & \\
\hline & Rühren, Filtern & \\
\hline & Vor der Nutzung 0,5 \% Essigsäure hinzufügen & \\
\hline \multirow[t]{2}{*}{$3 \% \mathrm{H}_{2} \mathrm{O}_{2}$} & $45 \mathrm{~mL}$ PBS & Immunhistochemie \\
\hline & $5 \mathrm{~mL} \mathrm{H}_{2} \mathrm{O}_{2}, 30 \%$ & \\
\hline \multirow[t]{2}{*}{$1 \% \mathrm{HCl}$} & Isopropanol, $70 \%$ & Histochemie \\
\hline & $1 \% \mathrm{HCl}$ absolut & \\
\hline \multirow[t]{4}{*}{ LFB Lösung } & 1 L Ethanol, $100 \%$ & Histochemie \\
\hline & $1 \mathrm{~g} \mathrm{LFB}$ & \\
\hline & 5 mL Essigsäure, 10 \% & \\
\hline & Filtern & \\
\hline PBS & $1 \mathrm{~L}$ Aqua bidest & Immunhistochemie \\
\hline $0,1 \mathrm{M}$ & 9,55 g PBS Pulver & \\
\hline \multirow[t]{2}{*}{$1 \%$ Periodsäure } & $1 \mathrm{~L}$ Aqua bidest & Histochemie \\
\hline & $10 \mathrm{~g}$ Periodsäure-Pulver & \\
\hline Tris-EDTA-Puffer & $1 \mathrm{~L}$ Aqua bidest & Immunhistochemie \\
\hline \multirow[t]{3}{*}{ pH 9} & $1,21 \mathrm{~g}$ Tris & Antigendemaskierung \\
\hline & $1 \mathrm{~mL}$ EDTA, $1 \mathrm{~mol} / \mathrm{mL}, \mathrm{pH} 8$ & \\
\hline & Mit $\mathrm{NaOH}$ auf den gewünschten $\mathrm{pH}$-Wert titrieren & \\
\hline
\end{tabular}

Tabelle 5: Puffer für Gelelektrophorese

\begin{tabular}{lll} 
Puffer & Zusammensetzung & Verwendung \\
\hline TAE-Puffer (50x) & 1 L Aqua bidest & Gelelektrophorese \\
pH 8 & $242 \mathrm{~g}$ Tris & \\
& $100 \mathrm{~mL}$ EDTA, 0,5 M, pH 8 & \\
& $57,1 \mathrm{~mL}$ Essigsäure, $100 \%$ & \\
& Mit NaOH auf den gewünschten pH-Wert titrieren & \\
\hline
\end{tabular}


Tabelle 6: Zellkulturmedien und Kulturbedingungen

\begin{tabular}{lll} 
Zellkultur/Zelllinie & Medium & Kulturbedingungen \\
\hline Astrozyten & DMEM (High Glucose: $4,5 \mathrm{~g} / \mathrm{L}, \mathrm{L}$-Glutamin, & $37^{\circ} \mathrm{C}$ \\
Primär & Natriumpyruvat) & $5 \% \mathrm{CO}_{2}$ \\
Murin & $10 \% \mathrm{FCS}$ & \\
& $100 \mathrm{U} / \mathrm{mL}$ Penicillin & \\
& $0,1 \mathrm{mg} / \mathrm{mL}$ Streptomycin & \\
\hline U373MG & DMEM (High Glucose: $4,5 \mathrm{~g} / \mathrm{L}$, L-Glutamin, & $37^{\circ} \mathrm{C}$ \\
Astrozytom-Zellinie & Natriumpyruvat) & $10 \% \mathrm{CO}_{2}$ \\
Human & $10 \% \mathrm{FCS}$ & \\
& $100 \mathrm{U} / \mathrm{mL}$ Penicillin & \\
& $0,1 \mathrm{mg} / \mathrm{mL}$ Streptomycin & \\
\hline SH SY5Y & DMEM/F12 (L-Glutamin) & $37^{\circ} \mathrm{C}$ \\
Neuroblastom-Zellinie & $10 \% \mathrm{FCS}$ & $5 \% \mathrm{CO}_{2}$ \\
Human & $100 \mathrm{U} / \mathrm{mL}$ Penicillin & \\
& $0,1 \mathrm{mg} / \mathrm{mL}$ Streptomycin & \\
& &
\end{tabular}

Tabelle 7: Primäre Antikörper und deren Verwendung

\begin{tabular}{|c|c|c|c|c|}
\hline Antigen & $\begin{array}{l}\text { AK-Spezies } \\
\text { KIon, Ig-Typ }\end{array}$ & $\begin{array}{l}\text { Hersteller } \\
\text { Katalog-Nr. }\end{array}$ & Verdünnung & $\begin{array}{l}\text { Vorbehandlung } \\
\text { Puffer }\end{array}$ \\
\hline $\begin{array}{l}\text { CD3 } \\
\text { Human }\end{array}$ & $\begin{array}{l}\text { Rat } \\
\text { mk, Clone CD3-12 }\end{array}$ & $\begin{array}{l}\text { AbD Serotec } \\
\text { Puchheim, Germany } \\
\text { MCA1477 }\end{array}$ & $1: 50$ & $\begin{array}{l}\text { Mikrowelle } \\
\text { Citrat }\end{array}$ \\
\hline $\begin{array}{l}\text { CD68 / } \\
\text { KiM1P } \\
\text { Human }\end{array}$ & $\begin{array}{l}\text { Mouse } \\
\text { mk, Clone KiM1P }\end{array}$ & $\begin{array}{l}\text { Radzun, Heinz-Joachim } \\
\text { Pathologie Göttingen, Ger- } \\
\text { many }\end{array}$ & $1: 5000$ & $\begin{array}{l}\text { Mikrowelle } \\
\text { Citrat }\end{array}$ \\
\hline $\begin{array}{l}\text { GFAP } \\
\text { Human }\end{array}$ & $\begin{array}{l}\text { Mouse } \\
\text { mk, Clone 6F2, } \\
\text { lgG1 }\end{array}$ & $\begin{array}{l}\text { Dako Deutschland GmbH } \\
\text { Hamburg, Germany } \\
\text { M0761 }\end{array}$ & $1: 50$ & - \\
\hline $\begin{array}{l}\text { GFAP } \\
\text { Human }\end{array}$ & $\begin{array}{l}\text { Rabbit } \\
p k, \lg G\end{array}$ & $\begin{array}{l}\text { Dako Deutschland GmbH } \\
\text { Hamburg, Germany } \\
\text { Z0334 }\end{array}$ & 1:1000 & - \\
\hline $\begin{array}{l}\text { MBP } \\
\text { Human }\end{array}$ & $\begin{array}{l}\text { Rabbit } \\
p k, \lg G\end{array}$ & $\begin{array}{l}\text { Dako Deutschland GmbH } \\
\text { Hamburg, Germany } \\
\text { A0623 }\end{array}$ & $1: 2000$ & - \\
\hline $\begin{array}{l}\text { MBP } \\
\text { Human }\end{array}$ & $\begin{array}{l}\text { Rat } \\
\text { mk, Clone 12, } \\
\text { IgG2a }\end{array}$ & $\begin{array}{l}\text { Abcam } \\
\text { Cambridge, United Kingdom } \\
\text { ab7349 }\end{array}$ & $1: 200$ & $\begin{array}{l}\text { Mikrowelle } \\
\text { Citrat }\end{array}$ \\
\hline
\end{tabular}




\begin{tabular}{lllll} 
Antigen & AK-Spezies & Hersteller & Verdünnung & $\begin{array}{l}\text { Vorbehandlung } \\
\text { Puffer }\end{array}$ \\
& Klon, Ig-Typ & Katalog-Nr. & & Steamer \\
\hline Nrf2 & Rabbit & Lifespan BioSciences, Inc. & $1: 100$ & Tris-EDTA \\
Human & pk, IgG & $\begin{array}{l}\text { Seattle, Washington } \\
\text { LS-B3348 }\end{array}$ & & \\
& & AbD Serotec & $1: 100$ & Mikrowelle \\
\hline NQ01 & Mouse & Citrat \\
Human & mk, Clone A180, & Puchheim, Germany & & \\
& IgG1 & MCA2880GA & Mikrowelle \\
PLP & Mouse & AbD Serotec & Citrat \\
Human & mk, Clone plpc1, & Puchheim, Germany & & \\
& IgG2a & MCA839G & & Mikrowelle \\
\hline PRDX2 & Rabbit & Abcam & Citrat \\
Human & pk, IgG & Cambridge, United Kingdom & & \\
& & ab15572 & & \\
\hline
\end{tabular}

In der Tabelle 7 sind alle primären Antikörper aufgeführt, die zur immunhistochemischen Färbung des Gewebes (Formalin-fixiert und in Paraffin eingebettet) verwendet wurden. Zur Reduktion einer unspezifischen Hintergrundfärbung wurde die Gewebeschnitte vorweg mit $10 \%$ fetal calf serum (FCS) inkubiert/blockiert. Für die MBP-Färbung mit dem Anti-MBP-Antikörper (rabbit) hat sich die Inkubation mit $10 \%$ normal goat serum (NGS) bewährt. Abkürzungen: AK: Antikörper CD: cluster of differentiation; Ig: Immunglobulin; mk: monoklonal; pk: polyklonal

Tabelle 8: Sekundäre Antikörper und deren Verwendung

\begin{tabular}{|c|c|c|c|c|}
\hline $\begin{array}{l}\text { Fluorochroml } \\
\text { Biotinylierung } \\
\text { Zielantigen }\end{array}$ & $\begin{array}{l}\text { AK-Spezies } \\
\text { Klon, Ig-Typ }\end{array}$ & $\begin{array}{l}\text { Hersteller } \\
\text { Katalog-Nr. }\end{array}$ & Verdünnung & $\begin{array}{l}\text { Blocking } \\
\text { Buffer }\end{array}$ \\
\hline $\begin{array}{l}\text { Alexa Fluor } 488 \\
\text { anti Mouse lgG } \\
(\mathrm{H}+\mathrm{L})\end{array}$ & $\begin{array}{l}\text { Goat } \\
p k, \lg G\end{array}$ & $\begin{array}{l}\text { Life Technologies } \\
\text { Carlsbad, California } \\
\text { A11001 }\end{array}$ & $1: 200$ & $10 \%$ NGS \\
\hline $\begin{array}{l}\text { Alexa Fluor } 488 \\
\text { anti Rbb lgG } \\
(\mathrm{H}+\mathrm{L})\end{array}$ & $\begin{array}{l}\text { Goat } \\
p k, \lg G\end{array}$ & $\begin{array}{l}\text { Life Technologies } \\
\text { Carlsbad, California } \\
\text { A11034 }\end{array}$ & $1: 200$ & $10 \%$ NGS \\
\hline $\begin{array}{l}\text { Alexa Fluor } 647 \\
\text { anti Rat lgG } \\
(\mathrm{H}+\mathrm{L})\end{array}$ & $\begin{array}{l}\text { Goat } \\
\text { pk, lgG }\end{array}$ & $\begin{array}{l}\text { Life Technologies } \\
\text { Carlsbad, California } \\
\text { A21247 }\end{array}$ & $1: 200$ & $10 \%$ NGS \\
\hline $\begin{array}{l}\text { Biotinylated } \\
\text { anti Mouse IgG }\end{array}$ & $\begin{array}{l}\text { Sheep } \\
\text { pk, IgG }\end{array}$ & $\begin{array}{l}\text { GE-Healthcare Europe GmbH } \\
\text { Freiburg, Germany } \\
\text { RPN1001 }\end{array}$ & $1: 200$ & $10 \%$ FCS \\
\hline
\end{tabular}




\begin{tabular}{lllll}
$\begin{array}{l}\text { Fluorochrom/ } \\
\text { Biotinylierung } \\
\text { Zielantigen }\end{array}$ & $\begin{array}{l}\text { AK-Spezies } \\
\text { Klon, Ig-Typ }\end{array}$ & $\begin{array}{l}\text { Hersteller } \\
\text { Katalog-Nr. }\end{array}$ & Verdünnung & $\begin{array}{l}\text { Blocking } \\
\text { Buffer }\end{array}$ \\
\hline $\begin{array}{l}\text { Biotinylated } \\
\text { anti Rbb IgG }\end{array}$ & Goat & $\begin{array}{l}\text { Jackson ImmunoResearch Lab. } \\
\text { pk, IgG }\end{array}$ & $\begin{array}{l}\text { West Grove, Pennsylvania } \\
111-007-003\end{array}$ & $10 \%$ FCS \\
& & Jackson ImmunoResearch Lab. & $1: 200$ & $10 \%$ NGS \\
\hline Cy3 & Goat & West Grove, Pennsylvania & & \\
anti Rbb IgG & pk, IgG & 111-165-144 & & \\
& & &
\end{tabular}

In der Tabelle 8 sind alle sekundären Antikörper aufgeführt, die zur immunhistochemischen Färbung des Gewebes (Formalin-fixiert und in Paraffin eingebettet) nach Inkubation mit den in Tabelle 7 angeführten primären Antikörpern verwendet wurden. Zur Reduktion einer unspezifischen Hintergrundfärbung wurden die Schnitte vorweg teilweise erneut mit einem Blocking Buffer, bevorzugt aus der Spezies des sekundären Antikörpers, inkubiert. Abkürzungen: FCS: fetal calf serum; Ig: Immunglobulin; NGS: normal goat serum; pk: polyklonal; Rbb: rabbit

Tabelle 9: Proteine und Enzyme

\begin{tabular}{|c|c|c|}
\hline Protein, Enzym & $\begin{array}{l}\text { Verwendung } \\
\text { Beschreibung }\end{array}$ & Hersteller \\
\hline Brain-Derived Neurotrophic & Zellkultur & PeproTech Germany \\
\hline Factor (BDNF) & Rekombinanter Wachstumsfaktor & Hamburg, Germany \\
\hline \multicolumn{3}{|l|}{ Human/Mouse } \\
\hline \multirow[t]{2}{*}{ Glukose-Oxidase (GOD) } & Zellkultur & Sigma-Aldrich Chemie GmbH \\
\hline & Generation von Wasserstoffperoxid & Steinheim, Germany \\
\hline Interferon gamma (IFN-ү) & Zellkultur & PeproTech Germany \\
\hline Mouse & Rekombinantes Zytokin & Hamburg, Germany \\
\hline Interleukin 1 beta (IL-1 $\beta$ ) & Zellkultur & PeproTech Germany \\
\hline Mouse & Rekombinantes Zytokin & Hamburg, Germany \\
\hline \multirow[t]{2}{*}{ ExtrAvidin - Peroxidase } & Immunhistochemie & Sigma-Aldrich Chemie GmbH \\
\hline & Avidin-Konjugierte Peroxidase (POX) & Steinheim, Germany \\
\hline \multirow{2}{*}{$\begin{array}{l}\text { Transforming Growth Factor } \\
\text { beta } 1 \text { (TGF- } \beta 1 \text { ) Human }\end{array}$} & Zellkultur & PeproTech Germany \\
\hline & Rekombinanter Wachstumsfaktor & Hamburg, Germany \\
\hline \multirow{2}{*}{$\begin{array}{l}\text { Tumor Necrosis Factor alpha } \\
\text { (TNF-a) Mouse }\end{array}$} & Zellkultur & PeproTech Germany \\
\hline & Rekombinantes Zytokin & Hamburg, Germany \\
\hline \multirow[t]{2}{*}{ Trypsin } & Zellkultur & Sigma-Aldrich Chemie GmbH \\
\hline & Ablösen Adhärenter Zellen & Steinheim, Germany \\
\hline
\end{tabular}


Tabelle 10: Verwendete Kits

\begin{tabular}{lll} 
Kit & Verwendung & Hersteller \\
\hline High-Capacity cDNA Reverse & Reverse Transkription & Life Technologies GmbH \\
Trancription Kit with RNase Inhibitor & RNA $\rightarrow$ cDNA & Darmstadt, Germany \\
\hline miRNeasy Mini Kit & RNA-Extraktion aus Zellen & Qiagen GmbH \\
& und Geweben & Hilden, Germany \\
\hline qPCR Core Kit & Real Time/Quantitative & Eurogentec Deutschland \\
& PCR & GmbH \\
& & Köln, Germany \\
\hline QuantiNova SYBR Green PCR Kit & Real Time/Quantitative & Qiagen GmbH \\
& PCR & Hilden, Germany \\
\hline Wizard SV Gel and PCR Clean-Up & Extraktion von DNA aus & Promega GmbH \\
System & Agarosegel & Mannheim, Germany \\
\hline
\end{tabular}

Tabelle 11: TaqMan Expression Assays/Primer für die Genexpressions-Analyse muriner Zellen

\begin{tabular}{ll} 
RNA Spezifität & Hersteller \\
\hline ACTB & Applied Biosystems: Mm00607939_s1 \\
ß-Actin & Life Technologies GmbH \\
& Darmstadt, Germany \\
\hline GAPDH & Applied Biosystems: Mm99999915_g1 \\
Glycerinaldehyd-3-phosphat-Dehydrogenase & Life Technologies GmbH \\
& Darmstadt, Germany \\
\hline NQ01 & Applied Biosystems: Mm0125356_m1 \\
NAD(P)H:quinone oxidoreductase 1 & Life Technologies GmbH \\
& Darmstadt, Germany \\
\hline PRDX2 & Applied Biosystems: Mm04208313_g1 \\
Peroxyredoxin 2 & Life Technologies GmbH \\
& Darmstadt, Germany \\
\hline
\end{tabular}


Tabelle 12: Oligonukleotidprimer für die Genexpressions-Analyse humaner Zellen

\begin{tabular}{ll|ll|l}
$\begin{array}{llll}\text { Gen } \\
\text { Symbol }\end{array}$ & CCDS Nr. & Primer & Herkunft \\
\hline h-ACTB & 5341.1 & ACTGCCCTGGCACCCAGCAC & FW & Bestand/Primerdesign \\
& & ACATCTGCTGGAAGGTGGA & REV & Andreas Junker \\
\hline h-GAPDH & 8549.1 & GAAGGTGAAGGTCGGAGTC & FW & Bestand/Primerdesign \\
& & GAAGATGGTGATGGGATTTC & REV & Andreas Junker \\
\hline h-NQ01 & 10883.1 & GGGATCCACGGGGACATGAATG & FW & Im Rahmen dieser Arbeit \\
& & ATTTGAATTCGGGCGTCTGCTG & REV & entwickelt. Kapitel 2.5.6 \\
\hline h-PRDX2 & 12281.1 & CGTCTCGGTGGACTCTCAGT & FW & Im Rahmen dieser Arbeit \\
& & AGTGATCTGGCGAAGGACAC & REV & entwickelt. Kapitel 2.5.6 \\
\hline
\end{tabular}

Herstellung der Oligonukleotide durch: Metabion international AG, Planegg/Steinkirchen, Germany Abkürzungen: CCDS: consensus coding DNA sequences, FW: forward, $\mathbf{h}$ : human, REV: reverse

Tabelle 13: Verbrauchsmaterialien

\begin{tabular}{ll} 
Material & Hersteller \\
\hline 96 Well PCR Platte Biosphere Plus & Sarstedt, Nümbrecht, Germany \\
\hline E-Cup $(2 \mathrm{~mL}, 1,5 \mathrm{~mL})$ & Sarstedt, Nümbrecht, Germany \\
\hline Falcon-Röhrchen $(50 \mathrm{~mL}, 15 \mathrm{~mL})$ & BD Bioscience, Heidelberg, Germany \\
\hline Messpipetten $(25 \mathrm{~mL}, 10 \mathrm{~mL}, 5 \mathrm{~mL})$ & Sarstedt, Nümbrecht, Germany \\
\hline Objektträger mit silanisierter Oberfläche & Gerhard Menzel GmbH, Braunschweig, Germany \\
\hline Zellkulturflaschen $\left(75 \mathrm{~cm}^{2}\right)$ & Greiner bio-one, Kremsmuenster, Austria \\
\hline Zellkulturplatte $(12$ Well, 24 Well) & Greiner bio-one, Kremsmuenster, Austria \\
\hline
\end{tabular}

Tabelle 14: Technische Geräte

\begin{tabular}{lll} 
Technisches Gerät & Verwendung & Hersteller \\
\hline Cellstar incubator & Inkubator für Zellkulturen & $\begin{array}{l}\text { Nunc GmbH \& Co. KG } \\
\text { Wiesbaden, Germany }\end{array}$ \\
\hline Centrifuge 5415 R & Zentrifuge für E-Cups & $\begin{array}{l}\text { Eppendorf } \\
\text { Hamburg, Germany }\end{array}$ \\
\hline Centrifuge 5810 R & Zentrifuge für Falcon-Röhrchen und & Eppendorf \\
& PCR-Platten & Hamburg, Germany \\
\hline Mastercycler gradient & PCR Thermocycler & Eppendorf \\
& & Hamburg, Germany \\
\hline
\end{tabular}




\begin{tabular}{lll} 
Technisches Gerät & Verwendung & Hersteller \\
\hline Mikrotom SM2000R & $\begin{array}{l}\text { Schlittenmikrotom zum Schneiden } \\
\text { von Paraffinblöcken }\end{array}$ & $\begin{array}{l}\text { Leica } \\
\text { Wetzlar, Germany }\end{array}$ \\
\hline Mikrowelle NN E201 WM & $\begin{array}{l}\text { Immunhistochemie } \\
\text { Antigendemaskierung }\end{array}$ & $\begin{array}{l}\text { Panasonic } \\
\text { Wiesbaden, Germany }\end{array}$ \\
\hline Mikroskop BX41 & Lichtmikroskop & Olympus Europa GmbH \\
& & Hamburg, Germany \\
\hline Mikroskop IX51 & Licht- und Fluoreszenzmikroskop & Olympus Europa GmbH \\
+ DP71 digital camera & & Hamburg, Germany \\
+ XM10 monochrome camera & & \\
\hline NanoDrop ND-1000 & Messen von RNA- und DNA-Kon- & Peqlab Biotechnologie GmbH \\
& zentrationen & Erlangen, Germany \\
\hline Neubauer-Zählkammer & Zellkultur & Assistent Karl Hecht \\
& Zellzahl in deffiniertem Volumen & Sondheim/Rhön, Germany \\
\hline iQ5 Real-Time & qPCR Thermocycler & Bio-Rad Laboratories GmbH \\
PCR Detection System & & München, Germany \\
\hline pH-Meter inoLab & pH-Wert in Lösungen bestimmen & WTW GmbH \\
& & Weilheim, Germany \\
\hline Sicherheitswerkbank & Sterilbank für Zellkulturexperimente & Heraeus Kendro Laboratory \\
HERAsafe & & Products GmbH \\
& & Hanau, Germany \\
\hline Wasserbad & Vorwärmen und Warmhalten von & GFL GmbH \\
\hline & Zellkulturmedien & Burgwedel, Germany \\
\hline
\end{tabular}

Tabelle 15: Software

\begin{tabular}{lll} 
Software & Verwendung & Hersteller \\
\hline Adobe CS4 & Graphische Illustration & $\begin{array}{l}\text { Adobe Systems Inc. } \\
\text { San José, California }\end{array}$ \\
\hline GraphPad Prism 5.01 & Graphische Darstellung von Ergebnissen & $\begin{array}{l}\text { GraphPad Software Inc. } \\
\text { La Jolla, California }\end{array}$ \\
& Statistische Analysen & National Institutes of Health \\
\hline ImageJ 1.49p & Morphometrische Analysen & Bethesda, Maryland \\
\hline $\begin{array}{lll}\text { iQ5 Optical System } \\
\text { Software }\end{array}$ & Darstellung und Auswertung der qPCR & Bio-Rad Laboratories GmbH \\
\hline Online Sequence Editor & Ermittlung antiparalleler, komplementärer & München, Germany \\
& oder inverser DNA und RNA Sequenzen & \\
\hline
\end{tabular}




\subsection{VerWENDETES AUtOPSIEGEWEBE}

Für die histologischen Untersuchungen wurde mittels Formalin fixiertes und in Paraffin eingebettetes humanes Autopsiegewebe des ZNS aus dem Archiv der Neuropathologie Göttingen verwendet. Die klinischen Angaben zu den Patienten, deren Gewebe verwendet wurde, sind in Tabelle 16 aufgeführt. Alle in der Arbeit durchgeführten Arbeiten an humanem Material wurden durch die Ethikkommission der Universitätsmedizin Göttingen genehmigt (Ethikvotum 19/9/10).

Tabelle 16: Klinische Angaben zu den Autopsiefällen

\begin{tabular}{|c|c|c|c|c|}
\hline Fall & Alter & Geschlecht & Todesursache & $\begin{array}{l}\text { Entzündliche Ereignisse } \\
\text { zum Zeitpunkt des Todes }\end{array}$ \\
\hline MS-01 & 74 & $F$ & Pneumonie & Harnwegsinfektion \\
\hline MS-02 & 63 & M & & \\
\hline MS-03 & 57 & M & Pneumonie & Sepsis \\
\hline MS-04 & 51 & $\mathrm{~F}$ & $\begin{array}{l}\text { Zentrales Regulationsversagen } \\
\text { aufgrund von Demyelinisierung }\end{array}$ & Nein \\
\hline MS-05 & 49 & M & & \\
\hline MS-06 & 49 & M & Drogen-Intoxikation & Nein \\
\hline MS-07 & 47 & $\mathrm{~F}$ & & \\
\hline MS-08 & 44 & $\mathrm{~F}$ & & \\
\hline MS-09 & 41 & M & Lungenembolie & Nein \\
\hline MS-10 & 34 & M & Krampfanfall & Nein \\
\hline \multirow[t]{2}{*}{ CON-01 } & 67 & $F$ & Lungenversagen & Panzytopenie \\
\hline & & & & Aspergillusinfektion der Lunge \\
\hline CON-02 & 63 & $\mathrm{~F}$ & Kardiopulmonales Versagen & Nein \\
\hline CON-03 & 56 & M & & \\
\hline CON-04 & 49 & M & Multi-Organ-Versagen & Sepsis \\
\hline CON-05 & 48 & $\mathrm{~F}$ & Kardiopulmonales Versagen & Nein \\
\hline CON-06 & 40 & $F$ & Kardiopulmonales Versagen & Nein \\
\hline CON-07 & 35 & $\mathrm{~F}$ & Lungenembolie & Nein \\
\hline
\end{tabular}

Klinische Angaben zu den Patienten mit Multipler Sklerose (MS) und den Kontrollfällen (CON), deren Gewebe in der Studie verwendet wurde. Als Kontrollfälle dienten Patienten ohne neurologische oder neuropathologisch diagnostizierte Erkrankung. Bei fehlenden oder ungenügenden Informationen zur Todesursache und den perimortalen Umständen (entzündliche Ereignisse zum Zeitpunkt des Todes) wurde der Eintrag in der Tabelle leer gelassen. Von nahezu allen aufgeführten Fällen wurden Gewebeproben sowohl der weißen als auch der grauen Substanz untersucht. Von Fall MS-04 ging lediglich Gewebe der weißen Substanz in die Studie ein. 
Das MS-Autopsiematerial wurde so ausgewählt, dass nach Möglichkeit sowohl Kortex (graue Substanz) als auch subkortikales Marklager (weiße Substanz) auf den Gewebeblöcken vorhanden war. Unterschieden wurde zwischen Gewebeproben aus frontalen, okzipitalen und temporalen Hirnregionen. Neben den unterschiedlichen Hirnregionen sollten ein möglichst breites Altersspektrum sowie ein ausgewogenes Verhältnis der Geschlechter in dem untersuchten Kollektiv zur Darstellung kommen. Durch eine gründliche mikroskopische Untersuchung des Materials wurden andere demyelinisierende Erkrankungen (z. B. Akute disseminierte Enzephalomyelitis) und andere entzündliche Erkrankungen ausgeschlossen.

Entsprechend dem vorhandenen MS-Autopsiematerial wurden Kontrollfälle ohne erkennbare Pathologie des ZNS ausgesucht. Dabei wurde besonders auf eine Übereinstimmung (match) der Hirnregionen und des Alters geachtet (Tabelle 17).

Tabelle 17: Anzahl und statistische Charakteristika der verwendeten Gewebeproben

\begin{tabular}{l|cc|cc} 
& \multicolumn{2}{|c|}{ Weiße Substanz } & \multicolumn{2}{c}{ Graue Substanz } \\
& MS & Kontrollen & MS & Kontrollen \\
\hline Anzahl der Patienten & 10 & 7 & 9 & 7 \\
\hline Alter (Mittelwert) & 51 & 51 & 51 & 51 \\
\hline Geschlecht & & & & \\
Weiblich & 4 & 5 & 3 & 5 \\
Männlich & 6 & 2 & 6 & 2 \\
\hline Anzahl der Gewebeproben & & & & \\
Gesamt & 17 & 7 & 19 & 7 \\
Frontal & $10(59 \%)$ & $5(71 \%)$ & $11(58 \%)$ & $5(71 \%)$ \\
Okzipital & $4(23 \%)$ & $2(29 \%)$ & $5(26 \%)$ & $2(29 \%)$ \\
Temporal & $3(18 \%)$ & 0 & $3(16 \%)$ & 0 \\
\hline
\end{tabular}

\subsection{Histologische ARBeitSMEthoden}

Von allen ausgewählten, bereits durch Formalin (4 \%) fixierten und in Paraffin eingebetteten Autopsiegewebe-Blöcken wurden mit dem Mikrotom Schnitte von 0,5-1 $\mu$ m Dicke angefertigt und auf Objektträger mit silanisierter Oberfläche aufgezogen. Allen im Folgenden beschriebenen Färbemethoden ging eine Entparaffinierung durch Wärme $\left(60^{\circ} \mathrm{C}\right.$ für $60 \mathrm{~min}$ ) und eine absteigende Xylol-Alkohol-Reihe (Xylol, Xylol-Isopropanol, Isopropanol $100 \%$, $90 \%$, $70 \%, 50 \%$ ) voraus. 


\subsubsection{HISTOCHEMISCHE FÄRBUNGEN}

Übersichtsfärbung Hämatoxylin-Eosin (HE): Hämatoxylin/Hämalaun reagiert mit anionischen (sauren/basophilen) Strukturen der Zelle (z. B. DNA, RNA) und färbt daher insbesondere die Zellkerne blau. Eosin reagiert mit kationischen (basischen/azidophilen) Strukturen der Zelle (z. B. Proteine im Zytoplasma) und färbt diese zart rosa. Protokoll: 5 min Mayer's Hämalaun, differenziert in $1 \%$ HCl-Alkohol, 10 min gebläut in Leitungswasser, 5 min $1 \%$ Eosin.

\section{Myelinscheidenfärbung Luxol Fast Blue kombiniert mit der Periodic Acid Shiff-} Reaktion (LFB-PAS): Die starke Blaufärbung der Myelinscheiden durch Luxol Fast Blue (LFB) kommt durch eine Bindung von sulfoniertem Kupfer-Phtalocyanin an Lecitin/Phosphatidylcholin bzw. der Cholin-Gruppe dieses Phospholipids zustande (Riedelsheimer und Büchl-Zimmermann 2015, S. 251). Phtalocyanin ist in seiner chemischen Struktur den Porphyrinen ähnlich und durch die angehängte Sulfongruppe in Isopropanol löslich. Die Periodic-Acid-Schiff(PAS)-Reaktion/Färbung bringt Polysaccharide (z. B. Glykogen), Mykopolysaccharide (auf Schleimhäuten), Glykoproteine (z. B. als Bestandteil der Basalmembran), Glykolipide und intraneuronale Lipofuszingranula zur Darstellung (Lüllmann-Rauch 2006, S. 596) und färbt Makrophagen zart rot-violett. Protokoll: Die Gewebeschnitte wurden in der Xylol-Alkohol-Reihe bis zur 90 \% Isopropanol-Lösung entparaffiniert/gewässert, über Nacht bei $60^{\circ} \mathrm{C}$ in LFB-Lösung inkubiert und anschließend mit Lithiumcarbonat (0,05 \%) und Isopropanol (70 \%) so differenziert, dass sich die Markscheiden in der weißen Hirnsubstanz kräftig blau darstellen und gut von der schwach blau angefärbten grauen Hirnsubstanz abgrenzbar sind (Kluver und Barrera 1953). Anschließend folgte die PAS-Färbung (5 min 1 \% Periodsäure, 5 min Leitungswasser, kurz mit deionisiertem Wasser gespült, 20 min Schiff'sches Reagenz) und Kerngegenfärbung (2 min Mayer's Hämalaun, differenziert in 1 \% HCl-Alkohol, 10 min gebläut in Leitungswasser).

\subsubsection{IMMUNHISTOCHEMISCHE FÄRBUNGEN}

Zur Färbung bestimmter antigener Strukturen mit Antikörpern (AK) muss das Gewebe, nachdem es geschnitten und entparaffiniert wurde, teilweise noch mit weiteren Methoden vorbehandelt werden. Diese Vorbehandlung ist nötig, um die durch die Gewebefixation mit Formalin vernetzten Proteine zu demaskieren und Zielstrukturen (Antigene, Epitope) für die eingesetzten AK zugänglich zu machen. Die geeignetste Vorbehandlung muss für jeden AK empirisch ermittelt werden. Die von uns für die einzelnen AK angewandten 
Vorbehandlungen sind in Tabelle 7 (Seite 24) aufgeführt. Die Objektträger mit den Gewebeschnitten wurden dazu in einem geeigneten Puffer (10 mM Citrat-Puffer pH 6 oder Tris-EDTA-Puffer) entweder in der Mikrowelle ( 5 x 3 min bei $800 \mathrm{~W}$ ) oder in einem Steamer/Heißluftdämpfer (30 min) gekocht.

Wenn die Färbung der Antigene (AG) durch ein Peroxidase-System vorgesehen war (siehe unten), erfolgte eine Blockade der endogenen Oxidasen im Gewebe durch eine Wasserstoffperoxid-Vorbehandlung (20 $\min 3 \% \mathrm{H}_{2} \mathrm{O}_{2}$ ).

Um eine unspezifische Bindung der Antikörper zu verhindern, wurden die Schnitte anschließend für 20 min mit $10 \%$ fetal calf serum (FCS) in phosphate-buffered saline (PBS) inkubiert, was auch „blockieren“ genannt wird. Für manche AK, insbesondere sekundäre AK (Tabelle 8, Seite 25), kann es sinnvoll sein, das Serum des Tieres zu verwenden, aus dem der AK stammt, um eine unnötige Hintergrundfärbung zu vermeiden. Für die MBPund die Fluoreszenz-Doppelfärbungen verwendeten wir 10 \% normal goat serum (NGS). Die sich anschließende Inkubation mit primären Antikörpern in der empirisch ermittelten optimalen Konzentration (Tabelle 7, Seite 24) erfolgte über Nacht.

Zur lichtmikroskopischen Darstellung der Bindung des primären AK an Epitope in Zellen und Geweben bedient man sich enzymatischer Reaktionen, bei denen das Enzym in Kombination mit einem geeigneten Substrat einen Farbumschlag katalysiert. Ein häufig verwendetes Enzym ist die Meerrettich-Peroxidase, deren Substrat Diaminobenzidin (DAB) durch Oxidation ein braunes, sowohl in wässriger als auch organischer Lösung stabiles und unlösliches Präzipitat bildet. Um den Farbumschlag auf die Orte zu beschränken an denen sich die gesuchten AG befinden, muss die Peroxidase mit dem primären AK verbunden werden. Dies lässt sich durch verschiedene Methoden bewerkstelligen (Abbildung 1, Seite 34). Die immunhistochemischen Färbungen im Rahmen dieser Arbeit basierten alle auf der Labelled-(Strept)Avidin-Biotin(LSAB)-Methode. Die Schnitte wurden mit dem passenden, gegen die Spezies des Primär-Antikörpers gerichteten, biotinylierten Sekundär-Antikörper (60 min) und anschließend mit ExtAvidin-Peroxidase (60 min) inkubiert. Die Entwicklung erfolgte mit $25 \mathrm{mg}$ DAB in $50 \mathrm{~mL}$, versetzt mit $20 \mu \mathrm{L}$ $30 \% \mathrm{H}_{2} \mathrm{O}_{2}$. Je nach AK dauerte die Entwicklung 1-20 min.

Anschließend erfolgte eine Kerngegenfärbung mit Hämalaun (30 sec Mayer's Hämalaun, kurz in HCl-Alkohol getaucht, 10 min mit Leitungswasser gebläut), eine Entwässerung (aufsteigende Alkohol-Xylol-Reihe) und das Eindecken der Schnitte mit DePex. 


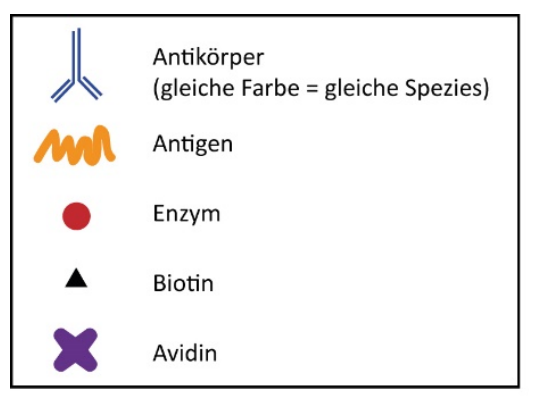

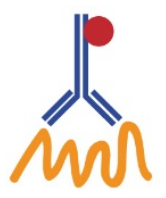

1) Direkt

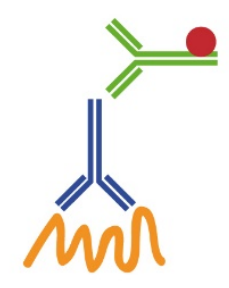

2) Indirekt

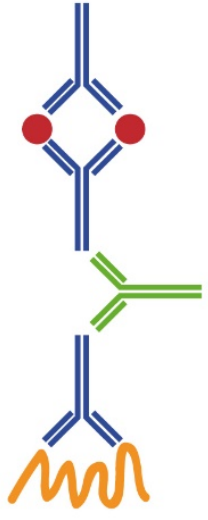

3) PAP

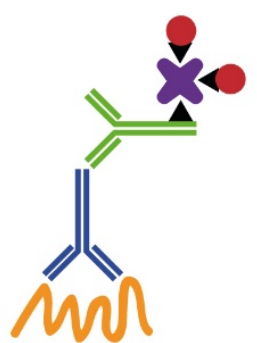

4a) $A B C$

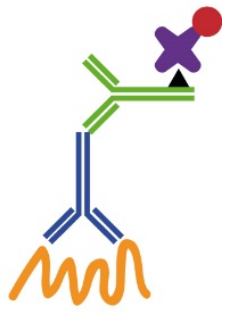

4b) LSAB

\section{Abbildung 1: Schematische Darstellung verschiedener immunhistochemischer Verfahren}

(1) Direkte Methode: Das Enzym ist an den primären Antikörper (AK) gebunden. (2) Indirekte Methode: Das Enzym ist an den sekundären AK gebunden. (3) Peroxidase-Antiperoxidase(PAP)-Methode: Die Peroxidase (Enzym) wird durch einen Anti-Peroxidase-AK gebunden. Dieser stammt aus derselben Spezies wie der eingesetzte primäre AK gegen das zu detektierende Antigen (AG) im Gewebe (Gewebe-AK). Durch einen weiteren AK (sog. Brückenantikörper) gegen diese Spezies werden der Gewebe-AK und der PeroxidaseAntiperoxidase-AK-Komplex miteinander verbunden und so das Enzym an die Richtige Stelle platziert. (4) Avidin-Biotin-Methoden: Grundlage dieser Methoden sind die starke Bindung von Biotin (Vitamin B7) durch Avidin, einem Glykoprotein im Eiweiß von Vogeleiern. (4a) Avidin-Biotin-Complex(ABC)-Methode: Sowohl der eingesetzte Sekundär-AK, als auch das Enzym sind biotinyliert (posttranslationale kovalente Bindung von Biotin) und es entsteht durch eine gemeinsame Inkubation mit Avidin ein Komplex aus AK und Enzym. (4b) Labelled-(Strept)Avidin-Biotin(LSAB)-Methode: Nur der Sekundär-AK ist biotinyliert, die Peroxidase ist an (Strept)Avidin gebunden und bindet dadurch direkt an den AK. Abbildung in Anlehnung an Mulisch (2015, S. 424-429) mit freundlicher Genehmigung der Verwendung durch Springer Nature. 


\subsubsection{LOKALISATION MEHRERER ANTIGENE: FLUORESZENZ-DOPPELFÄRBUNG}

Um mehrere AG gleichzeitig im selben Schnitt darzustellen, bedient man sich der Möglichkeit, die einzelnen AG mit primären AK zu detektieren, die entweder direkt mit verschiedenen Fluorochromen markiert sind oder sich hinsichtlich ihrer Herkunft (Spezies) unterscheiden. Bei letzterer, von uns angewandten, Methode wird der primäre AK anschließend mit einem nur gegen die Spezies seiner Herkunft gerichteten fluoreszierenden sekundären AK detektiert. Dabei unterscheiden sich die gegen verschiedene Spezies gerichteten Sekundär-AK durch ihre Fluorochrome d.h. durch ihre Absorptions- und Emissions-Maxima und sind dadurch getrennt mit dem Fluoreszenzmikroskop darstellbar.

Praktisch entsprachen die ersten Schritte (fixieren, einbetten, schneiden, entparaffinieren, vorbehandeln) der Fluoreszenz-Doppelfärbung der in Kapitel 2.3.2 (Seite 32) beschriebenen Vorgehensweise. Auf die Wasserstoffperoxid-Vorbehandlung konnte verzichtet werden, da keine anschließende Färbung mittels Peroxidase erfolgte. Der erste primäre AK wurde über Nacht auf dem Gewebe inkubiert. Es folgte eine erneute mindestens 6-stündige Inkubation mit dem zweiten primären Antikörper aus einer anderen Spezies. Anschließend wurden hintereinander für je 30 min die passenden (gegen die Spezies der primären AK gerichteten) fluoreszenzmarkierten sekundären AK auf die Schnitte gegeben. Nach einer Kerngegefärbung (10 min) mit dem Fluoreszenzfarbstoff Diaminophenylindol (DAPI; bindet an Doppelstrang-DNA) wurden die Schnitte mit deionisiertemWasser gewaschen und mit Fluorescent Mounting Medium eingedeckt.

\subsection{MORPHOMETRISCHE AUSWERTUNG DER IMMUNHISTOCHEMISCH GEFÄRBTEN GEWEBESCHNITTE}

Um die Läsionsarchitektur abzubilden wurden sämtliche Quantifikationen in verschiedenen Bereichen durchgeführt: im Läsionszentrum, am Läsionsrand, in der Läsionsumgebung (2-3 mm von der Läsion entfernt), in der NAWM und der NAGM.

Mikroglia und Makrophagen wurden durch den CD68-äquivalenten Antikörperklon KiM1P immunhistochemisch gefärbt und durch die Kalkulation des Anteils der gefärbten Fläche (in Prozent) ausgewertet. Dazu wurden bei 200-facher Vergrößerung fünf bis sieben Areale des auszuwertenden Bereiches (z. B. Läsionszentrum) fotografiert. Die Fotos wurden mit ImageJ ausgewertet, indem das Tool „Color Threshold“ im „Hue, Saturation, Brightness (HSB)“ Modus genutzt wurde. Folgende Einstellungen wurden gemacht: 
Hue: $\min =40, \max =210$ stop; Saturation: $\min =40, \max =255$ pass; Brightness: $\min =0$, max $=255$ pass.

Anschließend wurde durch die Funktion „Analyze Particles...“ (size=0-10000 circularity=0.00-1.00 show=Masks include summarize) die gefärbte Fläche in Prozent ermittelt (\%Area). Diese Methode ist mit dem KiM1P-Antikörper dank der sehr dezidierten Darstellung von Makrophagen und Mikroglia ohne große Hintergrundfärbung möglich. Trotzdem wurde jedes Bild und der dazugehörige Wert auf Fehler, z. B. eine falsch positive Färbung von auf dem Schnitt befindlichen Partikeln, überprüft. Teilweise wurden die Einstellungen leicht modifiziert, um eine unspezifische Hintergrundfärbung, beispielsweise Neuronen, nicht mit zu messen.

T-Zellen, immunhistochemisch mit einem Anti-CD3-Antikörper gefärbt, wurden direkt am Mikroskop mit Hilfe eines im Okular befindlichen Zählgitters quantifiziert. Es wurden bei 200-facher Vergrößerung acht Quadrate (je 0,25 $\mathrm{mm}^{2}$ ) pro Läsionsbereich bzw. NAWM/NAGM gezählt.

Zur Quantifikation der Anzahl PRDX2 und NQO1 gefärbter Astrozyten pro Fläche wurden bei 200-facher Vergrößerung fünf bis sieben Bilder (je 0,144 $\mathrm{mm}^{2}$ ) pro Läsionsbereich bzw. NAWM/NAGM gemacht und die gefärbten Zellen am Bildschirm gezählt.

\subsection{IN-VITRO-EXPERIMENTE UND DEREN AUSWERTUNG}

In-vitro-Experimente ermöglichen es, einzelne zelluläre Mechanismen unter kontrollierten Bedingungen zu untersuchen. Im Rahmen dieser Arbeit wurden verschiedene humane Zelllinien und primäre murine Astrozyten in vitro entweder oxidativem Stress oder bestimmten Zytokinen ausgesetzt. Anschließend wurde mittels quantitativer polymerase chain reaction (PCR) die Expression von PRDX2 und NQO1 untersucht.

\subsubsection{ISOLATION PRIMÄRER ASTROZYTEN AUS NEONATALEN MÄUSEN}

Die primären murinen Astrozyten für die Zellkulturexperimente wurden aus dem ZNS neugeborener Mäuse (P0) isoliert (Aktenzeichen der Tötungsmitteilung: T11/15). Die Mäuse wurden dazu dekapitiert, das Gehirn aus dem Schädel entnommen, in $37^{\circ} \mathrm{C}$ warme Pufferlösung (Hank's Balanced Salt Solution, HBSS, mit $\mathrm{Ca}^{2+}$ und $\mathrm{Mg}^{2+}$ ) überführt und von den Meningen befreit, um das Wachstum meningealer Fibroblasten in der Zellkultur 
zu minimieren. Die Gehirne wurden manuell zerkleinert und mit 0,05 \% Trypsin-EDTALösung (500 $\mu \mathrm{L}$ pro Gehirn) für 10 min bei $37^{\circ} \mathrm{C}$ enzymatisch verdaut. Da FCS das Enzym Trypsin durch ein Substratüberangebot inhibiert, wurden die Zellen anschließend in FCS-haltigem Medium suspendiert, 10 min lang mit 800 Umdrehungen pro Minute (U/min) zentrifugiert und nach Absaugen des Überstandes in Zellkulturmedium (DMEM, 10 \% FCS, 100 U/mL Penicillin, 0,1 mg/mL Streptomycin) resuspendiert. Die Zellen wurden in Poly-L-Lysin (PLL) beschichteten Zellkulturflaschen (25 $\mathrm{cm}^{2}$ pro Gehirn) bei $37^{\circ} \mathrm{C}$ in $5 \% \mathrm{CO}_{2}$ für zehn bis14 Tage kultiviert. Alle drei bis vier Tage wurde ein Teil des Zellkulturmediums gewechselt, wobei nie ein kompletter Mediumwechsel durchgeführt wurde, da sich die Zellen selbst ein Milieu schaffen, das ihr Wachstum begünstigt. Sobald die Zellen konfluent waren, wurden Oligodendrozyten und Mikroglia, die verglichen mit Astrozyten weniger adhärent wachsen, durch kräftiges Schütteln der Flasche und anschließendes Absaugen aus der Kultur entfernt.

\subsubsection{Allgemeine ZelLkULtur-Verfahren}

Zum Einfrieren adhärenter Zellen wurden diese mit $37^{\circ} \mathrm{C}$ warmem Trypsin vorsichtig von den Zellkulturflaschen gelöst, das Trypsin anschließend durch Zugabe von FCS-haltigem Zellkulturmedium inaktiviert und die Zellen $10 \mathrm{~min}$ lang mit $1000 \mathrm{U} / \mathrm{min}$ bei $4^{\circ} \mathrm{C}$ abzentrifugiert. Nach Absaugen des Überstandes wurden die Zellen in $1 \mathrm{~mL}$ eiskalter $10 \%$ Dimethylsulfoxid(DMSO)-FCS-Lösung resuspendiert, in ein Eppendorf-Reaktionsgefäß (E-Cup) überführt und in einer Styroporbox bei $-80^{\circ} \mathrm{C}$ eingefroren.

Zum Auftauen der Zellen wurde das E-Cup in handwarmem Wasser erwärmt und die zellhaltige DMSO-FCS-Lösung in $10 \mathrm{~mL}$ vorgewärmtes Zellkulturmedium überführt um das zytotoxische DMSO zu verdünnen. Nach 10 min Zentrifugation mit $1000 \mathrm{U} / \mathrm{min}$ bei $24^{\circ} \mathrm{C}$ und Absaugen des Überstandes wurden die Zellen in $15 \mathrm{~mL}$ Zellkulturmedium resuspendiert und in einer $75 \mathrm{~cm}^{2}$-Zellkulturflasche im Brutschrank kultiviert (siehe Tabelle 6: Zellkulturmedien und Kulturbedingungen, Seite 24).

Kultivierte Zellen werden nach einer gewissen Zeit konfluent, d.h. ihnen steht kein Platz mehr zum Wachsen zur Verfügung und sie verlangsamen ihr sonst logarithmisches Wachstum. Es ist daher wichtig von konfluenten Zellkulturen Subkulturen mit einer geringeren Zellzahl pro Volumen bzw. Fläche anzulegen. Ein Verteilen von Zellen auf neue Gefäße, z. B. Platten mit vielen kleinen Kavitäten (wells), ist ebenfalls nötig, wenn die Zellen für Experimente verwendet werden sollen. Zum Überführen in neue Gefäße wurden adhärente Zellen mit $37^{\circ} \mathrm{C}$ warmem Trypsin (2 mL für $75 \mathrm{~cm}^{2}$-Flaschen) von der 
Zellkulturflasche gelöst und nach Zugabe von FCS-haltigem Zellkulturmedium für 10 min mit 1000 U/min bei Raumtemperatur zentrifugiert. Nach Absaugen des Überstandes wurden die Zellen in $10 \mathrm{~mL}$ Zellkulturmedium resuspendiert. Um die Zellkonzentration zu bestimmen wurden $10 \mu \mathrm{L}$ der Suspension mit $90 \mu \mathrm{L}$ Trypanblau gemischt und davon $10 \mu \mathrm{L}$ in eine Neubauer-Zählkammer pipettiert. Vitale Zellen mit intakter Zellmembran färben sich durch Trypanblau nicht an. Unter dem Mikroskop wurde die Anzahl der vitalen Zellen in vier Quadranten der Zählkammer gezählt und daraus die Zellkonzentration der Suspension mit folgender Formel berechnet:

$$
\text { Zellzahl pro } \mathrm{mL} \text { Suspension }=10 * 10^{4} * \mathrm{X} / \mathrm{n}
$$

Dabei ergibt sich der erste Faktor (10) aus der Verdünnung mit Trypanblau, es folgt der Multiplikationsfaktor der Neubauer-Zählkammer $\left(10^{4}\right)$ und anschließend steht $\mathrm{X}$ für die Summe der in allen Quadranten gezählten Zellen und n für die Anzahl der ausgezählten Quadranten.

Subkulturen wurden mit 106 Zellen in $15 \mathrm{~mL}$ Medium in $75 \mathrm{~cm}^{2}$-Zellkulturflaschen angelegt. Bei 12-well-Platten wurden 100-150 * 103 Zellen in $1 \mathrm{~mL}$ Medium in jedes well gegeben. Bei 24-well-Platten wurden 70-100* 103 Zellen in 0,5 mL Medium in jedes well gegeben.

\subsubsection{StIMULATION VON ZELLKULTUREN MIT GLUKOSE-OXIDASE UND ZYTOKINEN}

Einen Tag nach dem Verteilen der Zellen auf die Platten wurde entweder Glukose-Oxidase oder bestimmte Zytokine in das Zellkulturmedium einzelner wells gegeben. Glukose-Oxidase (GOD) katalysiert in Anwesenheit von Sauerstoff $\left(\mathrm{O}_{2}\right)$ die Oxidation von Glukose zu Gluconolacton. Dabei fällt Wasserstoffperoxid $\left(\mathrm{H}_{2} \mathrm{O}_{2}\right)$ an. Zunächst wurde visuell ermittelt, bei welcher GOD-Aktivität im Zellkulturmedium die Zellen untergehen. Kultivierte murine Astrozyten zeigten, 24 h nach Zugabe von GOD, bis zu einer GOD-Aktivität von 24 mU/mL keine morphologischen Veränderungen oder den Untergang einzelner Zellen. Die humanen Neuroblastomzellen (SH SY5Y) waren ähnlich sensibel bzw. zeigten schon bei einer GOD-Aktivität von $18 \mathrm{mU} / \mathrm{mL}$ den Untergang einiger Zellen. Die humane Astrozytom-Zelllinie U373MG erwies sich als robuster: $32 \mathrm{mU} / \mathrm{mL}$ GOD wurden von den Zellen toleriert ohne dass untergehende Zellen zu beobachten waren. Die Stimulation der Zellen mit Zytokinen erfolgte ebenfalls in unterschiedlichen Konzentrationen. Die eingesetzten Zytokin-Konzentrationen sind im Ergebnisteil (Kapitel 3.4.2, Seite 60) dargestellt. 24 h nach Zugabe von GOD oder Zytokinen wurden das 
Medium entfernt, die Zellen mit PBS gewaschen, in QiAzol Lysis Reagent (500 $\mu \mathrm{L}$ ) lysiert und bei $-80^{\circ} \mathrm{C}$ eingefroren.

\subsubsection{FLUORESZENZ-FÄRBUNG VON ZELLKULTUR-ZELLEN}

Die allgemeinen Methoden einer Fluoreszenz-Färbung durch Antikörper sind in Kapitel 2.3.2 (Seite 32) erläutert. Die verwendeten primären und sekundären Antikörper finden sich in Tabelle 7 (Seite 24) und Tabelle 8 (Seite 25). Zur Fluoreszenz-Färbung der adhärent wachsenden humanen Neuroblastomzellen (SH SY-5Y), wurden diese auf kleinen Glasplättchen (coverslides) kultiviert und vor der Färbung für 30 min mit Paraformaldehyd (PFA 4 \%) fixiert. Anschließend fand eine Behandlung mit Triton X 100 (5\% in PBS) über 10 min und mit Blocking Buffer (10 \% FCS in PBS) über 30 min statt. Es folgte nacheinander die Inkubation mit dem primären Antikörper (45 min), dem sekundären Antikörper (15 min) und mit DAPI (15 min). Zwischen den einzelnen InkubationsSchritten wurden die Glasplättchen mit PBS gewaschen und zuletzt mit der adhärenten Zellschicht nach unten auf einem Objektträger in einem Tropfen Fluorescent Mounting Medium eingedeckt.

\subsubsection{RNA-EXTRAKTION UND REVERSE TRANSKRIPTION}

Um die Ribonukleinsäure (ribonucleic acid, RNA) aus dem Zell-Lysat zu isolieren wurde das miRNeasy Mini Kit (Qiagen GmbH) entsprechend den Herstellerangaben verwendet. Die RNA wurde in $20 \mu \mathrm{L}$ Wasser eluiert und ihre Konzentration mittels NanoDrop bestimmt.

Um die RNA in cDNA umzuschreiben (reverse Transkription) wurde das High-Capacity cDNA Reverse Transcription Kit (Life Technolgies GmbH) verwendet. Für einen $20 \mu \mathrm{L}$ Ansatz wurden 200 ng RNA, RT-Buffer, 4 mM dNTPs, $10 \mu$ M Random Hexamers (Hexamerprimer), $1 \mathrm{U} / \mu \mathrm{L}$ RNase Inhibitor und 2,5 U/ $\mathrm{LL}$ MultiScribe Reverse Transkriptase verwendet. Die reverse Transkription fand unter folgenden Konditionen im Thermocycler statt: 10 min Hybridisierung der Hexamerprimer bei $25^{\circ} \mathrm{C}, 120$ min reverse Transkription bei $37^{\circ} \mathrm{C}$ und $5 \mathrm{sec}$ Inaktivierung der Transkriptase bei $85^{\circ} \mathrm{C}$. Durch Zugabe von Wasser wurde die cDNA im Anschluss auf eine Konzentration von $2 \mathrm{ng} / \mu \mathrm{L}$ verdünnt. 


\subsubsection{ENTWICKLUNG UND TeSt VON PRIMERN fÜR hUMANe ZeLLeN}

Zur Expressionsanalyse von PRDX2 und NQO1 in humanen Zelllinien mittels qPCR wurden entsprechende Oligonukleotidprimer entwickelt und getestet. Die kodierenden Sequenzen (consensus coding DNA sequences, CCDS) von PRDX2 und NQO1, sowie die Sequenzen der entwickelten Oligonukleotidprimer sind in Tabelle 12 (Seite 28) aufgeführt.

Zunächst erfolgte eine ausführliche Datenbank-Analyse. Informationen zu den Genen PRDX2 und NQO1 wurden mit dem NCBI-Tool (national center for biotechnology information) Gene gesucht (http://www.ncbi.nlm.nih.gov/gene). Die kodierenden Sequenzen der gesuchten Gene inklusive ihrer Exongrenzen wurden mit der CCDS-Database (Pruitt et al. 2009) des NCBI recherchiert (https://www.ncbi.nlm.nih.gov/CCDS). Die Primer wurden mit Hilfe des NSBI-Tools Primer-BLAST (Ye et al. 2012) entwickelt und auf ihre Eigenschaften (Lage, Länge, Schmelztemperatur/GC-Gehalt, selbst-komplementäre Sequenzen), sowie die zu erwartenden PCR-Produkte (Spezifität, Produktlänge) getestet (http://www.ncbi.nlm.nih.gov/tools/primer-blast). Es wurde darauf geachtet, dass die Primer in verschiedenen Exonen oder über Exongrenzen hinweg zu liegen kommen, um eine Amplifikation genomischer DNA zu vermeiden. Im Anschluss an die virtuelle Prüfung der Primer wurden deren Sequenzen an Metabion international AG (Planegg/Steinkirchen, Germany, http://www.metabion.com) zur Herstellung der Oligonukleotide übermittelt.

Die Oligonukleotidprimer wurden mit mehreren cDNA-Proben aus verschiedenen humanen Zelllinien (SH SY5Y und U373MG) mittels PCR getestet. Der PCR-Ansatz enthielt F-518 Phusion HF Reaction Buffer, $200 \mu \mathrm{M}$ dNTPs, 0,1 $\mu$ M Primer, 5 ng cDNA und 0,25 $\mu \mathrm{L} / 20 \mu \mathrm{L}$ Polymerase.

Nach beendeter PCR wurde zu den jeweiligen PCR-Proben (20 $\mu$ L PCR-Reaktionsvolumen) $4 \mu \mathrm{L}$ DNA Loading Dye hinzugefügt um die Proben für die Gelelektrophorese blau zu färben. Zur Analyse der PCR-Produkte wurden $12 \mu \mathrm{L}$ PCR-Probe auf ein $1 \%$ Agarosegel (1 g/100 mL Agarose in TAE-Puffer, $6 \mu \mathrm{L} / 100 \mathrm{~mL}$ Ethidiumbromid) aufgetragen und elektrophoretisch (100 Volt, 40-50 min Laufzeit) aufgetrennt. 


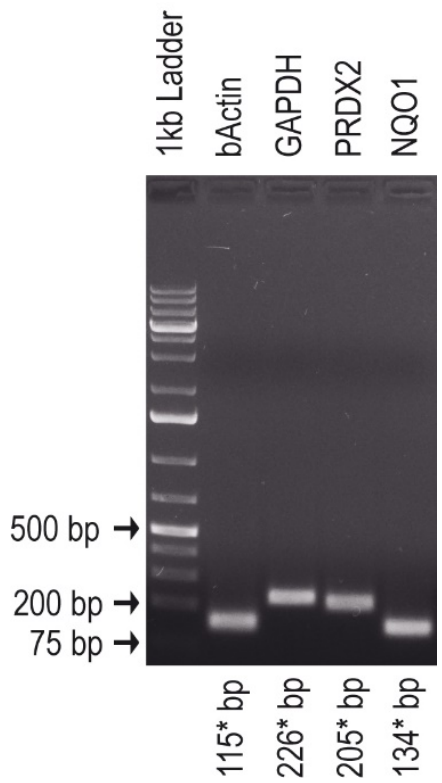

Abbildung 2: PCR-Produkte der Primer in der Gelelektrophorese

Die errechneten Längen $\left({ }^{*}\right)$ der PCR-Proukte, angegeben in Basenpaaren (bp), stimmen mit der Lokalisation der Banden im Agarosegel überein. Als Referenz dient die links aufgetragene GeneRuler 1kb Plus DNA Ladder. Gel: 1\% Agarose in TAE-Puffer, $6 \mu \mathrm{L} / 100 \mathrm{~mL}$ Ethidiumbromid. Aufgetragene Probe: $12 \mu \mathrm{L}$ der PCR-Probe (incl. DNA Loading Dye). Elektorphorese: 50 min Laufzeit bei 100 Volt.

Um festzustellen, ob es sich um die gewünschten PCR-Produkte handelte, wurden die PRDX2- und NQO1-Banden aus dem Gel ausgeschnitten und die DNA aus den Gelstücken extrahiert. Dazu wurde das Kit Wizard SV Gel and PCR Clean-Up System (Promega GmbH, Mannheim, Germany) gemäß dem Protokoll des Herstellers verwendet.

Je nach PCR-Produktlänge wurde 30-50 ng Proben-DNA gemeinsam mit 30 pmol forward-Oligonukleotid-Primer in $15 \mu \mathrm{L}$ Ansatzvolumen zur Sequenzierung an Seqlab (Sequence Laboratories Göttingen GmbH, Göttingen, Germany) geschickt. Die von Seqlab übermittelten Nukleotidsequenzen wurden mit dem NCBI-Tool BLAST (basic local alignment search tool, www.ncbi.nlm.nih.gov/BLAST) im Hinblick auf ihre Spezifität für PRDX2 bzw. NQO1 überprüft (Tabelle 18).

Tabelle 18: Übereinstimmung der sequenzierten PCR-Produkte mit den Referenzsequenzen

\begin{tabular}{llll} 
Primer-Paar & Homo sapiens RefSeq RNA & Übereinstimmung \\
\hline h-PRDX2 & NM_005809.5 & (PRDX2, mRNA) & $100 \%$ \\
\hline h-NQO1 & NM_001286137.1 & (NQO1, transcript variant 4, mRNA) & $100 \%$ \\
& NM_000903.2 & (NQO1, transcript variant 1, mRNA) & $100 \%$ \\
& NM_001025434.1 & (NQO1, transcript variant 3, mRNA) & $100 \%$ \\
& NM_001025433.1 & (NQO1, transcript variant 2, mRNA) & $100 \%$
\end{tabular}

Vollständige Auflistung aller Referenzsequenzen der Datenbank (www.ncbi.nlm.nih.gov/BLAST), die mit den sequenzierten PCR-Produkten übereinstimmen. Die fett markierten RNA-Referenzsequenzen entsprechen den von Primer-BLAST (http://www.ncbi.nlm.nih.gov/tools/primer-blast) für die verwendeten Primer errechneten Ziel-Sequenzen. 


\subsubsection{QUANTITATIVE PCR}

Mittels PCR können DNA-Sequenzen gezielt vervielfältigt werden. Wie bereits beschrieben, werden dazu Oligonukleotide (Primer) eingesetzt, die zu einem bekannten Abschnitt der zu vervielfältigenden DNA komplementär sind. Vorausgesetzt die gesuchte DNA (Template) befindet sich in der Probe, binden die Primer an das Template und fungieren als Ausgangspunkt für die Polymerase, die am 3'-Ende des Primers beginnt, das Template zu kopieren. Dieser Prozess findet in mehreren Schritten statt. Zunächst wird die Doppelstrang-DNA des Templates durch Hitze (je nach Polymerase z. B. bei 98,5 C) denaturiert. An die dadurch vorliegende Einzelstrang-DNA können bei ca. $60^{\circ} \mathrm{C}$ (die optimale Temperatur wird durch den GC-Gehalt der eingesetzten Oligonukleotide determiniert) die Primer binden (Hybridisierung/annealing). Die Primer werden anschließend bei $72^{\circ} \mathrm{C}$ durch die Polymerase am 3'-Ende elongiert und es entsteht eine Kopie der DNA. Stehen genug Primer und Desoxynukleosidtriphosphate (dNTPs) zur Verfügung, kann diese Reaktion zyklisch wiederholt werden. Da jede angefertigte DNA-Kopie wieder als Template dient, kommt es zu einer exponentiellen Amplifikation des (zwischen forwardund reverse-Primer befindlichen) DNA-Abschnittes.

Die Anzahl der sich in dem PCR-Ansatz befindenden DNA-Kopien kann mittels fluoreszenzmarkierter Sonden (TaqMan Expression Assays) oder durch interkalierende Fluorochrome (SYBR Green) nach jedem durchlaufenen PCR-Zyklus gemessen werden (quantitative PCR oder real time PCR). Je mehr Template von Anfang an in der Lösung war, desto schneller steigt die Anzahl der DNA-Kopien und damit die Fluoreszenz-Intensität an. Der PCR-Zyklus, bei dem die Fluoreszenz-Intensität einen festgelegten Wert überschreitet, wird als CT-Wert (threshold cycle) abgelesen. Durch den jeweiligen CTWert kann die Menge des Templates in Relation zu anderen Proben ermittelt werden.

Für die Expressionsanalyse von PRDX2, NQO1 und $\beta$-Actin (ACTB) in humanen Zelllinien (SH SY5Y, U373MG) wurden die selber entworfenen und getesteten Primer zusammen mit dem QuantiNova SYBR Green PCR Kit entsprechend den Herstellerangaben verwendet. Es wurden auf $20 \mu \mathrm{L}$ PCR-Ansatz 10 ng cDNA und die Primer in einer Konzentration von 0,3 $\mu \mathrm{M}$ eingesetzt. Die verwendeten PCR-Konditionen sind in Tabelle 19 (Seite 43) aufgeführt.

Für die Expressionsanalyse von PRDX2, NQO1 und ACTB in primären murinen Astrozyten wurde das qPCR Core Kit (Eurogentec Deutschland GmbH) zusammen mit den 
TaqMan Expression Assays (Life Technologies GmbH) entsprechend den Herstellerangaben verwendet. Eingesetzt wurden 10 ng cDNA auf $20 \mu \mathrm{L}$ PCR-Ansatz. Die verwendeten PCR-Konditionen sind in Tabelle 19 aufgeführt.

Tabelle 19: PRC-Konditionen für die quantitative PCR

\begin{tabular}{llll} 
PCR-Schritt & $\begin{array}{l}\text { Temperatur } \\
{\left[{ }^{\circ} \mathrm{C}\right]}\end{array}$ & $\begin{array}{l}\text { QuantiNova SYBR } \\
\text { Green PCR Kit }\end{array}$ & $\begin{array}{l}\text { TaqMan Expression } \\
\text { Assays }\end{array}$ \\
\hline $\begin{array}{l}\text { Initiale Denaturierung und Akti- } \\
\text { vierung der Polymerase }\end{array}$ & 95 & $2 \mathrm{~min}$ & $10 \mathrm{~min}$ \\
\hline$\underline{40 \text { Zyklen }}$ & & & \\
Denaturierung & 95 & $5 \mathrm{~s}$ & $15 \mathrm{~s}$ \\
Annealing und Elongation & 60 & $10 \mathrm{~s}$ & $60 \mathrm{~s}$ \\
\hline Schmelzkurve & $55-95$ & $\mathrm{Ja}$ & Nein \\
\hline
\end{tabular}

Die Proben wurden im Duplikat pipettiert. Probenpaare die sich um mehr als 0,5 CTWerte unterschieden wurden nicht ausgewertet. Die Expression von ACTB diente als Referenz (housekeeping gene, HKG) für die cDNA-Menge in der Probe. Glycerinaldehyd3-phosphat Dehydrogenase (GAPDH) erwies sich als HKG weniger zuverlässig. Die Expression von PRDX2 und NQO1 wurden mit folgender Formel in Relation zum HKG gesetzt:

$$
\Delta \mathrm{CT}_{\text {Probe }}=\mathrm{CT}_{\mathrm{PRDX} / \mathrm{NQO}}-\mathrm{CT}_{\mathrm{HKG}}
$$

Um die Proben miteinander zu vergleichen, wurde die Differenz der $\Delta$ CT-Werte mit folgender Formel errechnet:

$$
\Delta \Delta \mathrm{CT}=\Delta \mathrm{CT} \text { Ziel-Probe }-\Delta \mathrm{CT} \text { Kontroll-Probe }
$$

Da der $\Delta \Delta \mathrm{CT}$-Wert die Genexpression logarithmisch (log2) darstellt und damit keine intuitiv lesbare Analyse liefert, wurden die Daten als Fold Change dargestellt. Es handelt sich dabei um den Faktor, mit dem die Expression des analysierten Gens in der Kontrollprobe multipliziert werden müsste, um auf die Expression in der Ziel-Probe zu kommen: 


\subsection{Statistische Analysen}

Alle erhobenen Daten wurden mit GraphPad Prism 5.01 grafisch dargestellt und statistisch ausgewertet. Mit dem Mann-Whitney U-Test wurde getestet, ob unabhängige Gruppen eines nonparametrisch verteilten Datensatzes sich signifikant voneinander unterscheiden. Die Signifikanzen der Unterschiede mehrerer abhängiger Gruppen parametrisch verteilter Daten wurden mittels One-Way ANOVA (Varianzanalyse) geprüft. Um den Zusammenhang zweier metrisch skalierter, unabhängiger Variablen zueinander zu beschreiben wurde der Korrelationskoeffizient nach Pearson berechnet. Der Korrelationskoeffizient $r$ gibt das Ausmaß der Korrelation an (Assoziationsmaß). Auch für die Korrelation wurde berechnet, mit welcher Wahrscheinlichkeit es sich um eine scheinbare Korrelation aufgrund der Stichprobe handelt (Signifikanz). Für sämtliche Analysen wurden ein p-Wert unter 0,05 als statistisch signifikant angesehen und durch einen Stern $\left(^{*}\right)$ in den Abbildungen gekennzeichnet. P-Werte unter 0,01 wurden durch zwei Sterne (**) markiert. 


\section{ERGEBNISSE}

\subsection{NeUROPATHOLOGISCHE BEURTEILUNGEN DES GeWEBES / KLASSIFIKATION DER LÄSIONEN}

Für den histologischen Teil der Studie wurde Autopsiegewebe des zentralen Nervensystems (ZNS) von Patienten mit Multipler Sklerose (MS) sowie einer Patientenkohorte ohne neurologisch oder neuropathologisch diagnostizierte Erkrankung (Kontrollgruppe) verwendet. Genaue Angaben zu den Patienten finden sich in Tabelle 16 (Seite 30). Zur allgemeinen neuropathologischen Beurteilung wurde zunächst von jeder Gewebeprobe ein Schnitt Hämatoxylin-Eosin(HE)-gefärbt. Um die Myelinisierung/Demyelinisierung darzustellen, wurden Schnitte von allen Blöcken mit Luxol Fast Blue in Kombination mit der Periodic-Acid-Schiff-Färbung (LFB-PAS) sowie immunhistochemisch mit Antikörpern gegen die Myelinproteine myelin basic protein (MBP) und proteolipid protein (PLP) gefärbt. Zur Beschreibung der entzündlichen Aktivität wurden Schnitte von jeder Gewebeprobe immunhistochemisch mit dem Antikörperklon KiM1P gefärbt, der, äquivalent zu anderen gegen das cluster of differentiation (CD) 68 gerichteten Antikörpern, Makrophagen und Mikroglia zur Darstellung bringt. T-Lymphozyten wurden durch eine immunhistochemische Färbung des Transmembranproteins CD3 identifiziert. Entsprechend der Zusammenschau aus den verschiedenen Färbungen wurde jeder Gewebeblock kurz skizziert (Abbildung 3, Seite 46), die vorhandenen Läsionen im Kortex und im Marklager wurden markiert, nummeriert und nach den in der Einleitung beschriebenen Klassifikationen eingeteilt (siehe Kapitel 1.3.1 bzw. 1.3.2 auf den Seiten 4 bzw. 6).

Insgesamt wurde die weiße Hirnsubstanz (Marklager), im Folgenden als white matter (WM) bezeichnet, von zehn MS-Autopsien und sieben Kontrollautopsien untersucht. Vier white matter lesions (WML) von drei verschiedenen MS-Patienten wiesen ein erhöhten T-Zell-Infiltrat und schaumzellige, im Randbereich Myelin-phagozytierende, Makrophagen auf. Diese WML wurden als chronisch aktive Plaques (CAP) klassifiziert. Fünf Läsionen von drei weiteren MS-Patienten wiesen ein hypozelluläres Läsionszentrum mit geringer randbetonter Immunzellinfiltration auf und wurden daher als chronisch inaktive Plaques (CIP) bezeichnet. Des Weiteren wurde die WM von vier MS-Fällen ohne nachweisbare Läsion als normal-appearing white matter (NAWM) in die Studie eingeschlossen. 
Unabhängig davon wurde der Kortex, im Folgenden als grey matter (GM) bezeichnet, von insgesamt neun MS-Autopsien und sieben Kontrollautopsien untersucht. Zusammengenommen wurden acht grey matter lesions (GML) in dem Material von fünf MS-Patienten gefunden und davon fünf als leukokortikale Läsion (GML Typ I) und drei als subpiale Läsion (GML Typ III) klassifiziert. Die GM von vier MS-Fällen ohne nachweisbare Läsion wurde als normal-appearing grey matter (NAGM) in die Studie eingeschlossen.
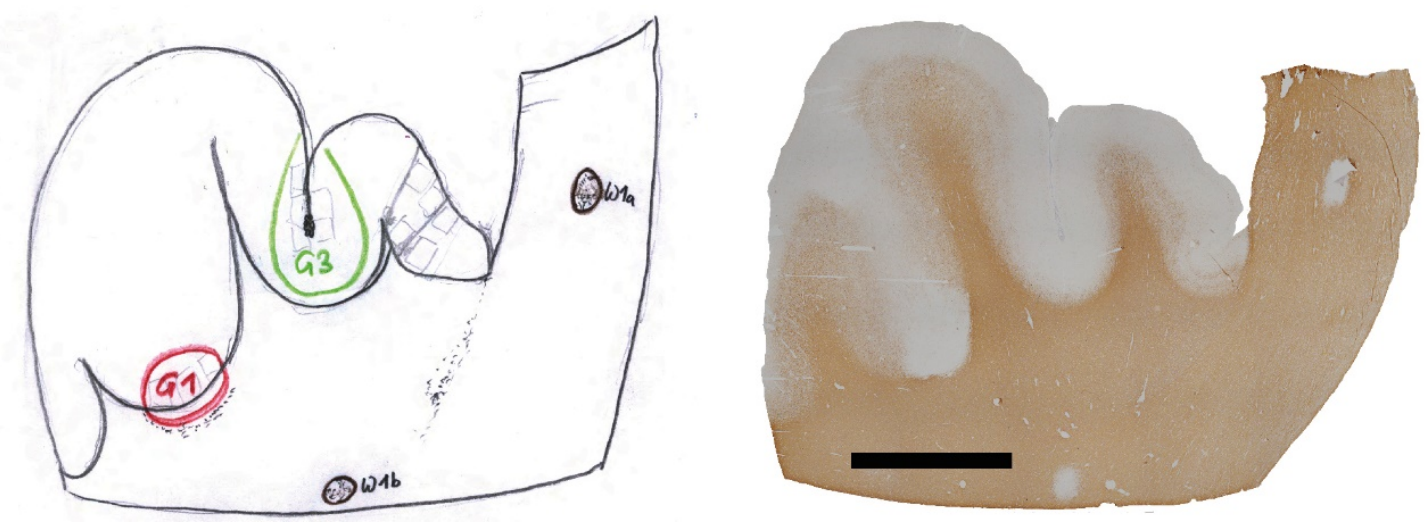

\section{Abbildung 3: Skizze und Foto eines Gewebeblocks}

Die Abbildung zeigt links eine Skizze des cingulären Kortex mit subkortikalem Marklager und einen Anschnitt des Corpus callosum. Eine subpiale (G3, grün) und eine leukokortikale (G1, rot) Läsion, sowie zwei Läsionen im Marklager (W1a und W1b, braun) sind eingezeichnet. Das Foto rechts zeigt einen Schnitt des skizzierten Blockes, in dem das Myelinprotein PLP immunhistochemisch gefärbt wurde (braun) und die Läsionen gut zu erkennen sind. Messbalken: $5 \mathrm{~mm}$ 


\subsection{PeROXYREDOXIN 2 IN DER WEIBEN SUBSTANZ I WHITE MATTER}

\subsubsection{PRDX2 WIRD VORWIEGEND VON ASTROZYTEN EXPRIMIERT}

Um die Lokalisation von Peroxiredoxin 2 (PRDX2) im ZNS zu untersuchen, wurden von allen verwendeten Gewebeproben weitere Schnitte angefertigt und diese immunhistochemisch mit einem Anti-PRDX2-Antikörper gefärbt. In der WM kam durch diese Färbung vor allem das Zytoplasma sternförmiger Zellen mit rundem Kern zur Darstellung, die morphologisch dem Aussehen von Astrozyten entsprachen.

Um die Identität dieser Zellen eingehender zu klären, wurde in einer Fluoreszenz-Doppelfärbung PRDX2 und das astrozytäre Intermediärfilament glial fibrillary acidic protein (GFAP) gefärbt. Sowohl in der Kohorte mit MS, als auch in den Kontrollfällen, erwiesen sich die meisten PRDX2 exprimierenden Zellen als GFAP-positiv (Abbildung 4, Seite 48). In der PRDX2-Färbung kam das Zytoplasma der Zellen mitsamt den sternförmigen Zellfortsätzen zur Darstellung. Teilweise umschlossen diese Zellfortsätze sichtbar Blutgefäße, was als membrana limitans gliae perivascularis für Astrozyten typisch ist. Eine PRDX2-Färbung von Endothel zeigte sich nicht. Erythrozyten, die bekanntlich viel PRDX2 enthalten, wiesen eine deutliche PRDX2-Färbung auf und waren erwartungsgemäß GFAP-negativ. Diese Beobachtungen sprachen dafür, dass PRDX2 innerhalb der WM in Kontroll- und MS-Fällen vorwiegend von Astrozyten exprimiert wird.

Um festzustellen, ob PRDX2 auch von Makrophagen/aktivierter Mikroglia exprimiert wird, wurde PRDX2 in einer Fluoreszenz-Doppelfärbung mit dem CD68-äquivalenten Panmakrophagen-/Mikrogliamarker KiM1P gefärbt (Abbildung 5, Seite 49). Diese Doppelfärbung zeigte, dass es sich auch in WML mit entzündlicher Aktivität bei einem Großteil der PRDX2-positiven Zellen nicht um Makrophagen/Mikroglia handelte. Vereinzelt fand sich eine schwache, mehr granuläre zytoplasmatische PRDX2-Färbung von KiM1Ppositiven Zellen. 

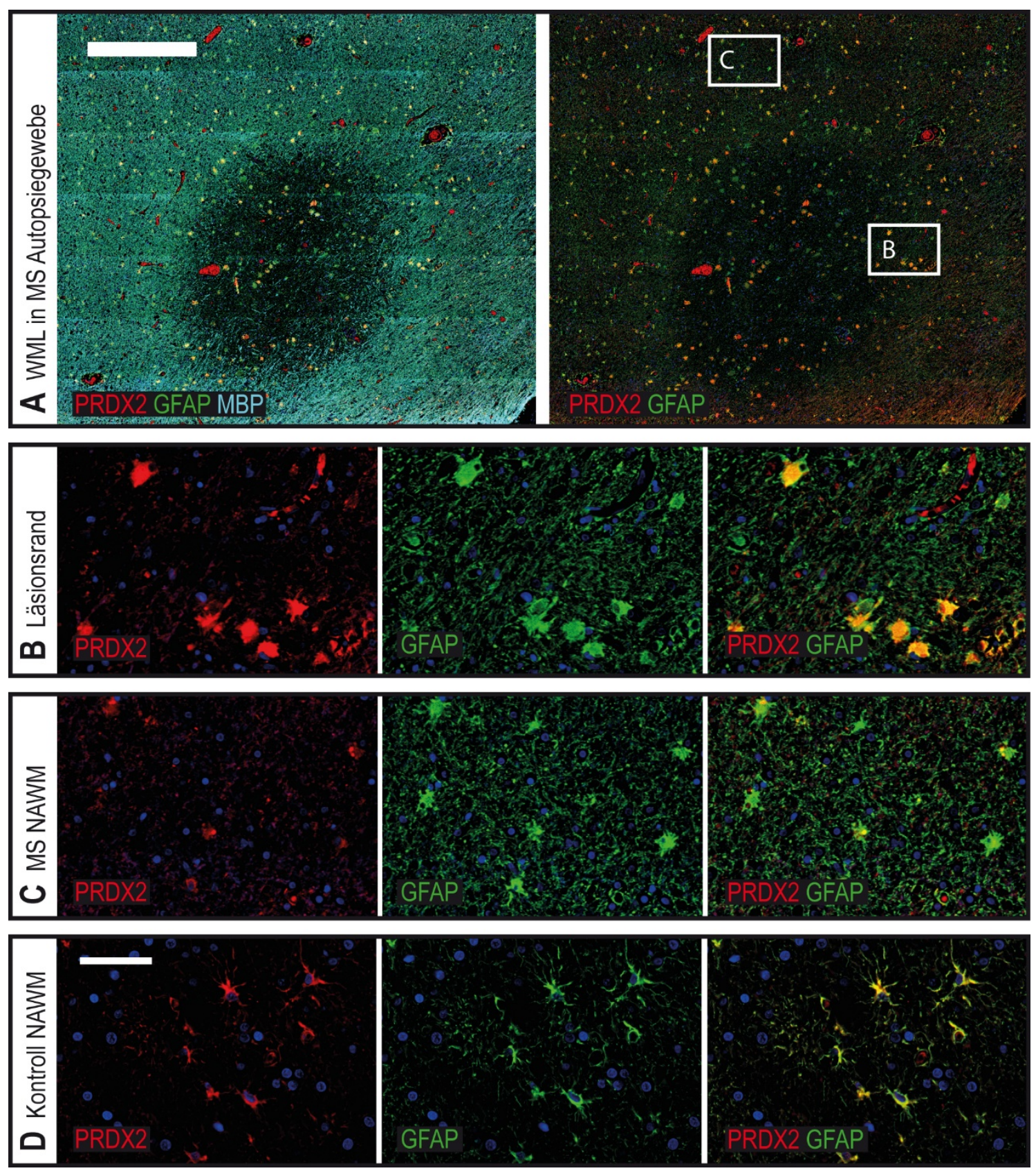

\section{Abbildung 4: PRDX2 findet sich in MS- und Kontrollfällen vorwiegend in Astrozyten}

Die Abbildung zeigt PRDX2 (rot) und das astrozytäre Intermediärfilament GFAP (grün) in MS- (A-C) und Kontrollgewebe (D). Der abgebildete MS-Fall enthält eine white matter lesion (WML), die durch die zusätzliche Färbung des Myelinproteins MBP (cyan) in der Übersichtsaufnahme deutlich zu erkennen ist (A). Besonders ausgeprägt ist die astrozytäre PRDX2-Expression im Randbereich der WML (B), während in der normal-appearing white matter (NAWM) nur eine geringe Expression von PRDX2 in vereinzelten Astrozyten zu sehen ist (C). Auch in Kontrollgewebe sind PRDX2-positive Astrozyten zu finden (D). Miterfasste Erythrozyten zeigen eine deutliche PRDX2-Färbung und sind erwartungsgemäß GFAP-negativ. Messbalken: A: $200 \mu \mathrm{m}, \mathbf{B}-\mathbf{C}$ : Markierte Areale in A, D: $50 \mu \mathrm{m}$. Teile der Abbildung sind bereits veröffentlicht (Voigt et al. 2017). 

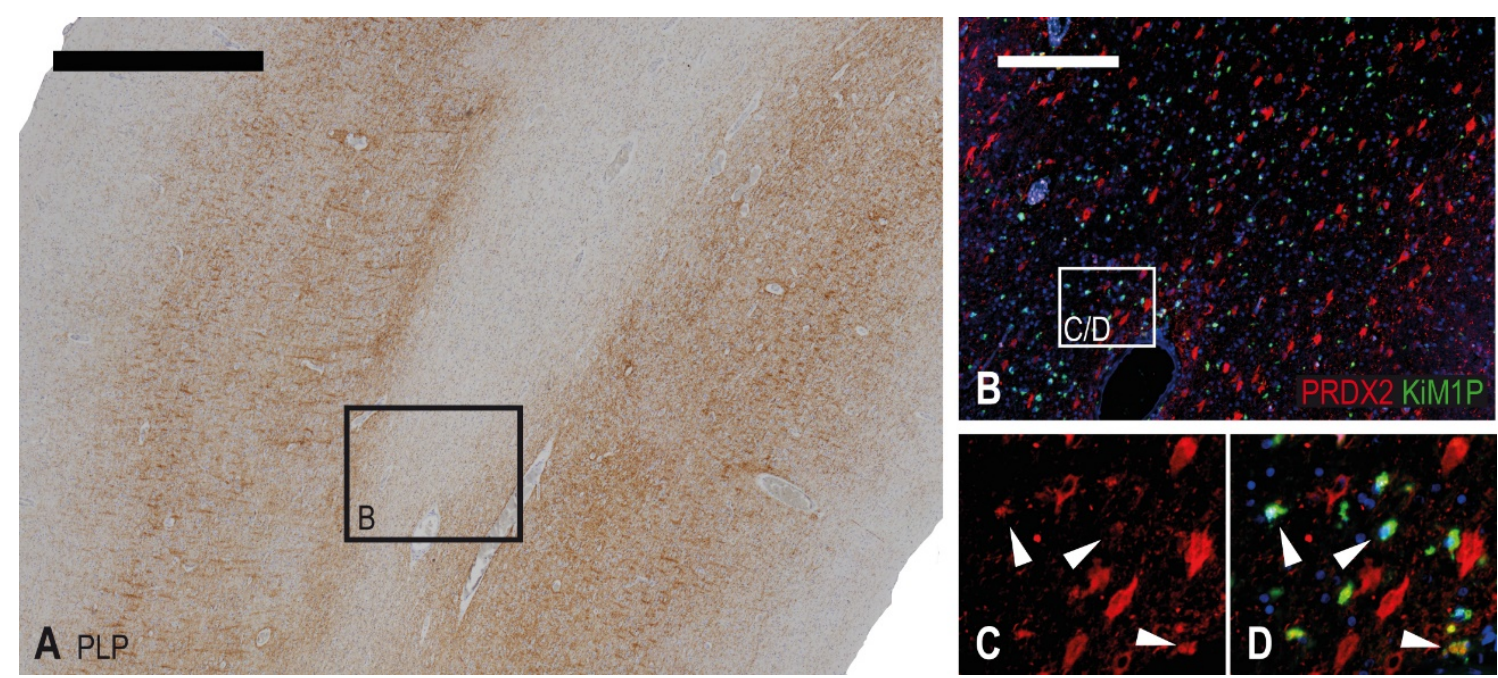

Abbildung 5: PRDX2 findet sich nur vereinzelt in schaumzelligen Makrophagen/aktivierter Mikroglia Die Übersichtsaufnahme links (A) zeigt eine subkortikale MS-Läsion in der immunhistochemischen Färbung des Myelinproteins PLP (braun). Der markierte Läsionsbereich in A ist rechts vergrößert in einer Fluoreszenz-Doppelfärbung des Moleküls PRDX2 (rot) und der Makrophagen/Mikroglia (KiM1P, grün) dargestellt (B). Gut zu erkennen sind größere PRDX2-exprimierende Zellen und dazwischen verstreut liegende Makrophagen/Mikroglia. Bei höherer Vergrößerung zeigt sich, dass die KiM1P-positiven Makrophagen/Mikroglia allenfalls eine schwache, granuläre, zytoplasmatische PRDX2-Färbung aufweisen (C-D, Pfeile). Messbalken: A: 1 mm, B: $200 \mu \mathrm{m}, \mathbf{C}-\mathbf{D}$ : Markiertes Areal in B. Teile der Abbildung sind bereits veröffentlicht (Voigt et al. 2017).

\subsubsection{DIE ASTROZYTÄRE EXPRESSION VON PRDX2 KORRELIERT MIT DEM ENTZÜNDUNGSGRAD UND DEM OXIDATIVEN STRESS}

Die bereits beschriebenen Untersuchungen zeigten, dass PRDX2 in der WM vorwiegend von Astrozyten exprimiert wird. Bei genauer Betrachtung erwies sich die astrozytäre PRDX2-Expression in ihrer Ausprägung von Region zu Region unterschiedlich. Eine besonders starke Expression und eine besonders große Anzahl PRDX2-positiver Astrozyten fand sich in Assoziation zu WMLs mit Myelin-phagozytierenden, schaumzelligen Makrophagen/aktivierter Mikroglia, die als CAPs klassifiziert worden waren (Abbildung 6, Seite 50). Aber auch ohne Läsionsassoziation in der NAWM fanden sich unter den MSFällen Areale, die durch eine vermehrte astrozytäre Expression von PRDX2 auffielen. Ob es sich dabei um den Randbereich einer außerhalb des Schnittes befindlichen WML handelte, ließ sich auch durch das Betrachten tieferer Schnittebenen nicht immer klären. Auffällig war auch in diesen Arealen eine verstärkte Mikrogliaaktivierung. 

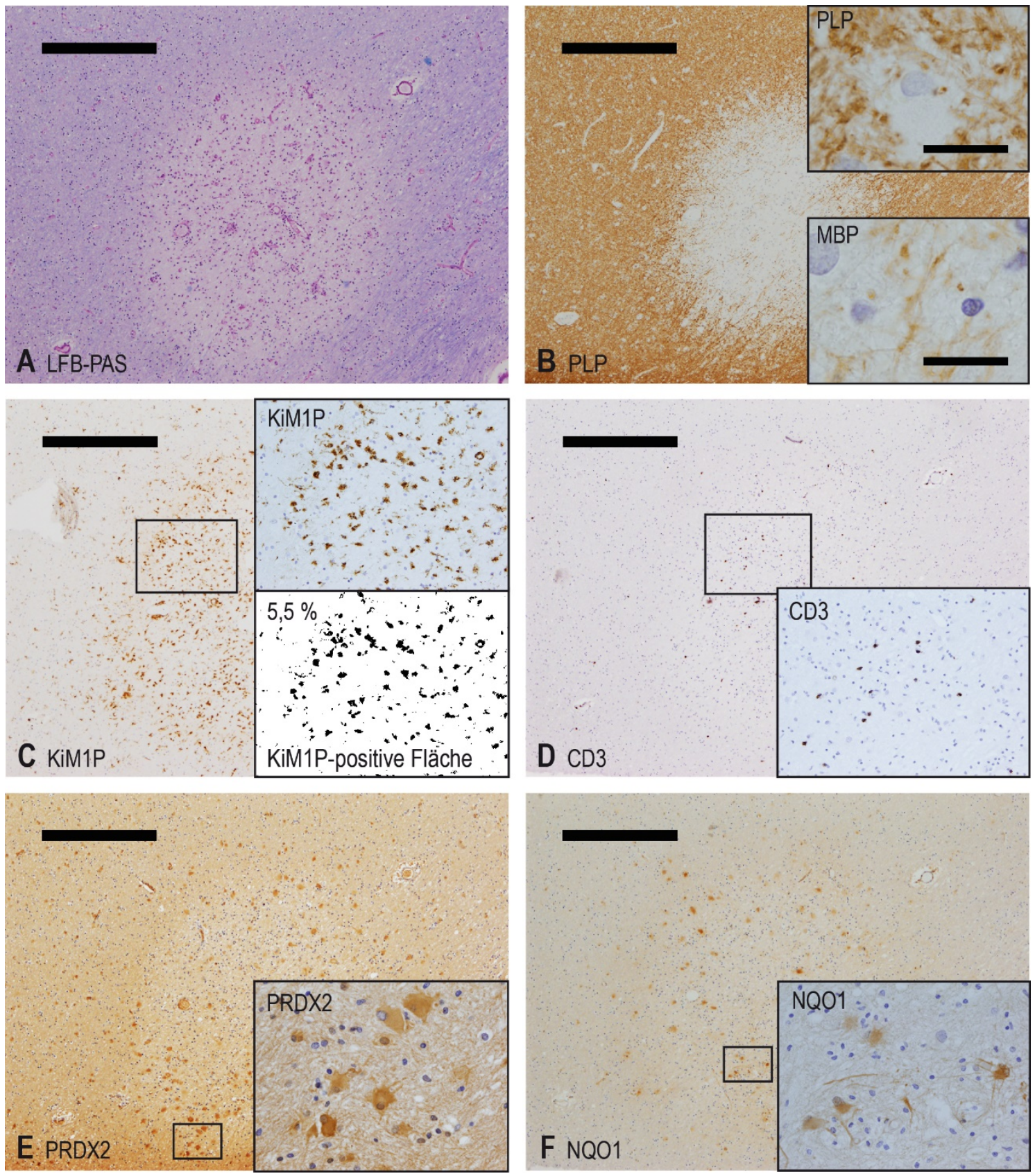

Abbildung 6: PRDX2- und NQO1-positive Astrozyten finden sich vermehrt in CAPs

Die Abbildung zeigt verschiedene Färbungen des selben chronisch aktiven MS-Plaques (CAP). Der Verlust der Myelinscheiden ist in der LFB-PAS-Färbung $(\mathbf{A})$ und in der immunhistochemischen Färbung des Myelinproteins PLP (B) gut zu sehen. Vereinzelt finden sich phagozytierte Myelinproteine (MBP und PLP) in den Makrophagen am Läsionsrand (vergrößerte Ausschnitte in B). Makrophagen und Mikroglia sind mit dem CD68-äquivalenten Marker KiM1P gefärbt und automatisiert ausgewertet (C). T-Zellen sind mit einem Anti-CD3-Antikörper gefärbt und lassen sich gut manuell zählen (D). Deutlich ist eine vermehrte astrozytäre Expression von PRDX2 (E) und NQO1 (F) im Zentrum und Randbereich der Läsion zu erkennen. Messbalken: A-F: $500 \mu \mathrm{m}$, vergrößerte Ausschnitte in B: $20 \mu \mathrm{m}$. Teile der Abbildung sind bereits veröffentlicht (Voigt et al. 2017). 
Um den Zusammenhang zwischen Entzündung und astrozytärer PRDX2-Expression detaillierter zu charakterisieren, wurde die Anzahl der PRDX2-positiven Astrozyten, die Mikrogliaaktivierung (KiM1P-Färbung) und das T-Zell-Infiltrat (CD3-Färbung) quantifiziert. Untersucht wurde die NAWM von MS- und Kontrollfällen sowie die vorhandenen WMLs. Wie bereits beschrieben, wurden bei den WMLs zwischen chronisch aktiven (CAP) und chronisch inaktiven (CIP) Plaques unterschieden. Im Hinblick auf die Läsionsarchitektur wurden das Zentrum, der Randbereich und die unmittelbare Umgebung von WMLs getrennt voneinander quantifiziert. Die Ergebnisse sind in Abbildung 7 (Seite 53) grafisch dargestellt.

Erwartungsgemäß fand sich die stärkste Mikrogliaaktivierung, gemessen in Prozent der KiM1P-gefärbten Fläche, im Zentrum (10,4 \pm 2,7 \% Fläche, angegeben ist der Mittelwert \pm Standardfehler des arithmetischen Mittels) und im Randbereich (7,9 \pm 2,3 \% Fläche) von CAPs. Eine gegenüber der NAWM der MS-Fälle (1,3 \pm 0,2 \% Fläche) ebenfalls signifikant erhöhte Mikrogliaaktivierung zeigte sich in der unmittelbaren Umgebung von CAPs (2,4 \pm 0,5 \% Fläche) und im Randbereich von CIPs (3,6 \pm 0,5 \% Fläche).

Die gleiche Verteilung fand sich für T-Lymphozyten, gemessen als Anzahl der CD3positiven Zellen pro $\mathrm{mm}^{2}$. Die meisten T-Lymphozyten wurden im Zentrum (35,8 \pm 6,9 Zellen $\left./ \mathrm{mm}^{2}\right)$ und Randbereich $\left(27,3 \pm 6,2\right.$ Zellen $\left./ \mathrm{mm}^{2}\right)$ von CAPs gezählt. Gegenüber der NAWM der MS-Fälle (3,3 \pm 0,9 Zellen/ $\mathrm{mm}^{2}$ ) ebenfalls signifikant erhöht war die Anzahl der T-Zellen in der unmittelbaren Umgebung von CAPs $(12,3 \pm 4,7$ Zellen/mm²) und im Randbereich von CIPs $(12,6 \pm 2,8$ Zellen/mm²).

Die meisten PRDX2 exprimierenden Astrozyten fanden sich im Randbereich von CAPs $(114,6 \pm 29,9$ Zellen/mm²). Ebenfalls signifikant gegenüber der NAWM in den MS-Fällen (27,9 \pm 7,1 Zellen/mm²) erhöht war die Anzahl der PRDX2-positiven Astrozyten im Zentrum von CAPs $\left(77,1 \pm 8,5\right.$ Zellen $\left./ \mathrm{mm}^{2}\right)$.

Im Hinblick auf die wichtige zytoprotektive antioxidative Funktion von PRDX2 (Wood et al. 2003; Peskin et al. 2007; Winterbourn 2008), sollte die Expression von PRDX2 in Astrozyten nicht nur im Zusammenhang mit der Entzündung, sondern auch in Verbindung mit oxidativem Stress untersucht werden. Im Unterschied zu Immunzellen lassen sich reaktive Sauerstoff- und Stickstoffverbindungen, im Weiteren als reactive oxygen species (ROS) und reactive nitrogen species (RNS) bezeichnet, aufgrund ihrer kurzen Halbwertszeit nicht direkt in Autopsiegewebe nachweisen. Indirekt kann das Vorhandensein spezifischer Zellschäden (z. B. oxidierte Phospholipide, nitrosyliertes Tyrosin oder oxidierte DNA) Auskunft über die (ehemalige) Anwesenheit von ROS/RNS im Gewebe 
geben. Diese Zellschäden treten erst bei hohen ROS/RNS-Konzentrationen auf und sind in akuten MS-Läsionen detektierbar (Haider et al. 2011). Aber auch in geringen, nicht massiv zellschädigenden Konzentrationen scheinen ROS/RNS eine Rolle zu spielen und verändern den funktionellen Zustand von Zellen z. B. über die Aktivierung des Transkriptionsfaktors NF-E2-related factor 2 (Nrf2). Ein durch Nrf2 reguliertes Protein ist die $N A D(P) H: q u i n o n e ~ o x i d o r e d u c t a s e ~ 1$ (NQO1), die bereits in Astrozyten chronischer MSLäsionen beschrieben wurde (Van Horssen et al. 2006). Die Expression von NQO1 wurde als Marker für die Aktivierung von Nrf2 und damit für oxidativen Stress verwendet (Abbildung 6, Seite 50).

Bezogen auf den Läsionstyp und die Läsionsarchitektur fand sich eine fast deckungsgleiche Verteilung der NQO1 exprimierenden Zellen und des zuvor untersuchten Immunzellinfiltrates (Abbildung 7, Seite 53). Die höchste Anzahl NQO1-positiver Zellen pro $\mathrm{mm}^{2}$ fand sich im Zentrum (96,0 \pm 30,8 Zellen/mm²), im Randbereich (81,5 \pm 19,8 Zellen/mm²) und der unmittelbaren Umgebung (46,5 \pm 14,0 Zellen/mm²) von CAPs. In allen drei Regionen war die Anzahl NQO1 exprimierender Zellen verglichen mit der NAWM der MS-Fälle $(6,4 \pm 3,0$ Zellen/mm²) signifikant erhöht.

Die erhobenen Daten legten einen lokalen Zusammenhang zwischen Entzündung, oxidativem Stress und astrozytärer PRDX2-Expression nahe. Da sowohl das Immunzellinfiltrat als auch die PRDX2- und NQO1-Expression in denselben, gut dokumentierten Hirnregionen/Läsionsbereichen gemessen worden waren, konnten im Anschluss alle Werte gegeneinander aufgetragen werden (Abbildung 7, Seite 53). So ließ sich eine schwache, wenn auch signifikant positive Korrelation zwischen der regionalen Anzahl der PRDX2positiven Astrozyten und der Mikrogliaaktivierung (Pearson $r=0,50$ ) bzw. den CD3positiven T-Lymphozyten (Pearson $r=0,51$ ) feststellen. Die Anzahl der NQO1 exprimierenden Zellen korrelierte besonders mit der Anzahl der CD3-positiven T-Lymphozyten signifikant positiv (Pearson $r=0,69$ ). Darüber hinaus wurde eine starke positive Korrelation zwischen der regionalen Anzahl der PRDX2- und der NQO1-positiven Astrozyten gefunden (Pearson $r=0,73$ ). 

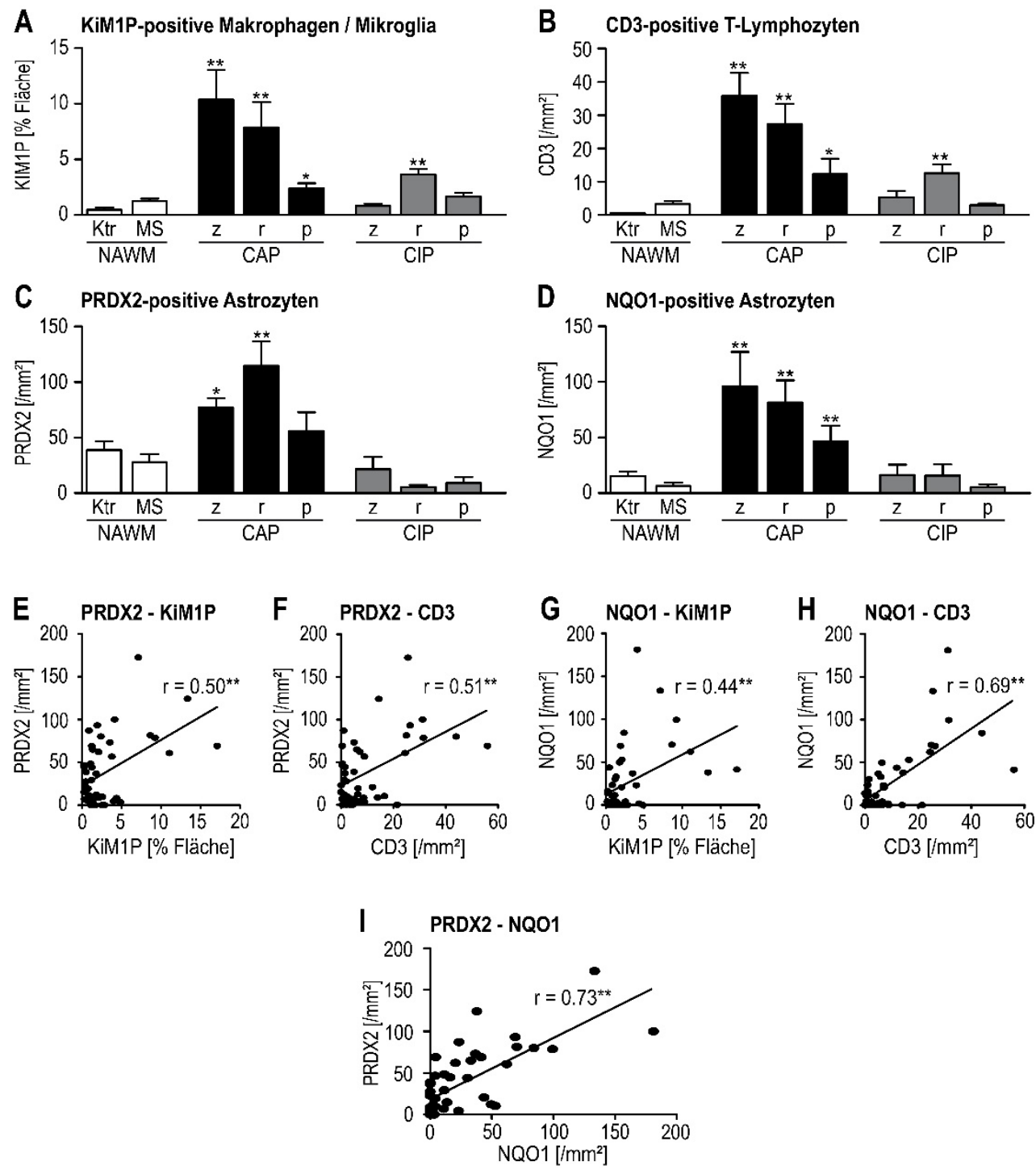

\section{Abbildung 7: Die PRDX2-Expression korreliert mit dem Entzündungsausmaß und dem oxidativen} Stress

Evaluation der Makrophagen/Mikrogliaaktivierung (KiM1P, A) und des T-Zell-Infiltrates (CD3, B) sowie der Anzahl PRDX2- und NQO1-positiver Astrozyten (C, D). Die Abbildung zeigt die erhobenen Werte aus der normal-appearing white matter (NAWM) von MS und Kontrollfällen (Ktr) sowie aus vier chronisch aktiven Plaques (CAP) und fünf chronisch inaktiven Plaques (CIP). Die Messwerte aus dem Läsionszentrum (z), dem Läsionsrand ( $r$ ) und der unmittelbaren Umgebung der Läsion ( $p$ ) sind getrennt voneinander aufgeführt. Bezogen auf den Läsionstyp und die Läsionsareale zeigt sich eine ähnliche Verteilung der Makrophagen/aktivierten Mikroglia, der T-Lymphozyten und der PRDX2- sowie NQO1-Expression (A-D). Alle erhobenen Werte sind im Zentrum und Randbereich von CAPs gegenüber der NAWM der MS-Fälle signifikant erhöht (Mann-Whitney U-Test). Die Anzahl der PRDX2 und NQO1 exprimierenden Astrozyten zeigt eine signifikant positive Korrelation (Pearson r) mit dem Grad der Entzündung (E-H). Zudem besteht eine stark positive Korrelation zwischen der regionalen PRDX2- und NQO1-Expression (I). Angegeben ist der Mittelwert \pm Standardfehler des arithmetischen Mittels. ${ }^{*} p<0,05,{ }^{*} p<0,01$. Teile der Abbildung sind bereits veröffentlicht (Voigt et al. 2017). 


\subsection{PeROXYREDOXIN 2 In DER KORTIKALEN GRAUEN SUBSTANZ I CORTICAL GREY MATTER}

Neben der WM enthielt das im Rahmen dieser Studie verwendete Autopsiematerial viele kortikale Gewebeanteile, hier vereinfacht als GM bezeichnet. Die GM enthält per definitionem die neuronalen Perikaryen und ist bei MS entscheidend mitbetroffen. Neben der bereits in frühen Krankheitsstadien auftretenden und im Verlauf ausgedehnten kortikalen Demyelinisierung (Brownell und Hughes 1962; Stadelmann et al. 2008; Lucchinetti et al. 2011) kommt es bei MS zu einer neuronalen Degeneration, die unter anderem auf oxidativen Stress und mitochondriale Veränderungen zurückgeführt wird (Fischer et al. 2013).

Anhand der Myelinfärbungen (PLP, MBP) wurde die Myelinisierung/Demyelinisierung in der GM untersucht und die GML entsprechend ihrer Lokalisation eingeteilt (Kapitel 3.1, Seite 45). Anschließend wurde die Entzündung in der GM charakterisiert. Mit den bereits für die WM angewandten Methoden wurden die Mikrogliaaktivierung (KiM1PFärbung) und die Anzahl der T-Lymphozyten (CD3-Färbung) quantifiziert. Untersucht wurden die NAGM von MS und Kontrollfällen sowie die vorhandenen GMLs. Das Zentrum, der Rand und die unmittelbare Umgebung von GMLs wurden getrennt voneinander quantifiziert. Bei leukokortikalen Läsionen (GML Typ I) wurde zwischen dem an die GM und dem an die WM grenzenden Läsionsrand unterschieden. Die Ergebnisse sind in Abbildung 8 (Seite 55) grafisch dargestellt.

Die stärkste Mikrogliaaktivierung, gemessen in Prozent der KiM1P-gefärbten Fläche, fand sich in leukokortikalen Läsionen (GML Typ I). Bei diesem Läsionstyp war die Mikrogliaaktivierung im Randbereich zur WM am ausgeprägtesten (2,46 \pm 0,30 \% Fläche) und signifikant gegenüber der NAWM der MS-Fälle (1,3 \pm 0,2 \% Fläche) erhöht. Aber auch am Läsionsrand zur GM (1,0 \pm 0,5 \% Fläche) und im Läsionszentrum (0,5 \pm $0,2 \%$ Fläche) von leukokortikalen Läsionen zeigte sich eine gegenüber der NAGM der MS-Fälle (0,3 \pm 0,1 \% Fläche) erhöhte Mikrogliaaktivierung. Lediglich gering erhöhte Werte fanden sich in subpialen Läsionen (GML Typ III).

Eine ähnliche Verteilung zeigte sich für die T-Lymphozyten, gemessen als Anzahl der CD3-positiven Zellen pro mm². In leukokortikalen Läsionen (GML Typ I) war die Anzahl der T-Zellen insbesondere im Zentrum (4,4 \pm 1,9 Zellen/ $\left.\mathrm{mm}^{2}\right)$ und am Läsionsrand zur WM $\left(14,7 \pm 1,2\right.$ Zellen/ $\left.\mathrm{mm}^{2}\right)$ erhöht. Eine geringere, aber ebenfalls gegenüber der NAGM der MS-Fälle $\left(0,5 \pm 0,2\right.$ Zellen/ $\left.\mathrm{mm}^{2}\right)$ signifikant erhöhte Anzahl an T-Lymphozyten fand sich in leukokortikalen Läsionen am Läsionsrand zur GM (1,9 \pm 0,7 Zellen/mm²) und in der Läsionsumgebung (1,3 \pm 0,3 Zellen $\left./ \mathrm{mm}^{2}\right)$. 

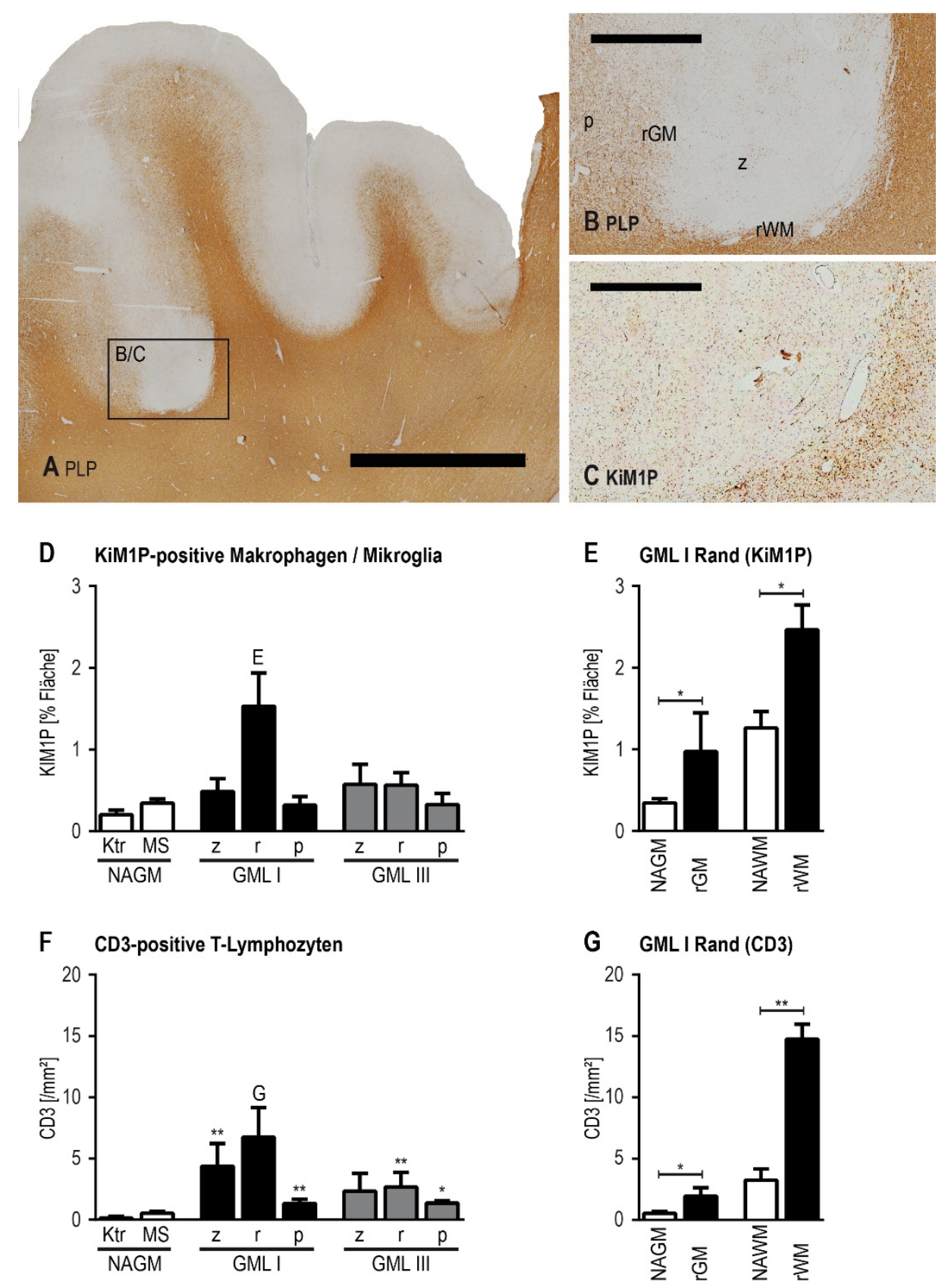

\section{Abbildung 8: In leukokortikalen Läsionen zeigt sich eine erhöhte Entzündungsaktivität}

Die Abbildung zeigt einen MS-Fall mit leukokortikaler grey matter lesion (GML I) in der Färbung des Myelinproteins PLP (A, B) und der Makrophagen/Mikroglia (KiM1P, C) sowie das Ausmaß der Entzündung (D-G) in der normal-appearing grey matter (NAGM) von MS und Kontrollfällen (Ktr), in fünf leukokortikalen Läsionen (GML I) und drei subpialen Läsionen (GML III). Die Messwerte aus dem Läsionszentrum (z), dem Läsionsrand $(r)$ und der unmittelbaren Umgebung der Läsion (p) sind getrennt voneinander aufgeführt. Für GML I sind die erhobenen Werte aus dem Läsionsrand zur grauen Substanz (rGM) und dem zur weißen Substanz (rWM) gesondert dargestellt (illustriert in B, Messwerte in E und G). Vornehmlich in GML I zeigt sich am Läsionsrand zur weißen Substanz (rWM) eine gegenüber der normal-appearing white matter (NAWM) von MS-Fällen erhöhte Entzündungsaktivität. Messbalken: A: $5 \mathrm{~mm}, \mathbf{B}-\mathbf{C}: 1 \mathrm{~mm}$. Angegeben ist der Mittelwert \pm Standardfehler des arithmetischen Mittels. Mann-Whitney U-Test ${ }^{*} p<0,05,{ }^{* *} p<0,01$. 
Auch subpiale Läsionen (GML Typ III) wiesen am Läsionsrand (2,7 \pm 1,2 Zellen/mm²) und in der Läsionsumgebung $\left(1,4 \pm 0,2\right.$ Zellen/ $\left.\mathrm{mm}^{2}\right)$ eine geringe, aber signifikant erhöhte Anzahl an T-Zellen auf.

Eine präzise Auswertung der PRDX2- und NQO1-Expression kortikaler Zellen gestaltete sich aus verschiedenen Gründen als technisch problematisch. Neuronale Marker (NeuN, NSE und PGP 9.5) erwiesen sich an dem verwendeten Autopsiematerial als unzuverlässig, sodass eine gezielte Untersuchung der neuronalen PRDX2- bzw. NQO1-Expression nicht möglich war. Zudem ließ sich, in Anbetracht der häufig unspezifischen immunhistochemischen Färbung neuronaler Perikaryen und abgelagerter Lipofuszingranula, keine verlässliche Methode zur Quantifizierung PRDX2- oder NQO1-positiver kortikaler Zellen etablieren. Dennoch fanden sich bei der Durchsicht des vorhandenen Autopsiematerials und der vorhandenen Färbungen eindeutig PRDX2-positive Zellen mit neuronaler Morphologie (dreieckiger Zellkörper, großer aufgelockerter Zellkern mit Nukleolus). Insbesondere in leukokortikalen Läsionen schien die Dichte der PRDX2-exprimierenden Neuronen erhöht zu sein (Abbildung 9).
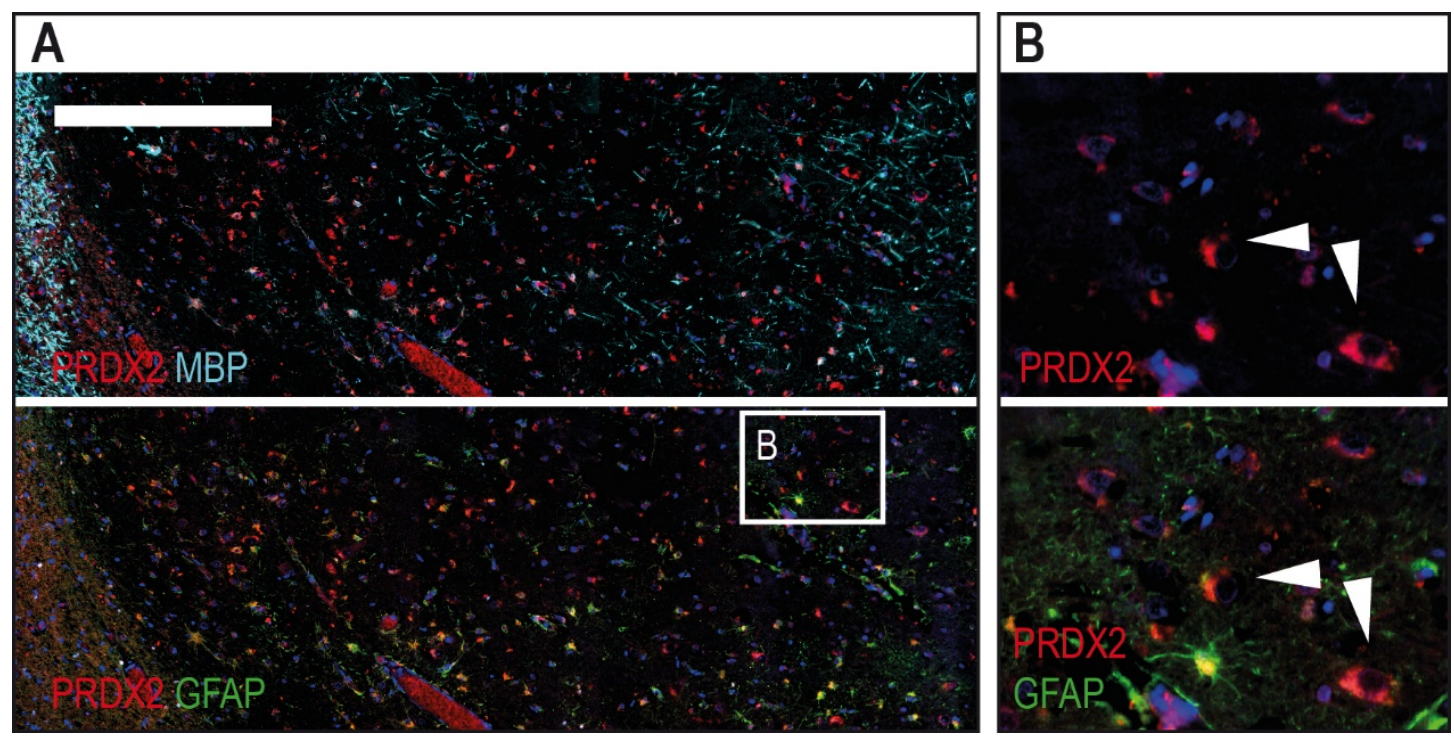

Abbildung 9: Insbesondere in leukokortikalen Läsionen finden sich PRDX2-positive Neurone Abgebildet ist eine leukokortikale MS-Läsion (GML Typ I) in einer Fluoreszenz-Färbung des Proteins PRDX2 (rot) gemeinsam mit dem Myelinproteins MBP (cyan) und dem Astrozytenmarker GFAP (grün). Sowohl in der Übersichtsaufnahme (A), als auch in dem vergrößert abgebildeten Läsionsbereich (B) sind PRDX2exprimierende Zellen zu erkennen, die GFAP-negativ sind (Pfeile) und eine neuronale Morphologie aufweisen. Messbalken: A: $500 \mu \mathrm{m}, \mathbf{B}$ : Markiertes Areal in A. Teile der Abbildung sind bereits veröffentlicht (Voigt et al. 2017). 


\subsection{EXPRESSION VON PRDX2 UND NQO1 IN VITRO}

\subsubsection{OXIDATIVER STRESS FÜHRT ZU EINER VERMEHRTEN ASTROZYTÄREN EXPRESSION VON NQO1, NICHT ABER VON PRDX2}

Die erhobenen Daten zeigten im Autopsiegewebe von MS-Patienten eine gemeinsame Lokalisation des entzündlichen Geschehens und der astrozytären PRDX2- sowie NQO1Expression. Entzündungszellen, insbesondere Mikroglia, sind eine potentielle Quelle reaktiver Sauerstoff- und Stickstoffverbindungen (Fischer et al. 2012). Mikroglia und TLymphozyten sezernieren darüber hinaus Zytokine und modulieren auf diese Weise entscheidend das Entzündungsgeschehen sowie die Expression verschiedenster Proteine im umliegenden Gewebe (Meeuwsen et al. 2003). Um den Einfluss von oxidativem Stress auf die Expression von PRDX2 und NQO1 gezielt untersuchen zu können, wurden humane Astrozytom- (U373MG) und Neuroblastomzellen (SH SY5Y) sowie murine Astrozyten in vitro mit verschiedenen Konzentrationen Glukose-Oxidase (GOD) inkubiert. Das Enzym GOD katalysiert die Oxidation von Glukose zu Gluconolacton; eine Reaktion, bei der Wasserstoffperoxid $\left(\mathrm{H}_{2} \mathrm{O}_{2}\right)$ anfällt. Die maximal eingesetzte GOD-Konzentration wurde in Vorversuchen so festgelegt, dass sich nach einer 24-stündigen Inkubation mit GOD keine, oder nur wenige untergehende Zellen in der Zellkultur befanden. Die Transkription von PRDX2 und NQO1 wurde nach 24-stündiger Inkubation der Zellen mit GOD mittels quantitativer polymerase chain reaction (qPCR) untersucht. Für die qPCR der humanen Zelllinien wurden die eigens dafür entwickelten Oligonukleotidprimer verwendet (siehe Kapitel 2.5.6, Seite 40), die qPCR der murinen Astrozyten wurde mithilfe von TaqMan Expression Assays durchgeführt. Zur Fluoreszenz-Färbung der Neuroblastomzellen wurden diese auf kleinen Glasplättchen (coverslides) kultiviert, nach der 24-stündigen Inkubation mit GOD durch Paraformaldehyd (PFA) fixiert und im Anschluss die Proteine PRDX2, NQO1 sowie der Transkriptionsfaktor Nrf2 entsprechend dem in Kapitel 2.5.4 (Seite 39) beschriebenen Protokoll gefärbt.

In den Neuroblastomzellen (SH SY5) zeigte sich nach einer 24-stündigen Inkubation mit GOD (Enzymaktivität $12 \mathrm{mU} / \mathrm{mL}$ ) auf Transkriptionsebene (qPCR) eine um das 4,8-fach gesteigerte NQO1-Expression, jedoch keine Veränderung der PRDX2-Expression. Passend zu diesen Ergebnissen fand sich auf Proteinebene in der Fluoreszenz-Färbung der mit GOD inkubierten Neuroblastomzellen ein gesteigertes zytoplasmatisches Vorkommen von NQO1, nicht aber von PRDX2. Bei näherer Betrachtung wurde in den mit GOD inkubierten Zellen zudem eine Translokation des Transkriptionsfaktor Nrf2 vom Zytoplasma in den Nukleus beobachtet. 
Keine bedeutenden Änderungen der Expression von PRDX2- und NQO1 auf Transkriptionsebene zeigten sich bei den Astrozytomzellen (U373MG). Die Ergebnisse sind in Abbildung 10 grafisch dargestellt.

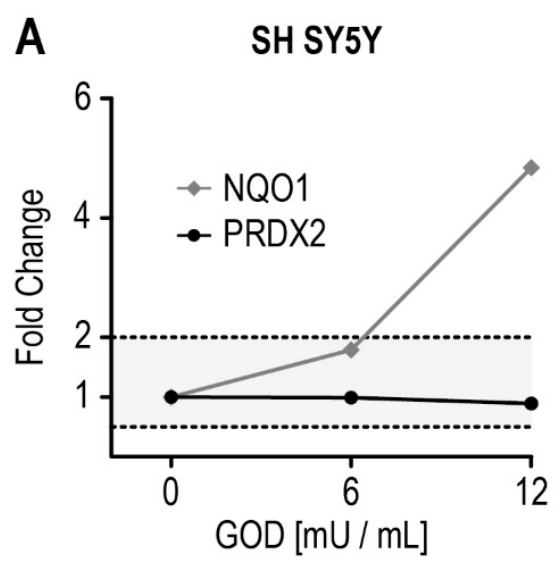

B Mit GOD stimulierte SH SY5Y

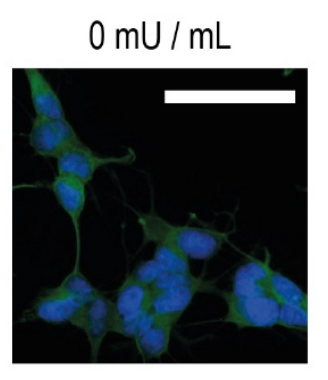

$12 \mathrm{mU} / \mathrm{mL}$

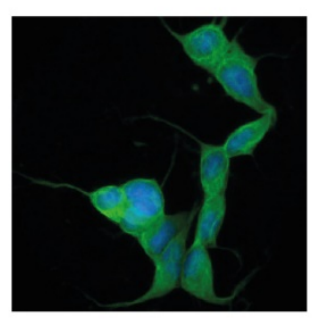

NQ01

DAPI
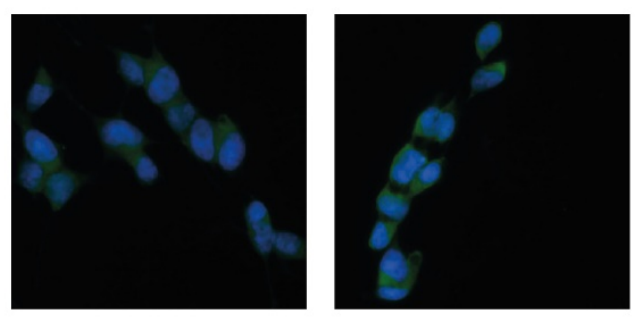

PRDX2

DAPI
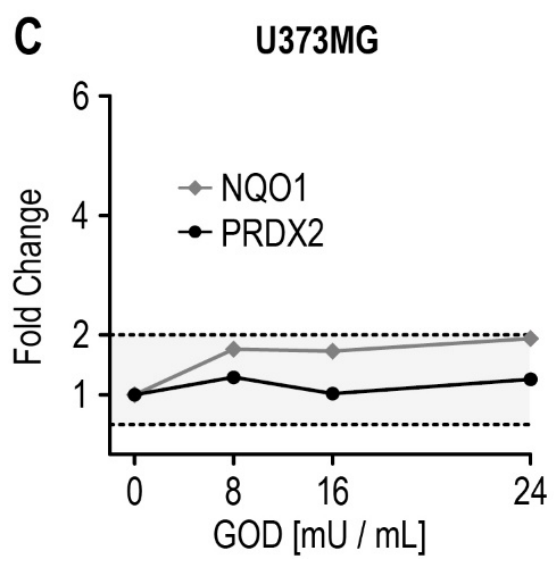
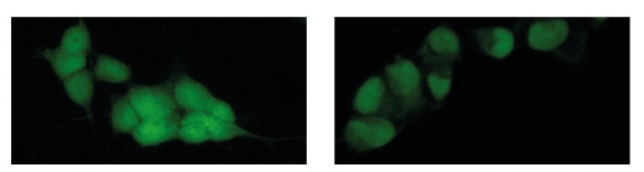

Nrf2
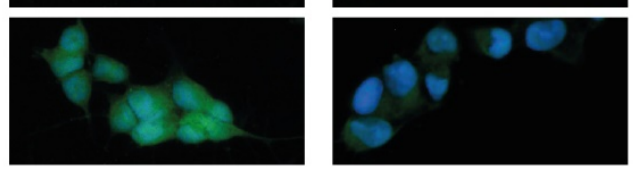

Nrf2

DAPI

Abbildung 10: PRDX2- und NQO1-Expression nach der Inkubation humaner Zelllinien mit GOD

Die Abbildung zeigt eine erhöhte Expression von NQO1, nicht aber von PRDX2, in humanen Neuroblastomzellen (SH SY5Y). Nach einer 24-stündigen Inkubation der Neuroblastomzellen mit Glukose-Oxidase (GOD) findet sich sowohl auf Transkriptionsebene mittels qPCR (A), als auch auf der Proteinebene mittels Fluoreszenz-Färbung (B) eine gesteigerte NQO1-Expression. Die Färbung des Transkriptionsfaktors Nrf2 zeigt nach GOD-Inkubation der Zellen eine vermindertes zytoplasmatisches, mehr nukleäres Vorkommen von Nrf2 (B unten). Die Zellkerne sind mit Diaminophenylindol (DAPI) blau gefärbt (B). In der humanen Astrozytom-Zelllinie U373MG findet sich in der qPCR weder eine Änderung der NQO1- noch der PRDX2-Expression (C). Messbalken: B: $50 \mu \mathrm{m}$. 
Eine vergleichbare Versuchsreihe wurde mehrmals mit murinen Astrozyten aus dem ZNS neugeborener Mäuse (P0) durchgeführt. Die murinen Astrozyten wurden ebenfalls für 24 h mit GOD inkubiert. In Vorversuchen zeigten sich bereits bei einer GOD-Aktivität von $32 \mathrm{mU} / \mathrm{mL}$ untergehende Zellen, sodass eine GOD-Aktivität von maximal $24 \mathrm{mU} / \mathrm{mL}$ für die Versuche zum Einsatz kam. Mittels qPCR zeigte sich, dass die Transkription von NQO1 nach $24 \mathrm{~h}$ bei einer GOD-Aktivität von $16 \mathrm{mU} / \mathrm{mL}$ um das 3,5-fache (Fold Change 3,5 \pm 0,5) und bei $24 \mathrm{mU} / \mathrm{mL}$ um das 8,3-fache (Fold Change 8,3 $\pm 1,2$ ) anstieg. Wie auch in den Versuchen mit humanen Zelllinien, fand sich in murinen Astrozyten keine Veränderung der PRDX2-Transkription nach einer Inkubation der Zellen mit GOD. Die beschriebenen Ergebnisse sind in Abbildung 11 grafisch dargestellt.

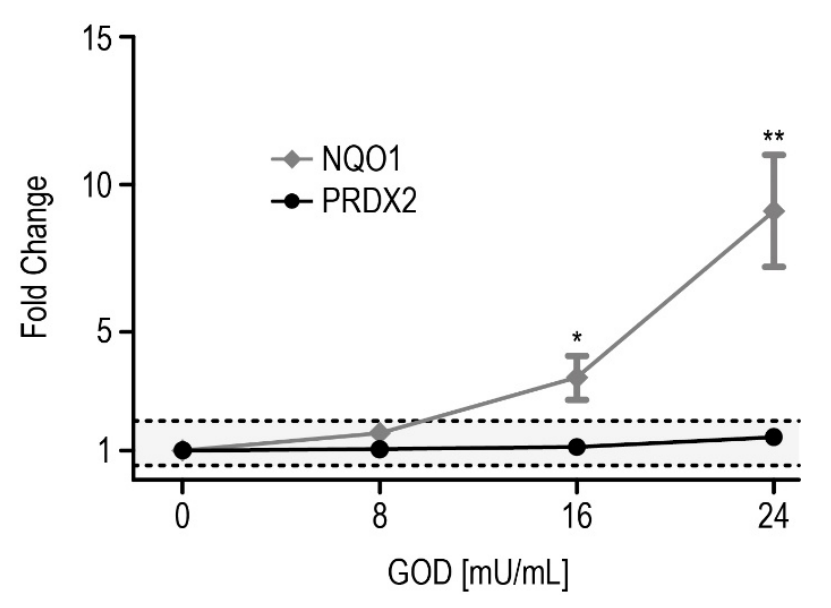

Abbildung 11: PRDX2- und NQO1-Expression nach der Inkubation muriner Astrozyten mit GOD

Abgebildet ist die mittels qPCR untersuchte Expression von PRDX2 (schwarz) und NQO1 (grau) nach 24stündiger Inkubation muriner Astrozyten mit verschiedenen Konzentrationen des Enzyms GOD. Während die Expression von PRDX2 unverändert bleibt, zeigt sich eine deutlich und signifikant gesteigerte NQO1Expression bei erhöhter GOD-Aktivität. Der Abbildung liegt eine mehrmals wiederholte Versuchsreihe zugrunde (Triplikat). Angegeben ist der Mittelwert \pm Standartabweichung aller erhobenen Messwerte. OneWay ANOVA ${ }^{*} p<0,05,{ }^{* *} p<0,01$. Teile der Abbildung sind bereits veröffentlicht (Voigt et al. 2017). 


\subsubsection{DURCH ZYTOKINE FINDET SICH KEINE VERÄNDERUNG DER ASTROZYTÄREN EXPRESSION VON PRDX2 UND NQO1}

Die beschriebenen Versuche, in denen die Auswirkung von oxidativem Stress auf die Expression von PRDX2 und NQO1 in vitro untersucht worden war, zeigten keine Änderung der PRDX2-Expression auf Transkriptionsebene durch die alleinige Anwesenheit von Wasserstoffperoxid in der Zellkultur. Gleichwohl legten die vorausgegangenen Untersuchungen des Autopsiegewebes von MS-Patienten ein Zusammenhang zwischen Entzündung und astrozytärer PRDX2-Expression nahe.

Das Entzündungsgeschehen bei MS wird entscheidend durch Zytokine vermittelt. Zytokine verändern über eine rezeptorvermittelte Wirkung unter anderem die Expression von Proteinen in Zellen des umliegenden Gewebes (Navikas und Link 1996). Astrozyten exprimieren beispielsweise Rezeptoren für Interferon gamma (IFN- $\gamma$ ), Interleukin 1 beta (IL-1 $\beta$ ), Tumornekrosefaktor alpha (TNF- $\alpha$ ), transforming growth factor beta 1 (TGF$\beta 1$ ) und brain-derived neurotrophic factor (BDNF) (Stadelmann et al. 2002; Meeuwsen et al. 2003). Insbesondere unter dem Einfluss von IFN- $\gamma$ und IL-1 $\beta$ kommt es zu einer reaktiven Astrogliose (Giulian et al. 1988; Yong et al. 1991). Alle genannten Zytokine spielen in MS-Läsionen eine wichtige Rolle. Die Wirkung von BDNF auf Astrozyten führt unter anderem zu einer vermehrten Expression von iNOS (Colombo et al. 2012) und ist untersucht worden, da eine Wechselwirkung zwischen PRDX2 und anderen Wachstumsfaktoren (platelet-derived growth factor, PDGF) beschrieben ist (Choi et al. 2005).

Um die Wirkung einzelner Zytokine auf die PRDX2-Expression zu untersuchen, wurden murine Astrozyten mit verschiedenen Konzentrationen einiger ausgewählter Zytokine (IFN- $\gamma$, IL-1 $\beta$, TNF- $\alpha$, TGF- $\beta 1$, BDNF) für 24 h inkubiert. Die eingesetzten Zytokinkonzentrationen sind von Andreas Junker, dem Betreuer dieser Arbeit, in vorangegangenen In-vitro-Studien etabliert worden. Neben der PRDX2- wurde die NQO1-Expression untersucht, um herauszufinden, ob NQO1 nicht nur durch oxidativen Stress, sondern auch durch die Anwesenheit von Zytokinen in seiner Expression beeinflusst wird.

Für keines der verwendeten Zytokine (IFN- $\gamma$, IL-1 $\beta$, TNF- $\alpha$, TGF- $\beta 1$, BDNF) fand sich eine bedeutende Änderung der Expression von PRDX2 oder NQO1 auf Transkriptionsebene (qPCR). Die Ergebnisse sind in Abbildung 12 (Seite 61) grafisch dargestellt. 

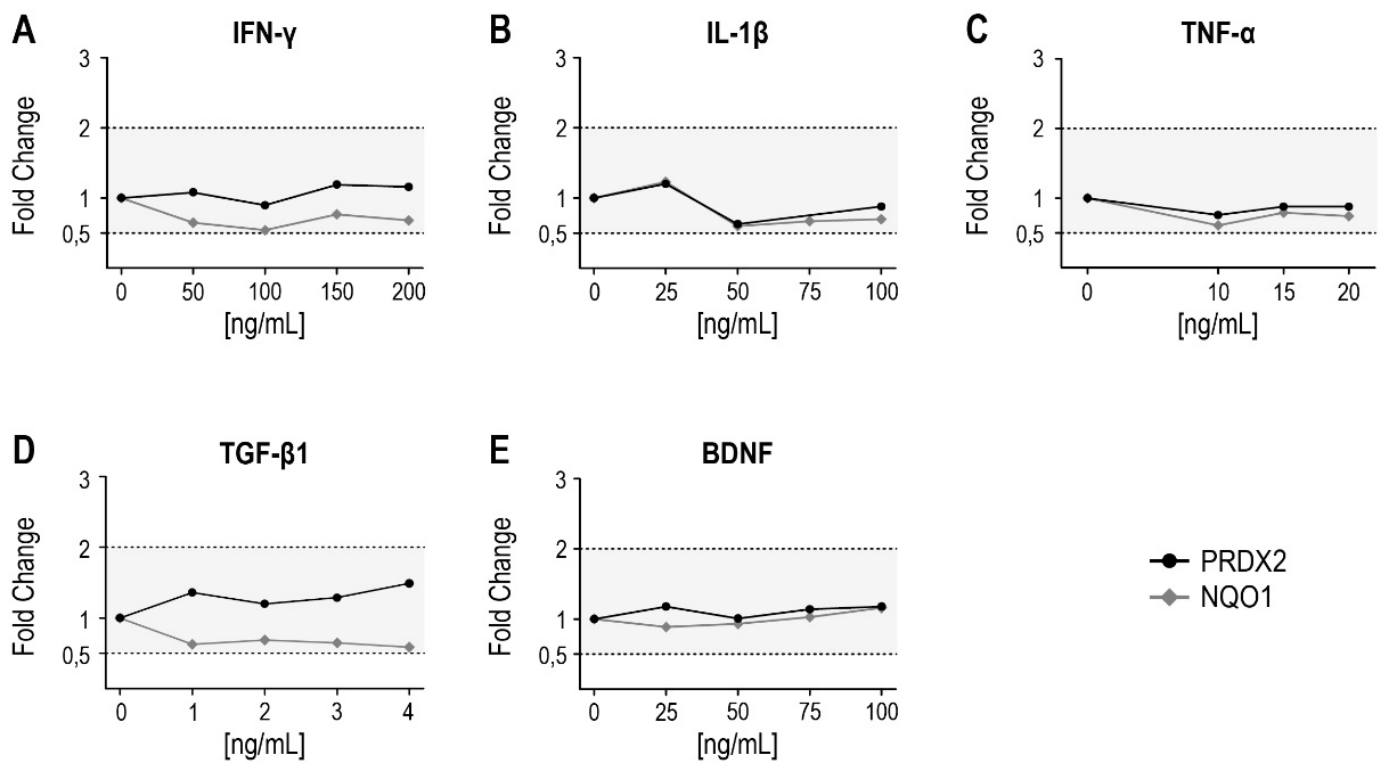

Abbildung 12: Inkubation primärer muriner Astrozyten mit Zytokinen

Die Abbildung zeigt die mittels qPCR untersuchten Veränderungen der PRDX2- (schwarz) und NQO1-EXpression (grau) nach 24-stündiger Inkubation muriner Astrozyten mit den Zytokinen IFN-y (A), IL-1B (B), TNF- $\alpha$ (C), TGF- $\beta 1$ (D) und BDNF (E). Keines der ausgewählten, ebenfalls in MS-Läsionen vorkommenden, Zytokine verändert die PRDX2- oder NQO1-Expression auf Transkriptionsebene in nennenswertem Umfang (Halbierung oder Verdoppelung der Expression). 


\section{DISKUSSION}

Im Rahmen dieser Arbeit wurde das antioxidative Enzym PRDX2 im Autopsiegewebe des ZNS von Patienten mit MS und in neuropathologisch unauffälligem Gewebe (Kontrollen) untersucht. Dabei fand sich, dass in der weißen Substanz (WM) PRDX2 vorwiegend von Astrozyten exprimiert wird. Eine verstärkte astrozytäre PRDX2-Expression zeigte sich in den MS-Fällen in Assoziation mit Läsionen der weißen Substanz (WML). Für die regionale Anzahl der PRDX2 exprimierenden Astrozyten ergab sich eine positive Korrelation mit dem lokalen Grad der Entzündung (Makrophagen/Mikrogliaaktivierung und T-Lymphozyten) sowie der Expression des Markers für oxidativen Stress NQO1. Im Kortex (vereinfacht GM) fanden sich vermehrt PRDX2-positive Neurone in leukokortikalen Läsionen (GML) bei MS. In vitro wurde der Einfluss von oxidativem Stress und Zytokinen auf die Expression von PRDX2 untersucht. Unter dem Einfluss von oxidativem Stress fand sich auf Transkriptionsebene eine verstärkte NQO1- nicht aber PRDX2Expression in humanen Neuroblastomzellen (SH SY5Y) und murinen Astrozyten. Die Inkubation von murinen Astrozyten mit Zytokinen veränderte weder die PRDX2- noch auf die NQO1-Transkription.

\subsection{PeROXIREDOXIN 2 TRÄGT ZUR WIDERSTANDSFÄHIGKEIT EINZELNER ZELLPOPULATIONEN GEGENÜBER OXIDATIVEM STRESS BEI}

Um die Lokalisation von PRDX2 im verwendeten MS- und Kontrollgewebe zu untersuchen, wurde mittels Immunhistochemie das Protein PRDX2 in dem Gewebe angefärbt. In der WM erwiesen sich in dieser Färbung vorwiegend Zellen mit astrozytärer Morphologie als PRDX2-positiv. In einer Fluoreszenz-Doppelfärbung mit dem astrozytären Intermediärfilament GFAP konnte gezeigt werden, dass es sich bei dem größten Teil der PRDX2-positiven Zellen um Astrozyten handelt. Die größte Anzahl PRDX2-exprimierender Astrozyten fand sich im Randbereich von chronisch aktiven Plaques (CAPs). Vereinzelt fand sich eine eher granuläre PRDX2-Färbung in Makrophagen/Mikroglia.

Diese Beobachtungen untermauern die Annahme, dass sich verschiedene Zellpopulationen des ZNS hinsichtlich ihrer Widerstandsfähigkeit gegenüber oxidativem Stress unterscheiden. Auf reaktive Sauerstoff- und Stickstoffverbindungen (ROS bzw. RNS) zurückführbare Zellschäden finden sich vorwiegend in Axonen und Oligodendrozyten. So lassen sich in aktiven entzündlichen WML oxidierte Phospholipide und Malondialdehyd in axonalen Sphäroiden und Oligodendrozyten nachweisen (Haider et al. 2011; Fischer et 
al. 2013). Nitrotyrosin findet sich in aktiven WML des Subtyps III in untergehenden Oligodendrozyten, ist interessanterweise aber auch in Astrozyten und Makrophagen demonstrierbar (Cross et al. 1998; Jack et al. 2007; Zeis et al. 2008). Oxidierte DNA (8Hydroxy-D-Guanosin) ist in aktiven entzündlichen WML ebenfalls vor allem in Oligodendrozyten nachzuweisen (Haider et al. 2011).

Astrozyten und Makrophagen/Mikroglia, die zudem als Quelle für ROS/RNS gelten, weisen eine deutlich bessere Ausstattung mit antioxidativen Molekülen auf. Superoxiddismutase und Katalase werden im ZNS vorwiegend von Astrozyten und Makrophagen/aktivierter Mikroglia exprimiert (Van Horssen et al. 2008). Thioredoxin 2, Peroxiredoxin 3 und Peroxiredoxin 5 kommen ebenfalls präferenziell in Astrozyten vor (Holley et al. 2007; Nijland et al. 2014). Eine verstärkte astrozytäre Expression von Hämoxigenase 1 und NQO1 in WML weist darauf hin, dass Astrozyten über eine Aktivierung des Transkriptionsfaktors Nrf2 auf oxidativen Stress reagieren und sich anpassen können (Van Horssen et al. 2006), was auch in vitro nachweisbar ist (Dowell und Johnson 2013). In welchem Umfang PRDX2 als einzelnes Enzym zur astrozytären Widerstandsfähigkeit gegenüber oxidativem Stress beiträgt, wäre in PRDX2-defizienten Zellen oder Organismen zu evaluieren. Studien der Enzymkinetik von PRDX2 weisen darauf hin, dass PRDX2, sofern es von Zellen exprimiert wird, nahezu alles Wasserstoffperoxid $\left(\mathrm{H}_{2} \mathrm{O}_{2}\right)$ abbaut (Winterbourn 2008).

Interessanterweise fand sich in der GM eine Expression von PRDX2 in neuronalen Perikaryen. Ein neuronales Vorkommen von PRDX2 wurde ebenfalls durch Sarafian et al. (1999) beschrieben, fand sich in unseren Untersuchungen aber verstärkt in den leukokortikalen GML der MS-Fälle. Verglichen mit anderen GML zeichnen sich leukokortikale GML, sowohl in unseren Untersuchungen als auch in der Literatur, durch ein verstärktes Entzündungsinfiltrat aus (Peterson et al. 2001; Lucchinetti et al. 2011). Dies deutet darauf hin, dass dem antioxidativen Enzym PRDX2 auch in der neuronalen Zellpopulation eine zytoprotektive Rolle im Rahmen von Entzündungsprozessen zukommt.

\subsection{DeR ZUSAMmenhang ZWISCHEN ENTZÜNDUNG UND DEM VoRKOMmEN VON PeroXIREDOXIN 2 IN AstrozyTEN}

In einer detaillierten topografischen Analyse der PRDX2-Expression im Autopsiegewebe zeigte sich, dass eine erhöhte Anzahl PRDX2-positiver Astrozyten in Regionen mit vermehrtem Entzündungsinfiltrat vorkommt. Für die Anzahl der PRDX2-exprimierenden Astrozyten konnte eine positive Korrelation mit der Mikrogliaaktivierung und der Anzahl 
im Gewebe befindlicher T-Lymphozyten nachgewiesen werden. Die angeführten Ergebnisse legen einen Zusammenhang zwischen Entzündung und dem Vorkommen von PRDX2 in Astrozyten nahe. Makrophagen/Mikroglia sind zum einen eine potentielle Quelle von ROS (Fischer et al. 2012). Zum anderen sezernieren Makrophagen/Mikroglia, Lymphozyten und Astrozyten Zytokine und beeinflussen auf diese Weise das Entzündungsgeschehen und die Zellen im umliegenden Gewebe (Navikas und Link 1996). Welche Faktoren zu einem veränderten Vorkommen von PRDX2 in Astrozyten führen, konnte im Rahmen dieser Arbeit nicht abschließend geklärt werden. Im Folgenden soll der Einfluss von oxidativem Stress und Zytokinen auf die PRDX2-Expression diskutiert werden. Abschließend wird auch die Möglichkeit eines scheinbar vermehrten Vorkommens von PRDX2 durch eine geänderte Quartärstruktur des Proteins erörtert.

\subsubsection{DER EINFLUSS VON OXIDATIVEM StRESS AUf DIE EXPRESSION VON PRDX2}

ROS/RNS führen in hohen Konzentrationen zu massiven Zellschäden (oxidierte Lipide, nitrosylierte Proteine und oxidierte DNA), die jedoch charakteristischerweise nicht in chronischen WML vorzufinden sind. Aber auch in geringerer Konzentration verändern ROS/RNS über den Transkriptionsfaktor Nrf2 die Expression verschiedener Proteine. NQO1 ist ein Nrf2-abhängig exprimiertes Protein (Li und Jaiswal 1994) und wurde im Rahmen dieser Arbeit als Marker für oxidativen Stress verwendet. Immunhistochemisch fand sich eine erhöhte Anzahl NQO1-positiver Zellen mit astrozytärer Morphologie im Zentrum und Randbereich von CAPs in MS-Fällen. Diese Beobachtungen stimmen mit denen von van Horssen et al. (2006) überein, der NQO1 in Astrozyten und schaumzelligen Makrophagen von CAPs beschreibt und dies als Hinweis auf oxidativen Stress in chronischen WML bei MS interpretiert. Zudem ist ein astrozytäres und vereinzelt neuronales Vorkommen von NQO1 in betroffenen Hirnregionen bei Alzheimer sowie bei Parkinson beschrieben (SantaCruz et al. 2004; Van Muiswinkel et al. 2004). Für beide Erkrankungen wird oxidativer Stress als pathophysiologisch wichtiger Mechanismus angenommen (Pappolla et al. 1992; Alam et al. 1997).

Über die isolierte Betrachtung von NQO1 hinaus fand sich eine stark positive Korrelation der astrozytären PRDX2 und NQO1-Expression im untersuchten Autopsiematerial. Dies deutet darauf hin, dass sich Astrozyten durch die Expression von PRDX2 vor oxidativem Stress schützen, sofern in ihrer Umgebung vermehrt ROS/RNS anfallen. Um herauszufinden, ob oxidativer Stress alleine zu einer veränderten PRDX2-Expression führt und ob NQO1 tatsächlich ein Marker für die Anwesenheit von ROS/RNS ist, wurde in vitro der 
Einfluss von oxidativem Stress auf die Expression dieser Proteine untersucht. Verschiedene humane Zelllinien und murine Astrozyten wurden in der Zellkultur dem Einfluss von Wasserstoffperoxid $\left(\mathrm{H}_{2} \mathrm{O}_{2}\right)$ ausgesetzt. Mittels qPCR konnte gezeigt werden, dass die Anwesenheit von Wasserstoffperoxid in der Zellkultur zu einer vermehrten NQO1- nicht aber zu einer veränderten PRDX2-Expression führt. Diese Ergebnisse untermauern die Bedeutung von NQO1 als Marker für oxidativen Stress und deuten darauf hin, dass die Transkription von PRDX2 nicht allein durch oxidativen Stress beeinflusst wird.

\subsubsection{DER EINFLUSS VON ZYTOKINEN AUF DIE EXPRESSION VON PRDX2}

Eine besonders ausgeprägte astrozytäre Expression von PRDX2 fand sich im Randbereich von CAPs in Astrozyten mit morphologisch hypertrophen Zellkörpern (reaktive Astrozyten). Seit Langem ist bekannt, dass insbesondere die Zytokine IFN- $\boldsymbol{\gamma}$ und IL-1 $\beta$ zu einer reaktiven Astrogliose führen (Giulian et al. 1988; Yong et al. 1991) und dass beide Zytokine in entzündlichen WML, auch in CAPs, eine wichtige, proinflammatorische Rolle spielen (Traugott und Lebon 1988). Ein weiterer entzündungsverstärkender Mediator ist TNF-a, der ebenfalls in CAPs vorkommt (Selmaj et al. 1991). In neueren Untersuchungen wird TNF- $\alpha$ neben IL-1 $\alpha$ und Komplementfaktor C1q als wichtiges, von aktivierter Mikroglia sezerniertes Zytokin beschrieben, das Astrozyten aktiviert und zu einem aggressiven Phänotyp (A1) differenziert (Liddelow et al. 2017). Neben den genannten pro-entzündlichen Zytokinen spielt sowohl in CAPs, als auch in CIPs TGF- $\beta 1$ für die Limitierung der Entzündungsreaktion und Initiation von Regenerationsprozessen eine Rolle (De Groot et al. 1999). TGF- $\beta 1$ inhibiert nicht nur die Produktion pro-entzündlicher Zytokine, wie IL-1 $\beta$ und TNF- $\alpha$ (Suzumura et al. 1993; Benveniste et al. 2001), sondern revidiert den Einfluss von TNF- $\alpha$ auf Astrozyten (Liddelow et al. 2017).

In vitro wurde im Rahmen dieser Arbeit der Einfluss der beschriebenen Zytokine sowie des Wachstumsfaktors BDNF auf die astrozytäre Expression von PRDX2 und NQO1 untersucht. BDNF wurde aufgrund seines Vorkommens in MS-Läsionen (Stadelmann et al. 2002) und beschriebener Wechselwirkungen zwischen PRDX2 und dem Wachstumsfaktor platelet-derived growth factor (Choi et al. 2005) in die Versuchsreihe mit aufgenommen. Keines der untersuchten Zytokine (IFN- $\gamma$, IL-1 $\beta$, TNF- $\alpha$, TGF- $\beta 1$, BDNF) führte in der Zellkultur zu einer Änderung der Expression von PRDX2 oder NQO1 in murinen Astrozyten auf Transkriptionsebene. Dieses Ergebnis legt nahe, dass die Expression von PRDX2 entweder auf posttranskriptionaler Ebene oder durch andere Faktoren reguliert ist, was gesondert zu untersuchen wäre. 
Während für andere Peroxiredoxine expressionsverändernde Faktoren identifiziert wurden, finden sich in der Literatur keine Faktoren, die die PRDX2-Expression verändern. Diet et al. (2007) beschreibt den Einfluss von IFN- $\gamma$ und Lipopolysacchariden (LPS) auf die Expression aller sechs im Menschen vorkommenden Peroxiredoxine in Makrophagen, findet jedoch nur eine gesteigerte Expression auf RNA- und Proteinebene von PRDX1, PRDX5 und PRDX6. Die endogene NO-Produktion scheint in den IFN- $\gamma /$ LPS-stimulierten Makrophagen einen Einfluss auf die Expression von PRDX1 und PRDX6 zu haben (Diet et al. 2007). Eine gesteigerte PRDX5-Expression durch IFN- $\gamma /$ LPS wird ebenfalls durch Abbas et al. (2009) in Makrophagen und durch Sun et al. (2010) in Mikroglia beschrieben.

Ein Einfluss der anderen untersuchten Zytokine auf die Expression von Peroxiredoxinen kann in der Literatur nicht gefunden werden. Beschrieben ist vielmehr, dass Peroxiredoxine ihrerseits die redoxabhängige intrazelluläre Signaltransduktion von Zytokinen beeinflussen (Choi et al. 2005; Sun et al. 2010).

\subsubsection{VERÄNDERTE QUARTÄRSTRUKTUR VON PRDX2 DURCH OXIDATIVEN STRESS}

Die katalytische Aktivität von PRDX2 wird durch zwei Cystein-Reste (Cys) im aktiven Zentrum ermöglicht, die als peroxidatic Cys $\left(C_{P}\right)$ und als resolving Cys $\left(C_{R}\right)$ bezeichnet werden (Wood et al. 2002). Der katalytische Mechanismus lässt sich in drei Reaktionsschritte unterteilen (Karplus 2015):

(1) Peroxidation: Zunächst reduziert Cp durch einen nukleophilen Angriff beispielsweise organisches Hydroperoxid (ROOH) zu Alkohol (ROH). Bei dieser Reaktion wird das $\mathrm{Cp}_{\mathrm{P}}$-Thiolat $\left(\mathrm{CP}_{\mathrm{P}} \mathrm{S}^{-}\right)$zu $\mathrm{Cp}$-Sufensäure $\left(\mathrm{CP}_{\mathrm{P}}-\mathrm{SO}^{-}\right)$oxidiert.

(2) Resolution: Anschließend bildet sich zwischen $C_{P}$ und $C_{R}$ unter Abspaltung von Wasser eine Disulfidbrücke: $\mathrm{CP}_{\mathrm{P}} \mathrm{SO}^{-}+\mathrm{H}^{+}+\mathrm{C}_{\mathrm{R}}-\mathrm{SH} \rightarrow \mathrm{C}_{\mathrm{P}}-\mathrm{S}-\mathrm{S}-\mathrm{C}_{\mathrm{R}}+\mathrm{H}_{2} \mathrm{O}$.

(3) Recycling: Die Reduktion der Disulfidbrücke (z. B. durch Thioredoxin) bringt PRDX2 wieder in den Ausgangszustand.

Die einzelnen Reaktionsschritte beeinflussen PRDX2 in seiner Tertiärstruktur und vice versa. So lassen sich zwei Faltungszustände voneinander unterscheiden, die als fully folded (FF) und locally unfolded (LU) bezeichnet werden (Perkins et al. 2015). Es wird davon ausgegangen, dass ohne Substrat stets ein Hin und Her, also ein Gleichgewicht, zwischen diesen Zuständen herrscht. Die Stabilisierung eines Substrates/Peroxids im aktiven Zentrum und der sich daraus ergebende erste Reaktionsschritt (peroxidation) ist allerdings nur in der FF-Form möglich. Die anschließende Bildung einer Disulfidbrücke (resolution) gelingt erst, indem sich $\mathrm{C}_{\mathrm{P}}$ und $\mathrm{C}_{\mathrm{R}}$ durch eine Formänderung näher kommen 
(LU-Form) und mit der Ausbildung einer Disulfidbrücke verbleibt PRDX2 in dieser Form bis die $\mathrm{C}_{\mathrm{P}} \mathrm{C}_{\mathrm{R}}$-Bindung durch Reduktion der Cystein-Reste (recycling) wieder gelöst wird. Diese Faltungszustände beeinflussen auch die Quartärstruktur von PRDX2. Während sich in der FF-Form zehn Moleküle PRDX2 zu einem ringförmigen (doughnut-shaped) Decamer zusammenlagern, dissoziiert dieser Komplex in der LU-Form zu fünf Dimeren.

Unter Berücksichtigung der beschriebenen Dissoziation von PRDX2 im Rahmen des Substratumsatzes ist zu diskutieren, ob die vermehrte PRDX2-Immunopositivät der Astrozyten im Rahmen von Entzündungsprozessen weniger auf eine veränderte Expression, als vielmehr auf eine geänderte Quartärstruktur von PRDX2 zurückzuführen ist. Der für die Immunhistochemie verwendete PRDX2-Antikörper (Abcam ab15572) detektiert die Aminosäurensequenz 104-115 von humanem PRDX2. Die Zusammenlagerung von PRDX2 zu Decameren geschieht im Wesentlichen über die Aminosäuren 40-44 (Region I), 73-84 (Region II), 99-100 (Region III) und 112-116 (Region IV) (Wood et al. 2002; Wood et al. 2003). Im Hinblick auf die Region IV, in der auch der verwendete Antikörper bindet, ist es daher nicht auszuschließen, dass das vom Antikörper detektierte Epitop durch eine Zusammenlagerung von PRDX2 verdeckt wird.

Zusammengefasst besteht die Möglichkeit, dass eine stärkere immunhistochemische Färbung in den Astrozyten durch die Dissoziation von PRDX2 und damit die Freigabe von Epitopen für den Antikörper zustande kommt. Dies wäre insofern interessant, als dass die immunhistochemische Färbung in dem Fall weniger das bloße Vorkommen von PRDX2 in den Zellen abbilden würde, als vielmehr den oxidierten Zustand von PRDX2 anzeigt. Damit wäre eine stärkere PRDX2-Färbung ein direkter Nachweis für oxidativen Stress im Hirngewebe und würde für die Anwesenheit von ROS/RNS in CAPs bei MS sprechen.

\subsection{ReleVAnz der ERgebnisse Und Ausblick}

MS ist eine chronische Erkrankung des ZNS, die histopathologisch durch einen unterschiedlich ausgeprägten Entzündungsprozess, durch Demyelinisierung, neuroaxonale Degeneration und astrozytäre Veränderungen charakterisiert wird (Brück und Stadelmann 2003). Seit Langem ist evident, dass bei MS auch oxidativer Stress zur Schädigung des Gewebes beiträgt und so eine von verschiedenen Wissenschaftlern unterschiedlich bewertete Rolle in der Pathophysiologie der Erkrankung spielt (Jack et al. 2007; Haider et al. 2011; Fischer et al. 2013). 
Auch wenn das ZNS verglichen mit anderen Geweben des menschlichen Körpers eine geringe Toleranz gegenüber oxidativem Stress hat und vergleichsweise anfällig für oxidative Schäden ist (Cobley et al. 2018), sind die Zellen des ZNS hochreaktiven Sauerstoff- und Stickstoffverbindungen nicht schutzlos ausgeliefert. Eine Reihe antioxidativer Moleküle baut ROS/RNS ab und ist bereits im ZNS, sowohl in gesundem als auch in krankhaftem Gewebe (z. B. bei MS), untersucht worden (Van Horssen et al. 2006; Gray et al. 2014; Licht-Mayer et al. 2015).

Die Proteinfamilie der auch als Thioredoxin-Peroxidasen bezeichneten Peroxiredoxine (PRDX oder PRX), wurde erst Anfang der 90er-Jahre gefunden (Chae et al. 1994). Aufgrund seiner vermeintlich geringen enzymatischen Aktivität wurden Peroxiredoxine als antioxidative Enzymgruppe lange unterschätzt (Karplus 2015). PRDX2 ist ein Enzym dieser Proteinfamilie, und in neueren Untersuchungen zeigt sich, dass PRDX2, sofern es von Zellen exprimiert wird, nahezu alles vorhandene Wasserstoffperoxid $\left(\mathrm{H}_{2} \mathrm{O}_{2}\right)$ abbaut (Winterbourn 2008). Die zytoprotektive Rolle von PRDX2 wird von der Beobachtung unterstrichen, dass PRDX2-defiziente Mäuse eine schwere hämolytische Anämie entwickeln (Low et al. 2007). Dies ist eine interessante Beobachtung, da Erythrozyten durch die Autooxidation von Hämoglobin chronisch oxidativem Stress ausgesetzt sind. Zukünftige Untersuchungen werden zeigen, wie sich im Mausmodell ein Verlust von PRDX2 in bestimmten Zellen im Rahmen von Entzündungsprozessen auswirkt.

Das mitochondrial vorkommende Peroxiredoxin 3 und Peroxiredoxin 5 wurde bereits im ZNS auch bei MS untersucht (Holley et al. 2007; Nijland et al. 2014). Studien zur Expression von PRDX2 im ZNS konnten hingegen nach ausführlicher Literaturrecherche nicht gefunden werden.

Damit bildet die vorliegende Studie eine Grundlage, auf der aufbauend die Rolle von PRDX2 als antioxidatives Enzym im ZNS weiter untersucht werden kann. Zu klären sind unter anderem folgende wichtige Punkte:

(1) In welchem Umfang trägt das Enzym PRDX2, unter Berücksichtigung aller antioxidativen Mechanismen, zur Widerstandsfähigkeit von Astrozyten gegenüber oxidativem Stress bei?

(2) Durch welche Faktoren ist das astrozytäre Vorkommen von PRDX2 reguliert?

(3) Schützt das Vorkommen von PRDX2 in Astrozyten in der WM lediglich die astrozytäre Zellpopulation oder auch das umliegende Gewebe (Oligodendrozyten und Axone)?

(4) Welche Rolle spielt PRDX2 im Kortex? 


\section{ZUSAMMENFASSUNG}

Multiple Sklerose (MS) ist eine chronisch entzündliche Erkrankung des zentralen Nervensystems (ZNS), die durch Demyelinisierung und axonale Schäden sowie durch Neurodegeneration charakterisiert ist. Oxidativer Stress trägt in entzündlichen MS Läsionen zur Demyelinisierung und zu neuroaxonalen Schäden bei und scheint auch bei chronisch neurodegenerativen Prozessen eine Rolle zu spielen. Eine gründliche Untersuchung antioxidativer Mechanismen bei MS ist essentiell, um zu verstehen, wie Zellen auf oxidativen Stress reagieren und auf welche Weise sie sich schützen können. Als wichtige antioxidative Enzymfamilie spielen Peroxiredoxine eine entscheidende zytoprotektive Rolle, indem sie reaktive Sauerstoffverbindungen abbauen, wobei besonders Peroxiredoxin 2 (PRDX2) eine hohe katalytische Aktivität aufweist. Erstmals wurde im Rahmen dieser Arbeit die Expression von PRDX2 im ZNS autopsierter MS-Patienten und in Kontrollfällen ohne neuropathologisch feststellbare Erkrankung charakterisiert.

Durch immunhistochemische Färbungen zeigte sich, dass PRDX2 in der weißen Hirnsubstanz vorwiegend von der astrozytären Zellpopulation exprimiert wird. Vermehrt PRDX2-positive Astrozyten fanden sich in chronisch aktiven MS-Läsionen der weißen Hirnsubstanz. Für die regionale Anzahl der PRDX2 exprimierenden Astrozyten zeigte sich eine positive Korrelation mit dem lokalen Grad der Entzündung (Makrophagen/Mikrogliaaktivierung und T-Lymphozyten). Zudem ergab sich eine positive Korrelation der PRDX2-Expression mit dem ebenfalls astrozytär exprimierten Protein $N A D(P) H: q u i n o n e ~ o x i d o r e d u c t a s e ~ 1(N Q O 1)$, das als Marker für oxidativen Stress verwendet wurde. In kortikalen Hirnregionen, insbesondere in leukokortikalen MS-Läsionen, wiesen auch neuronale Zellen eine PRDX2-Expression auf. In vitro wurde untersucht, welche Faktoren zu einer erhöhten PRDX2- und NQO1-Expression führen. Oxidativer Stress allein führte zu einer vermehrten NQO1-, nicht aber PRDX2-Transkription, in murinen Astrozyten und humanen Neuroblastomzellen, gemessen mittels qPCR. Für die Zytokine IFN- $\gamma$, IL-1 $\beta$, TNF- $\alpha$, TGF- $\beta 1$ und BDNF konnte in vitro kein Einfluss auf die Transkription von PRDX2 oder NQO1 muriner Astrozyten nachgewiesen werden.

Die Ergebnisse der Arbeit legen nahe, dass PRDX2 zur Widerstandsfähigkeit der astrozytären Zellpopulation gegenüber oxidativem Stress beiträgt. Die positive Korrelation des astrozytären PRDX2-Vorkommens mit dem lokalen Grad der Entzündung und der Expression von NQO1 als Marker für oxidativen Stress in MS-Läsionen lässt auf eine zytoprotektive, antioxidative Rolle von PRDX2 bei MS schließen. Die In-vitro-Ergebnisse der Arbeit bestätigen NQO1 als Marker für oxidativen Stress und deuten darauf hin, dass die PRDX2-Transkription nicht durch oxidativen Stress allein oder die Zytokine IFN- $\gamma$, IL-1 $\beta$, TNF- $\alpha$, TGF- $\beta 1$ oder BDNF reguliert wird. 


\section{LITERATURVERZEICHNIS}

Abbas K, Breton J, Picot CR, Quesniaux V, Bouton C, Drapier J-C (2009): Signaling events leading to peroxiredoxin 5 up-regulation in immunostimulated macrophages. Free Radic Biol Med 47, 794-802

Alam ZI, Jenner A, Daniel SE, Lees AJ, Cairns N, Marsden CD, Jenner P, Halliwell B (1997): Oxidative DNA Damage in the Parkinsonian Brain: An Apparent Selective Increase in 8-Hydroxyguanine Levels in Substantia Nigra. J Neurochem $\underline{69}, 1196-1203$

Albert M, Antel J, Brück W, Stadelmann C (2007): Extensive Cortical Remyelination in Patients with Chronic Multiple Sclerosis. Brain Pathol $\underline{17}, 129-138$

Barnett MH, Prineas JW (2004): Relapsing and remitting multiple sclerosis: Pathology of the newly forming lesion. Ann Neurol $\underline{55}, 458-468$

Beckman JS, Koppenol WH (1996): Nitric oxide, superoxide, and peroxynitrite: the good, the bad, and ugly. Am J Physiol Cell Physiol 271, C1424-C1437

Benveniste EN, Nguyen VT, O'Keefe GM (2001): Immunological aspects of microglia: relevance to Alzheimer's disease. Neurochem Int $\underline{39}$, 381-391

Bø L, Vedeler CA, Nyland H, Trapp BD, Mørk SJ (2003a): Intracortical multiple sclerosis lesions are not associated with increased lymphocyte infiltration. Mult Scler $\underline{9}, 323-331$

Bø L, Vedeler CA, Nyland HI, Trapp BD, Mørk SJ (2003b): Subpial demyelination in the cerebral cortex of multiple sclerosis patients. J Neuropathol Exp Neurol $\underline{62}, 723-732$

Brambilla R, Persaud T, Hu X, Karmally S, Shestopalov VI, Dvoriantchikova G, Ivanov D, Nathanson L, Barnum SR, Bethea JR (2009): Transgenic Inhibition of Astroglial NF-KB Improves Functional Outcome in Experimental Autoimmune Encephalomyelitis by Suppressing Chronic Central Nervous System Inflammation. J Immunol $\underline{182}, 2628-2640$

Brorson JR, Schumacker PT, Zhang H (1999): Nitric Oxide Acutely Inhibits Neuronal Energy Production. J Neurosci $\underline{19}, 147-158$

Brosnan CF, Raine CS (2013): The astrocyte in multiple sclerosis revisited. Glia $\underline{61}, 453-465$

Brownell B, Hughes JT (1962): The distribution of plaques in the cerebrum in multiple sclerosis. J Neurol Neurosurg Psychiatry $\underline{25}, 315-320$

Brück W, Stadelmann C (2003): Inflammation and degeneration in multiple sclerosis. Neurol Sci 24, s265-s267

Brück W, Porada P, Poser S, Rieckmann P, Hanefeld F, Kretzschmarch HA, Lassmann H (1995): Monocyte/macrophage differentiation in early multiple sclerosis lesions. Ann Neurol $\underline{38}, 788-796$

Bryk R, Griffin P, Nathan C (2000): Peroxynitrite reductase activity of bacterial peroxiredoxins. Nature 407, 211-215

Chae HZ, Robison K, Poole LB, Church G, Storz G, Rhee SG (1994): Cloning and sequencing of thiol-specific antioxidant from mammalian brain: alkyl hydroperoxide reductase and thiol-specific antioxidant define a large family of antioxidant enzymes. Proc Natl Acad Sci USA 91, 7017-7021

Charcot J-M (1868): Histologie de la sclérose en plaques. Gaz Hôp 41, 557-558

Choi MH, Lee IK, Kim GW, Kim BU, Han Y-H, Yu D-Y, Park HS, Kim KY, Lee JS, Choi C, et al. (2005): Regulation of PDGF signalling and vascular remodelling by peroxiredoxin II. Nature $\underline{435}, 347-353$ 
Cobley JN, Fiorello ML, Bailey DM (2018): 13 reasons why the brain is susceptible to oxidative stress. Redox Biol $\underline{15}$, 490-503

Colombo E, Cordiglieri C, Melli G, Newcombe J, Krumbholz M, Parada LF, Medico E, Hohlfeld R, Meinl E, Farina C (2012): Stimulation of the neurotrophin receptor TrkB on astrocytes drives nitric oxide production and neurodegeneration. J Exp Med 209, 521-535

Corral-Debrinski M, Horton T, Lott MT, Shoffner JM, Flint Beal M, Wallace DC (1992): Mitochondrial DNA deletions in human brain: regional variability and increase with advanced age. Nat Genet 2, 324-329

Costantino CM, Baecher-Allan CM, Hafler DA (2008): Human Regulatory T cells and Autoimmunity. Eur J Immunol $\underline{38}, 921-924$

Cox AG, Winterbourn CC, Hampton MB (2010): Mitochondrial peroxiredoxin involvement in antioxidant defence and redox signalling. Biochem J $\underline{425}, 313-325$

Cross AH, Manning PT, Keeling RM, Schmidt RE, Misko TP (1998): Peroxynitrite formation within the central nervous system in active multiple sclerosis. J Neuroimmunol $\underline{88}, 45-56$

De Groot CJ, Montagne L, Barten AD, Sminia P, Van Der Valk P (1999): Expression of transforming growth factor (TGF)-beta1, -beta2, and -beta3 isoforms and TGF-beta type I and type II receptors in multiple sclerosis lesions and human adult astrocyte cultures. J Neuropathol Exp Neurol $\underline{58}$, 174-187

De Stefano N, Matthews PM, Antel JP, Preul M, Francis G, Arnold DL (1995): Chemical pathology of acute demyelinating lesions and its correlation with disability. Ann Neurol $\underline{38}, 901-909$

De Stefano N, Matthews PM, Filippi M, Agosta F, De Luca M, Bartolozzi ML, Guidi L, Ghezzi A, Montanari E, Cifelli A, et al. (2003): Evidence of early cortical atrophy in MS: Relevance to white matter changes and disability. Neurology $\underline{60}, 1157-1162$

Diet A, Abbas K, Bouton C, Guillon B, Tomasello F, Fourquet S, Toledano MB, Drapier J-C (2007): Regulation of Peroxiredoxins by Nitric Oxide in Immunostimulated Macrophages. J Biol Chem 282, 36199-36205

Dobashi K, Pahan K, Chahal A, Singh I (1997): Modulation of Endogenous Antioxidant Enzymes by Nitric Oxide in Rat C6 Glial Cells. J Neurochem 68, 1896-1903

Dowell JA, Johnson JA (2013): Mechanisms of Nrf2 Protection in Astrocytes as Identified by Quantitative Proteomics and siRNA Screening. PLoS One $\underline{8}$, e70163

Dutta R, Trapp BD (2007): Pathogenesis of axonal and neuronal damage in multiple sclerosis. Neurology $\underline{68}, \mathrm{~S} 22-$ S31

Dutta R, McDonough J, Yin X, Peterson J, Chang A, Torres T, Gudz T, Macklin WB, Lewis DA, Fox RJ, et al. (2006): Mitochondrial dysfunction as a cause of axonal degeneration in multiple sclerosis patients. Ann Neurol $\underline{59}$, 478-489

Duvernoy HM, Delon S, Vannson JL (1981): Cortical blood vessels of the human brain. Brain Res Bull $\underline{7}$, 519-579

Ebers GC, Sadovnick AD, Risch NJ (1995): A genetic basis for familial aggregation in multiple sclerosis. Nature $\underline{377}$, 150

Fischer MT, Sharma R, Lim JL, Haider L, Frischer JM, Drexhage J, Mahad D, Bradl M, Van Horssen J, Lassmann H (2012): NADPH oxidase expression in active multiple sclerosis lesions in relation to oxidative tissue damage and mitochondrial injury. Brain $\underline{135}, 886-899$

Fischer MT, Wimmer I, Höftberger R, Gerlach S, Haider L, Zrzavy T, Hametner S, Mahad D, Binder CJ, Krumbholz M, et al. (2013): Disease-specific molecular events in cortical multiple sclerosis lesions. Brain $\underline{136}, 1799$ 1815 
Fisher E, Lee J-C, Nakamura K, Rudick RA (2008): Gray matter atrophy in multiple sclerosis: A longitudinal study. Ann Neurol $\underline{64}, 255-265$

Frischer JM, Bramow S, Dal-Bianco A, Lucchinetti CF, Rauschka H, Schmidbauer M, Laursen H, Sorensen PS, Lassmann $\mathrm{H}$ (2009): The relation between inflammation and neurodegeneration in multiple sclerosis brains. Brain 132, 1175-1189

Geurts JJG, Bø L, Pouwels PJW, Castelijns JA, Polman CH, Barkhof F (2005): Cortical Lesions in Multiple Sclerosis: Combined Postmortem MR Imaging and Histopathology. AJNR Am J Neuroradiol 266, 572-577

Gilmore CP, Bø L, Owens T, Lowe J, Esiri MM, Evangelou N (2006): Spinal Cord Gray Matter Demyelination in Multiple Sclerosis - A Novel Pattern of Residual Plaque Morphology. Brain Pathol 16, 202-208

Giulian D, Woodward J, Young DG, Krebs JF, Lachman LB (1988): Interleukin-1 injected into mammalian brain stimulates astrogliosis and neovascularization. J Neurosci $\underline{8}, 2485-2490$

Gray E, Thomas TL, Betmouni S, Scolding N, Love S (2008a): Elevated activity and microglial expression of myeloperoxidase in demyelinated cerebral cortex in multiple sclerosis. Brain Pathol $\underline{18}, 86-95$

Gray E, Thomas TL, Betmouni S, Scolding N, Love S (2008b): Elevated myeloperoxidase activity in white matter in multiple sclerosis. Neurosci Lett $\underline{444}, 195-198$

Gray E, Kemp K, Hares K, Redondo J, Rice C, Scolding N, Wilkins A (2014): Increased microglial catalase activity in multiple sclerosis grey matter. Brain Res $\underline{1559}, 55-64$

Haider L, Fischer MT, Frischer JM, Bauer J, Hoftberger R, Botond G, Esterbauer H, Binder CJ, Witztum JL, Lassmann $\mathrm{H}$ (2011): Oxidative damage in multiple sclerosis lesions. Brain $\underline{134}$, 1914-1924

Hardingham N, Dachtler J, Fox K (2013): The role of nitric oxide in pre-synaptic plasticity and homeostasis. Front Cell Neurosci $\underline{7}, 190$

Hawkes CH (2007): Smoking is a risk factor for multiple sclerosis: a metanalysis. Mult Scler $\underline{13}, 610-615$

Hayes JD, Dinkova-Kostova AT (2014): The Nrf2 regulatory network provides an interface between redox and intermediary metabolism. Trends Biochem Sci $\underline{39}$, 199-218

Hein T, Hopfenmüller W (2000): Hochrechnung der Zahl an Multiple Sklerose erkrankten Patienten in Deutschland. Nervenarzt $\underline{71}, 288-294$

Henderson APD, Barnett MH, Parratt JDE, Prineas JW (2009): Multiple sclerosis: Distribution of inflammatory cells in newly forming lesions. Ann Neurol $\underline{66}, 739-753$

Hiraku Y (2010): Formation of 8-nitroguanine, a nitrative DNA lesion, in inflammation-related carcinogenesis and its significance. Environ Health Prev Med $\underline{15}, 63-72$

Hofmann B, Hecht H-J, Flohé L (2002): Peroxiredoxins. Biol Chem 383, 347-364

Holley JE, Newcombe J, Winyard PG, Gutowski NJ (2007): Peroxiredoxin V in multiple sclerosis lesions: predominant expression by astrocytes. Mult Scler $\underline{13}, 955-961$

Hooper DC, Scott GS, Zborek A, Mikheeva T, Kean RB, Koprowski H, Spitsin SV (2000): Uric acid, a peroxynitrite scavenger, inhibits CNS inflammation, blood-CNS barrier permeability changes, and tissue damage in a mouse model of multiple sclerosis. FASEB J $\underline{14}, 691-698$

Hordijk PL (2006): Regulation of NADPH Oxidases The Role of Rac Proteins. Circ Res $\underline{98}, 453-462$

Inoue S, Kawanishi S (1995): Oxidative DNA damage induced by simultaneous generation of nitric oxide and superoxide. FEBS Lett $\underline{371}, 86-88$ 
International Multiple Sclerosis Genetics Consortium, Hafler DA, Compston A, Sawcer S, Lander ES, Daly MJ, De Jager PL, de Bakker PIW, Gabriel SB, Mirel DB, et al. (2007): Risk alleles for multiple sclerosis identified by a genomewide study. $N$ Engl J Med $\underline{357}, 851-862$

Jack C, Antel J, Brück W, Kuhlmann T (2007): Contrasting potential of nitric oxide and peroxynitrite to mediate oligodendrocyte injury in multiple sclerosis. Glia $\underline{55}, 926-934$

John GR, Lee SC, Brosnan CF (2003): Cytokines: Powerful Regulators of Glial Cell Activation. Neuroscientist $\underline{9}, 10$ 22

Karplus PA (2015): A primer on peroxiredoxin biochemistry. Free Radic Biol Med 80, 183-190

Kidd D, Barkhof F, McConnell R, Algra PR, Allen IV, Revesz T (1999): Cortical lesions in multiple sclerosis. Brain $\underline{122}, 17-26$

Kluver H, Barrera E (1953): A method for the combined staining of cells and fibers in the nervous system. J Neuropathol Exp Neurol 12, 400-403

Kornek B, Storch MK, Weissert R, Wallstroem E, Stefferl A, Olsson T, Linington C, Schmidbauer M, Lassmann H (2000): Multiple Sclerosis and Chronic Autoimmune Encephalomyelitis. Am J Pathol 157, 267-276

Kroner-Milsch A, Kleinschnitz C, Stadelmann-Nessler C, Raab P, Stangel M, Trebst C, Voß E, Cordes A-L: Multiple Sklerose und andere autoimmune ZNS-Erkrankungen. In: Stangel M (Hrsg.): Autoimmunerkrankungen in der Neurologie. 1. Auflage; Springer, Berlin 2012, 1-114

Krupp LB (2003): Fatigue in multiple sclerosis: definition, pathophysiology and treatment. CNS Drugs $\underline{17}, 225-234$

Kuchelmeister K: Zellen des Zentralnervensystems und ihre Reaktionsformen. In: Klöppel G, Kreipe HH, Remmele W, Paulus W, Schröder JM (Hrsg.): Neuropathologie. 3. Auflage; Springer, Berlin 2012, 3-28

Kuhlmann T, Lingfeld G, Bitsch A, Schuchardt J, Brück W (2002): Acute axonal damage in multiple sclerosis is most extensive in early disease stages and decreases over time. Brain $\underline{125}, 2202-2212$

Kuhns DB, Alvord WG, Heller T, Feld JJ, Pike KM, Marciano BE, Uzel G, DeRavin SS, Priel DAL, Soule BP, et al. (2010): Residual NADPH Oxidase and Survival in Chronic Granulomatous Disease. N Engl J Med $\underline{363}$, 2600-2610

Kumar V, Abbas AK, Aster JC (Hrsg.): Robbins and Cotran Pathologic Basis of Disease. 9. Auflage; Elsevier/Saunders, Philadelphia 2015

Kutzelnigg A, Lucchinetti CF, Stadelmann C, Brück W, Rauschka H, Bergmann M, Schmidbauer M, Parisi JE, Lassmann $\mathrm{H}$ (2005): Cortical demyelination and diffuse white matter injury in multiple sclerosis. Brain $\underline{128}$, 2705-2712

Kutzelnigg A, Faber-Rod JC, Bauer J, Lucchinetti CF, Sorensen PS, Laursen H, Stadelmann C, Brück W, Rauschka H, Schmidbauer M, Lassmann H (2007): Widespread Demyelination in the Cerebellar Cortex in Multiple Sclerosis. Brain Pathol $\underline{17}, 38-44$

Lassmann H (2011): Review: The architecture of inflammatory demyelinating lesions: implications for studies on pathogenesis. Neuropathol Appl Neurobiol $\underline{37}, 698-710$

Lassmann H, Van Horssen J (2016): Oxidative stress and its impact on neurons and glia in multiple sclerosis lesions. Biochim Biophys Acta Mol Basis Dis 1862, 506-510

Lee D-H, Gold R, Linker RA (2012): Mechanisms of Oxidative Damage in Multiple Sclerosis and Neurodegenerative Diseases: Therapeutic Modulation via Fumaric Acid Esters. Int J Mol Sci 13, 11783-11803 
Li Y, Jaiswal AK (1994): Human antioxidant-response-element-mediated regulation of type 1 NAD(P)H:quinone oxidoreductase gene expression. Effect of sulfhydryl modifying agents. Eur J Biochem 226, 31-39

Libbey JE, Cusick MF, Fujinami RS (2013): Role of Pathogens in Multiple Sclerosis. Int Rev Immunol 33, 266-283

Licht-Mayer S, Wimmer I, Traffehn S, Metz I, Brück W, Bauer J, Bradl M, Lassmann H (2015): Cell type-specific Nrf2 expression in multiple sclerosis lesions. Acta Neuropathol $\underline{130}, 263-277$

Liddelow SA, Guttenplan KA, Clarke LE, Bennett FC, Bohlen CJ, Schirmer L, Bennett ML, Münch AE, Chung W-S, Peterson TC, et al. (2017): Neurotoxic reactive astrocytes are induced by activated microglia. Nature $\underline{541}$, 481-487

Lin MT, Beal MF (2006): Mitochondrial dysfunction and oxidative stress in neurodegenerative diseases. Nature $\underline{443}$, 787-795

Liñares D, Taconis M, Maña P, Correcha M, Fordham S, Staykova M, Willenborg DO (2006): Neuronal Nitric Oxide Synthase Plays a Key Role in CNS Demyelination. J Neurosci $\underline{26}, 12672-12681$

Liu JS-H, Zhao M-L, Brosnan CF, Lee SC (2001): Expression of Inducible Nitric Oxide Synthase and Nitrotyrosine in Multiple Sclerosis Lesions. Am J Pathol $\underline{158}, 2057-2066$

Low FM, Hampton MB, Peskin AV, Winterbourn CC (2007): Peroxiredoxin 2 functions as a noncatalytic scavenger of low-level hydrogen peroxide in the erythrocyte. Blood 109, 2611-2617

Lucchinetti C, Brück W, Parisi J, Scheithauer B, Rodriguez M, Lassmann H (2000): Heterogeneity of multiple sclerosis lesions: implications for the pathogenesis of demyelination. Ann Neurol $\underline{47}, 707-717$

Lucchinetti CF, Popescu BFG, Bunyan RF, Moll NM, Roemer SF, Lassmann H, Brück W, Parisi JE, Scheithauer BW, Giannini C, et al. (2011): Inflammatory Cortical Demyelination in Early Multiple Sclerosis. N Engl J Med $\underline{365}, 2188-2197$

Lüllmann-Rauch R: Taschenlehrbuch Histologie. 2., komplett überarbeitete Auflage; Thieme, Stuttgart 2006

Magliozzi R, Howell OW, Reeves C, Roncaroli F, Nicholas R, Serafini B, Aloisi F, Reynolds R (2010): A Gradient of neuronal loss and meningeal inflammation in multiple sclerosis. Ann Neurol $\underline{68}, 477-493$

Magnus T, Schreiner B, Korn T, Jack C, Guo H, Antel J, Ifergan I, Chen L, Bischof F, Bar-Or A, Wiendl H (2005): Microglial expression of the B7 family member B7 homolog 1 confers strong immune inhibition: implications for immune responses and autoimmunity in the CNS. J Neurosci $\underline{25}$, 2537-2546

Mahad D, Ziabreva I, Lassmann H, Turnbull D (2008): Mitochondrial defects in acute multiple sclerosis lesions. Brain $\underline{131}, 1722-1735$

Manta B, Hugo M, Ortiz C, Ferrer-Sueta G, Trujillo M, Denicola A (2009): The peroxidase and peroxynitrite reductase activity of human erythrocyte peroxiredoxin 2. Arch Biochem Biophys $\underline{484}$, 146-154

Marletta MA (1993): Nitric oxide synthase structure and mechanism. J Biol Chem 268, 12231-12234

Matthews P, De Stefano N, Narayanan S, Francis G, Wolinsky J, Antel J, Arnold D (1998): Putting Magnetic Resonance Spectroscopy Studies in Context: Axonal Damage and Disability in Multiple Sclerosis. Semin Neurol $\underline{18}, 327-336$

Mäurer M, Ponath A, Kruse N, Rieckmann P (2002): CTLA4 exon 1 dimorphism is associated with primary progressive multiple sclerosis. J Neuroimmunol $\underline{131}, 213-215$

McDonald WI, Compston A, Edan G, Goodkin D, Hartung H-P, Lublin FD, McFarland HF, Paty DW, Polman CH, Reingold SC, et al. (2001): Recommended diagnostic criteria for multiple sclerosis: Guidelines from the international panel on the diagnosis of multiple sclerosis. Ann Neurol $\underline{50}$, 121-127 
Meeuwsen S, Persoon-Deen C, Bsibsi M, Ravid R, van Noort JM (2003): Cytokine, chemokine and growth factor gene profiling of cultured human astrocytes after exposure to proinflammatory stimuli. Glia $\underline{43}, 243-253$

Mitchell RN: The Cell as a Unit of Health and Disease. In: Kumar V, Abbas AK, Aster JC (Hrsg.): Robbins and Cotran Pathologic Basis of Disease. 9. Auflage; Elsevier/Saunders, Philadelphia 2015

Motohashi H, Katsuoka F, Engel JD, Yamamoto M (2004): Small Maf proteins serve as transcriptional cofactors for keratinocyte differentiation in the Keap1-Nrf2 regulatory pathway. Proc Natl Acad Sci USA 101, 63796384

Mulisch M: Immunlokalisation. In: Mulisch M, Welsch U (Hrsg.): Romeis - Mikroskopische Technik. 19. Auflage; Springer Spektrum, Berlin 2015, 417-443

Nathan C, Xie QW (1994): Regulation of biosynthesis of nitric oxide. J Biol Chem 269, 13725-13728

Navikas V, Link H (1996): Review: cytokines and the pathogenesis of multiple sclerosis. J Neurosci Res $\underline{45}, 322-333$

Nijland PG, Witte ME, Van het Hof B, van der Pol S, Bauer J, Lassmann H, Van der Valk P, De Vries HE, Van Horssen J (2014): Astroglial PGC-1alpha increases mitochondrial antioxidant capacity and suppresses inflammation: implications for multiple sclerosis. Acta Neuropathol Commun 2, 170

Noseworthy JH, Lucchinetti C, Rodriguez M, Weinshenker BG (2000): Multiple Sclerosis. N Engl J Med 343, 938952

Nunnari J, Suomalainen A (2012): Mitochondria: In Sickness and in Health. Cell 148, 1145-1159

Onorato JM, Thorpe SR, Baynes JW (1998): Immunohistochemical and ELISA Assays for Biomarkers of Oxidative Stress in Aging and Diseasea. Ann N Y Acad Sci $\underline{854}$, 277-290

Ota K, Matsui M, Milford EL, Mackin GA, Weiner HL, Hafler DA (1990): T-cell recognition of an immunodominant myelin basic protein epitope in multiple sclerosis. Nature $\underline{346}, 183-187$

Pappolla MA, Omar RA, Kim KS, Robakis NK (1992): Immunohistochemical evidence of oxidative [corrected] stress in Alzheimer's disease. Am J Pathol 140, 621-628

Perkins A, Nelson KJ, Parsonage D, Poole LB, Karplus PA (2015): Peroxiredoxins: guardians against oxidative stress and modulators of peroxide signaling. Trends Biochem Sci $\underline{40}, 435-445$

Peskin AV, Low FM, Paton LN, Maghzal GJ, Hampton MB, Winterbourn CC (2007): The High Reactivity of Peroxiredoxin 2 with $\mathrm{H} 2 \mathrm{O} 2$ Is Not Reflected in Its Reaction with Other Oxidants and Thiol Reagents. J Biol Chem $\underline{282}, 11885-11892$

Petersen G, Wittmann R, Arndt V, Göpffarth D (2014): Epidemiologie der Multiplen Sklerose in Deutschland. Der Nervenarzt $\underline{85}, 990-998$

Peterson JW, Bø L, Mørk S, Chang A, Trapp BD (2001): Transected neurites, apoptotic neurons, and reduced inflammation in cortical multiple sclerosis lesions. Ann Neurol $\underline{50}, 389-400$

Pette M, Fujita K, Kitze B, Whitaker JN, Albert E, Kappos L, Wekerle H (1990): Myelin basic protein-specific T lymphocyte lines from MS patients and healthy individuals. Neurology $\underline{40}$, 1770-1776

Polman CH, Reingold SC, Edan G, Filippi M, Hartung H-P, Kappos L, Lublin FD, Metz LM, McFarland HF, O'Connor PW, et al. (2005): Diagnostic criteria for multiple sclerosis: 2005 revisions to the "McDonald Criteria". Ann Neurol $\underline{58}, 840-846$

Polman CH, Reingold SC, Banwell B, Clanet M, Cohen JA, Filippi M, Fujihara K, Havrdova E, Hutchinson M, Kappos L, et al. (2011): Diagnostic criteria for multiple sclerosis: 2010 Revisions to the McDonald criteria. Ann Neurol $\underline{69}, 292-302$ 
Prieto D (2007): Physiological regulation of penile arteries and veins. Int J Impot Res $\underline{20}, 17-29$

Pruitt KD, Harrow J, Harte RA, Wallin C, Diekhans M, Maglott DR, Searle S, Farrell CM, Loveland JE, Ruef BJ, et al. (2009): The consensus coding sequence (CCDS) project: Identifying a common protein-coding gene set for the human and mouse genomes. Genome Res $\underline{19}$, 1316-1323

Quinlan CL, Perevoshchikova IV, Hey-Mogensen M, Orr AL, Brand MD (2013): Sites of reactive oxygen species generation by mitochondria oxidizing different substrates. Redox Biol $\underline{1}, 304-312$

Reis A, Spickett CM (2012): Chemistry of phospholipid oxidation. Biochim Biophys Acta Biomembr $\underline{1818}$, 2374-2387

Riedelsheimer B, Büchl-Zimmermann S: Färbungen. In: Mulisch M, Welsch U (Hrsg.): Romeis - Mikroskopische Technik. 19. Auflage; Springer Spektrum, Berlin 2015, 171-282

Rosen DR, Siddique T, Patterson D, Figlewicz DA, Sapp P, Hentati A, Donaldson D, Goto J, O'Regan JP, Deng H-X, et al. (1993): Mutations in Cu/Zn superoxide dismutase gene are associated with familial amyotrophic lateral sclerosis. Nature $\underline{362}, 59-62$

Rovaris M, Confavreux C, Furlan R, Kappos L, Comi G, Filippi M (2006): Secondary progressive multiple sclerosis: current knowledge and future challenges. Lancet Neurol $\underline{5}, 343-354$

Salzano S, Checconi P, Hanschmann E-M, Lillig CH, Bowler LD, Chan P, Vaudry D, Mengozzi M, Coppo L, Sacre S, et al. (2014): Linkage of inflammation and oxidative stress via release of glutathionylated peroxiredoxin-2, which acts as a danger signal. Proc Natl Acad Sci USA 111, 12157-12162

SantaCruz KS, Yazlovitskaya E, Collins J, Johnson J, DeCarli C (2004): Regional NAD(P)H:quinone oxidoreductase activity in Alzheimer's disease. Neurobiol Aging 25, 63-69

Sarafian TA, Verity MA, Vinters HV, Shih CC-Y, Shi L, Ji XD, Dong L, Shau H (1999): Differential expression of peroxiredoxin subtypes in human brain cell types. J Neurosci Res $\underline{56}, 206-212$

Seilheyn D, DeGirolami U, Gray F: Basic Pathology of the Central Nervous System. In: Gray F, Duyckaerts C, DeGirolami U, Escourolle R (Hrsg.): Escourolle \& Poirier's manual of basic neuropathology. 5. Auflage; Oxford University Press, Oxford 2014

Selmaj K, Raine CS, Cannella B, Brosnan CF (1991): Identification of lymphotoxin and tumor necrosis factor in multiple sclerosis lesions. J Clin Invest $\underline{\text { 87, }}$ 949-954

Shadel GS, Horvath TL (2015): Mitochondrial ROS Signaling in Organismal Homeostasis. Cell $\underline{163}, 560-569$

Shibutani S, Takeshita M, Grollman AP (1991): Insertion of specific bases during DNA synthesis past the oxidationdamaged base 8-oxodG. Nature $\underline{349}, 431-434$

Shichita T, Hasegawa E, Kimura A, Morita R, Sakaguchi R, Takada I, Sekiya T, Ooboshi H, Kitazono T, Yanagawa T, et al. (2012): Peroxiredoxin family proteins are key initiators of post-ischemic inflammation in the brain. Nat Med $\underline{18}, 911-917$

Singh S, Metz I, Amor S, Van der Valk P, Stadelmann C, Brück W (2013): Microglial nodules in early multiple sclerosis white matter are associated with degenerating axons. Acta Neuropathol $\underline{125}, 595-608$

Smith KJ, Lassmann H (2002): The role of nitric oxide in multiple sclerosis. Lancet Neurol 1 , 232-241

Smolders J, Menheere P, Kessels A, Damoiseaux J, Hupperts R (2008): Association of vitamin D metabolite levels with relapse rate and disability in multiple sclerosis. Mult Scler $\underline{14}, 1220-1224$

Sobotta MC, Liou W, Stöcker S, Talwar D, Oehler M, Ruppert T, Scharf AND, Dick TP (2015): Peroxiredoxin-2 and STAT3 form a redox relay for $\mathrm{H} 2 \mathrm{O} 2$ signaling. Nat Chem Biol $\underline{11}, 64-70$ 
Sofroniew MV, Vinters HV (2010): Astrocytes: biology and pathology. Acta Neuropathol $\underline{119}$, 7-35

Stadelmann C, Kerschensteiner M, Misgeld T, Brück W, Hohlfeld R, Lassmann H (2002): BDNF and gp145trkB in multiple sclerosis brain lesions: neuroprotective interactions between immune and neuronal cells? Brain $\underline{125}, 75-85$

Stadelmann C, Albert M, Wegner C, Brück W (2008): Cortical pathology in multiple sclerosis. Curr Opin Neurol $\underline{11}$, 229-234

Stadler J, Billiar TR, Curran RD, Stuehr DJ, Ochoa JB, Simmons RL (1991): Effect of exogenous and endogenous nitric oxide on mitochondrial respiration of rat hepatocytes. Am J Physiol Cell Physiol 260, C910-C916

Sun H-N, Kim S-U, Huang SM, Kim J-M, Park Y-H, Kim S-H, Yang H-Y, Chung K-J, Lee T-H, Choi HS, et al. (2010): Microglial peroxiredoxin $\mathrm{V}$ acts as an inducible anti-inflammatory antioxidant through cooperation with redox signaling cascades. J Neurochem $\underline{114}, 39-50$

Suzumura A, Sawada M, Yamamoto H, Marunouchi T (1993): Transforming growth factor-beta suppresses activation and proliferation of microglia in vitro. J Immunol 151, 2150-2158

Szabó C (1996): DNA strand breakage and activation of poly-ADP ribosyltransferase: A cytotoxic pathway triggered by peroxynitrite. Free Radic Biol Med 21, 855-869

Tabrizi SJ, Workman J, Hart PE, Mangiarini L, Mahal A, Bates G, Cooper JM, Schapira AHV (2000): Mitochondrial dysfunction and free radical damage in the Huntington R6/2 transgenic mouse. Ann Neurol $\underline{47}, 80-86$

Taylor DEW (1894): Zur pathologischen Anatomie der multiplen Sklerose. Dtsch Z Nervenheilkd $\underline{5}$, 1-26

Thacker EL, Mirzaei F, Ascherio A (2006): Infectious mononucleosis and risk for multiple sclerosis: A meta-analysis. Ann Neurol $\underline{59}$, 499-503

Thompson AJ, Banwell BL, Barkhof F, Carroll WM, Coetzee T, Comi G, Correale J, Fazekas F, Filippi M, Freedman MS, et al. (2018): Diagnosis of multiple sclerosis: 2017 revisions of the McDonald criteria. Lancet Neurol $\underline{17}, 162-173$

Trapp BD, Peterson J, Ransohoff RM, Rudick R, Mørk S, Bø L (1998): Axonal Transection in the Lesions of Multiple Sclerosis. N Engl J Med $\underline{338}, 278-285$

Traugott U, Lebon P (1988): Multiple sclerosis: Involvement of interferons in lesion pathogenesis. Ann Neurol $\underline{24}$, 243-251

Van der Goes A, Boorsma W, Hoekstra K, Montagne L, De Groot CJA, Dijkstra CD (2005): Determination of the sequential degradation of myelin proteins by macrophages. J Neuroimmunol $\underline{161}, 12-20$

Van der Valk P, De Groot CJ (2000): Staging of multiple sclerosis (MS) lesions: pathology of the time frame of MS. Neuropathol Appl Neurobiol $\underline{26}, 2-10$

Van Horssen J, Schreibelt G, Bø L, Montagne L, Drukarch B, Van Muiswinkel FL, De Vries HE (2006): NAD(P)H:quinone oxidoreductase 1 expression in multiple sclerosis lesions. Free Radic Biol Med $\underline{41}, 311-317$

Van Horssen J, Schreibelt G, Drexhage J, Hazes T, Dijkstra CD, Van der Valk P, De Vries HE (2008): Severe oxidative damage in multiple sclerosis lesions coincides with enhanced antioxidant enzyme expression. Free Radic Biol Med 4토 $1729-1737$

Van Horssen J, Drexhage JAR, Flor T, Gerritsen W, Van der Valk P, De Vries HE (2010): Nrf2 and DJ1 are consistently upregulated in inflammatory multiple sclerosis lesions. Free Radic Biol Med $\underline{49}, 1283-1289$ 
Van Muiswinkel F, De Vos R, Bol J, Andringa G, Jansen Steur E, Ross D, Siegel D, Drukarch B (2004): Expression of $\mathrm{NAD}(\mathrm{P}) \mathrm{H}$ :quinone oxidoreductase in the normal and Parkinsonian substantia nigra. Neurobiol Aging $\underline{25}$, 1253-1262

Vercellino M, Masera S, Lorenzatti M, Condello C, Merola A, Mattioda A, Tribolo A, Capello E, Mancardi GL, Mutani $\mathrm{R}$, et al. (2009): Demyelination, inflammation, and neurodegeneration in multiple sclerosis deep gray matter. J Neuropathol Exp Neurol $\underline{68}, 489-502$

Vukusic S, Confavreux C (2003): Prognostic factors for progression of disability in the secondary progressive phase of multiple sclerosis. J Neurol Sci 206, 135-137

Wegner C, Stadelmann C (2009): Gray matter pathology and multiple sclerosis. Curr Neurol Neurosci Rep $\underline{9}, 399$ 404

Wegner C, Esiri MM, Chance SA, Palace J, Matthews PM (2006): Neocortical neuronal, synaptic, and glial loss in multiple sclerosis. Neurology $\underline{67}, 960-967$

Williams DA, Tao W, Yang F, Kim C, Gu Y, Mansfield P, Levine JE, Petryniak B, Derrow CW, Harris C, et al. (2000): Dominant negative mutation of the hematopoietic-specific Rho GTPase, Rac2, is associated with a human phagocyte immunodeficiency. Blood 96, 1646-1654

Winterbourn CC (2008): Reconciling the chemistry and biology of reactive oxygen species. Nat Chem Biol 4 , 278286

Witte ME, Mahad DJ, Lassmann H, Van Horssen J (2014): Mitochondrial dysfunction contributes to neurodegeneration in multiple sclerosis. Trends Mol Med $\underline{20}, 179-187$

Wood ZA, Poole LB, Hantgan RR, Karplus PA (2002): Dimers to Doughnuts: Redox-Sensitive Oligomerization of 2Cysteine Peroxiredoxins. Biochemistry 41 , 5493-5504

Wood ZA, Schröder E, Robin Harris J, Poole LB (2003): Structure, mechanism and regulation of peroxiredoxins. Trends Biochem Sci $\underline{28}, 32-40$

Wucherpfennig KW, Strominger JL (1995): Molecular mimicry in T cell-mediated autoimmunity: Viral peptides activate human $\mathrm{T}$ cell clones specific for myelin basic protein. Cell $\underline{80}, 695-705$

Ye J, Coulouris G, Zaretskaya I, Cutcutache I, Rozen S, Madden TL (2012): Primer-BLAST: A tool to design targetspecific primers for polymerase chain reaction. BMC Bioinformatics $\underline{13}, 134$

Yermilov V, Rubio J, Becchi M, Friesen MD, Pignatelli B, Ohshima H (1995): Formation of 8-nitroguanine by the reaction of guanine with peroxynitrite in vitro. Carcinogenesis $\underline{16}, 2045-2050$

Yong VW, Moumdjian R, Yong FP, Ruijs TC, Freedman MS, Cashman N, Antel JP (1991): Gamma-interferon promotes proliferation of adult human astrocytes in vitro and reactive gliosis in the adult mouse brain in vivo. Proc Natl Acad Sci USA 요, 7016-7020

Zeis T, Probst A, Steck AJ, Stadelmann C, Brück W, Schaeren-Wiemers N (2008): Molecular Changes in White Matter Adjacent to an Active Demyelinating Lesion in Early Multiple Sclerosis. Brain Pathol 19, 459-466 